\title{
EL PIRINEO ARAGONÉS COMO PAISAJE CULTURAL
}

\section{The Aragón Pyrenees as a cultural landscape}

\author{
José M. García Ruiz ${ }^{1 * *}$, Teodoro Lasanta ${ }^{1}$ \\ ${ }^{1}$ Instituto Pirenaico de Ecología, Consejo Superior de Investigaciones Científicas (IPE-CSIC), \\ Campus de Aula Dei, Apartado 13.034, 50.080-Zaragoza, España. \\ Identificador ORCID de los autores y e-mail \\ José M. García Ruiz: http://orcid.org/0000-0002-8535-817X. e-mail: humberto@ipe.csic.es \\ Teodoro Lasanta: http://orcid.org/0000-0002-9658-8069. e.mail: fm@ipe.csic.es \\ *Autor corresponsal
}

\begin{abstract}
Recibido: 19-06-2018. Aceptado: 02-07-2018. Fecha de publicación on-line: 25/07/2018
Citation / Cómo citar este artículo: García Ruiz, J. M., Lasanta, T. (2018). El Pirineo Aragonés como paisaje cultural. Pirineos, 173, e038. https://doi.org/10.3989/pirineos.2018.173005

RESUMEN: Los paisajes culturales se han construido a lo largo de siglos o milenios como consecuencia de la adaptación de diferentes culturas a la heterogeneidad de los sistemas naturales. Son el resultado de una serie de iniciativas, generalmente colectivas, que dan lugar a la superposición de diferentes elementos que corresponden a distintos momentos históricos. En ambientes de montaña los factores más influyentes en la construcción de paisajes culturales son el escalonamiento altitudinal de los pisos geoecológicos, la diversidad topográfica y topoclimática, el crecimiento demográfico, los acontecimientos históricos (incluyendo la superposición de culturas) y la influencia de los mercados. El éxito de las sociedades montanas dependió de su conocimiento del medio y, especialmente, de la importancia de la gravedad en un ambiente de alta energía, con el fin de controlar la escorrentía y la erosión del suelo. Por eso, las áreas de montaña necesitan una organización social y territorial compleja, para hacer frente a la adversidad provocada por la rudeza del clima y la explotación de laderas pendientes. Naturalmente, este esfuerzo implica un gran gasto de energía en la conservación del paisaje, que puede desmoronarse de manera irreversible por muchas razones, entre ellas la despoblación y el abandono de tierras de cultivo, que conducen a lo que podemos llamar una deconstrucción del paisaje. Esta última representa la pérdida de un patrimonio cultural que, estudiado a fondo, nos enseña mucho acerca de la forma óptima de aprovechar los recursos naturales y también de los errores que se han cometido en el pasado. A pesar de los cambios recientes, quedan aún muchos restos de los paisajes culturales pirenaicos: campos cercados que representan una creciente individualización en la gestión del territorio, laderas aterrazadas, panares en el límite superior del piso montano, y los extensos pastos subalpinos, que representan la eliminación de un espacio forestal para favorecer los movimientos trashumantes.
\end{abstract}

PALABRAS CLAVE: Paisajes culturales; heterogeneidad de la montaña; adaptación cultural; pisos geoecológicos; terrazas; abandono de tierras; gestión del territorio.

ABSTRACT: Cultural landscapes have been constructed along centuries as a consequence of the adaptation of distinct cultures to the heterogeneity of natural systems. They are the result of a series of collective initiatives that result in the superposition of distinct elements and historical periods. In mountain environments, the most influent factors for landscape construction have been the altitudinal organization of geoecological belts, the topographic and topoclimatic diversity, the population growth, the historical events (including the cultural superposition) and the influence 


\section{• •. M. GARCÍA RUIZ, T. LASANTA}

of local and regional markets. The success of mountain societies depended on their knowledge on the environment and of the key role of gravity to control overland flow and soil erosion. For this reason, mountain areas needed a complex social and territorial organization, to face the adversities raised by climate and strong gradients. This effort implies a big energy waste for landscape conservation, although depopulation and land abandonment can lead to landscape deconstruction. This represents the loss of a cultural inheritance that could be an excellent example of the optimum way to manage natural resources and the mistakes from the past. In spite of recent changes, many rests of Pyrenean cultural landscapes still remain: closed fields that represent an increasing individualization of landscape management, hillslopes with terraced fields, panares (terraced fields cultivated with rye) in the upper montane belt, and the extensive subalpine grasslands, which correspond to the forest wasting to favour the transhumance movements.

KEYWORDS: Cultural landscapes; mountain heterogeneity; cultural adaptation; geoecological belts; terraced fields; land abandonment; landscape management.

\section{Introducción}

Existe un interés creciente por el estudio de los llamados paisajes culturales, incluyendo su estructura, organización espacial, etapas de construcción, superposición de distintas percepciones culturales y los servicios ecosistémicos que han prestado y todavía prestan (Antrop, 1997; Farina, 2000; Schmitz et al., 2003; Sayadi et al., 2009; Bernués et al., 2014). Tanto o más interés ha despertado la deconstrucción de esos paisajes como consecuencia del abandono rural (MacDonald et al., 2000; Lasanta-Martínez et al., 2005; García-Ruiz \& Lana-Renault, 2011; Arnáez et al., 2011; Lasanta et al., 2017a) o de su transformación reciente debida a la mecanización y creciente peso del mercado (Olarieta et al., 2008; Serra et al., 2008; Strijker, 2005). Por paisaje cultural se entiende aquel que se ha construido a lo largo de siglos o milenios (con frecuencia desde al menos el Neolítico) y que responde a la adaptación de diferentes culturas a la diversidad de la topografía y de los topoclimas, así como a la organización espacial de la fertilidad de los suelos y de los flujos hidrológicos, con el fin de obtener la máxima producción con una elevada inversión de mano de obra para reducir los riesgos de degradación del suelo. Es fácil deducir que, en general, un paisaje cultural es el resultado de la superposición de diferentes formas de entender las relaciones entre los grupos humanos y la naturaleza, mediatizadas en ocasiones por el mercado y el marco sociopolítico general. Martínez de Pisón (2009a, p. 63) afirma acertadamente que "la mayor parte de nuestros paisajes son productos históricos... sus formas documentan hoy el peso de nuestra cultura sobre su espacio como archivos a escala territorial". De ahí que, con frecuencia, se ha afirmado que los paisajes actuales, incluso los que responden a una concepción muy tradicional, aparentemente poco transformados, son como un palimpsesto en el que diferentes culturas o formas de aprovechamiento del territorio han ido dejando huellas que se superponen sucesivamente, a veces sin borrar del todo las huellas de transformaciones precedentes (Antrop, 2005; Blondel, 2006). De ahí el desarrollo relativamente reciente de una arqueología del paisaje que trata de desentrañar los momentos en que se han ido construyendo diferentes elementos del paisaje (ver, por ejemplo, Fernández Mier et al., 2013).
No debe olvidarse que, en el mundo rural, la cultura es una forma concreta (y en gran parte heredada) de percibir el territorio en que se vive, cómo moldearlo en función de las necesidades colectivas y cómo conservarlo para el futuro (Montserrat Recoder, 2009). Ya dice Martínez de Pisón (2009b) que "el paisaje es una concepción del mundo, un modo de entenderlo" ("y de transformarlo", añadimos nosotros). Por eso, el mismo autor insiste en que "el paisaje es un territorio interpretado culturalmente", porque no podría hacerse de otra manera, entendiendo el doble sentido de "culturalmente": (i) el paisaje como resultado de una cultura que aprovecha el territorio de la mejor forma posible, y (ii) el paisaje como palimpsesto que es interpretado de forma individualizada con la cultura de quien lo percibe. Debido a esa interacción entre el que construye el paisaje y el que lo percibe a través de unas determinadas emociones que nos ligan a la naturaleza (Puigdefábregas \& Pérez-García, 2018), hay tantas formas de aproximarse a un paisaje y de interpretarlo, de manera que el paisaje acaba siendo una suma de interpretaciones de quienes lo han construido y de quienes lo observan. De ahí que la preocupación por entender el significado de los paisajes, especialmente de los paisajes culturales, sea no sólo un objetivo científico (especialmente por parte de los geógrafos; también, más tarde, por los ecólogos) sino que forma parte "de una irrenunciable concepción poética del universo" (Martínez de Pisón, 2009b) a la que son atraídos numerosos escritores y personas de elevada sensibilidad cultural, como ocurrió en torno a la Institución Libre de Enseñanza (ver, por ejemplo, Ortega Cantero, 2012) y la Generación del 98 (Martínez de Pisón, 2012), tradición que se prolongará más tarde con Miguel Delibes y, quizás de manera aún más intensa y profunda, con Juan Benet en Volverás a Región o Herrumbrosas lanzas.

¿Por qué es tan importante que tratemos de entender el significado de los paisajes culturales? ¿Cómo se han formado y transformado los paisajes rurales? ¿Qué lecciones podemos aprender del pasado a partir del análisis actual de los paisajes? (Palang et al., 2005). Muchas respuestas son posibles, todas ellas basadas en una forma ética de entender nuestra aproximación a la naturaleza, pero queremos centrarnos en unos pocos aspectos: 
(i) Somos, querámoslo o no, parte de ese paisaje, herederos de una larga historia de intervención en el territorio, y de una suma de actitudes culturales, un poco a la manera en que lo entendía Giner de los Ríos, "como la expresión visible de un orden natural que comprende al hombre", sin olvidar su función pedagógica dado que la comprensión del paisaje "ayuda sustancialmente a mejorar la educación del hombre" y "permite formar la inteligencia $y$, al tiempo, la sensibilidad y la imaginación; ayuda a incrementar y afinar las capacidades intelectuales, éticas y estéticas de la persona" (Ortega Cantero, 2012, p. 684).

(ii) La construcción de un paisaje cultural es el resultado de un enorme esfuerzo físico e intelectual que debe ser reconocido como una herencia patrimonial de valor incalculable (por ejemplo, en el caso de las laderas aterrazadas; también en los paisajes en mosaico, con bosques y campos organizando un paisaje que percibimos como algo armonioso). Una vez más, la totalidad es mayor que la suma de sus partes (Tandaric, 2015). Sin duda que los agricultores y ganaderos pirenaicos han tenido, aunque fuera inconscientemente, una perspectiva holística que permitía discernir el impacto de cualquier acción sobre los distintos componentes de ese paisaje (Tandaric, 2015; Naveh, 2000).

(iii) La interpretación de esos paisajes culturales es quizás el principal medio para promover la conservación de una naturaleza humanizada y para mejorar nuestras relaciones con esta última; es probablemente la mejor oportunidad para disponer de una perspectiva interrelacionada acerca de la función de las actividades humanas en la evolución del paisaje, algo que ya estaba presente en el Cosmos de Humboldt (Wulf, 2016), en los textos de John Muir (por ejemplo, los agrupados en su Cuaderno de montaña, 2018) y en otras obras regionales elaboradas por geógrafos (citamos tres particularmente importantes en España: Terán, 1947; Daumas, 1976; García Fernández, 1975). Hablamos de geógrafos en general porque ellos disponían de una formación global para interpretar la complejidad de los paisajes y la influencia humana en su evolución pero, no obstante, se quedaron cortos en algunos aspectos: en ocasiones faltaba integración y, sobre todo, equilibrar más el peso de funcionalidades y estructuras, estas últimas siempre más presentes en las grandes tesis regionales.

(iv) Los paisajes culturales nos transmiten que la manera en que las sociedades humanas han transformado un paisaje es muy variable, y que los resultados finales muestran también una elevada gama de éxitos y fracasos, todos producto de la necesidad, del grado de conocimiento y sensibilidad, y de las circunstancias que induje- ron a la creación de un paisaje. Es importante, no obstante, evitar simplificaciones: el paisaje de hace 200 años, como el actual en el Pirineo aragonés, es fundamentalmente utilitarista y no necesariamente estético, aunque con mucha frecuencia las interacciones entre el hombre y la naturaleza llevan a la construcción de paisajes armónicos, que transmiten ideas complejas de biodiversidad; nada parece sobrar en ellos, pero no son el resultado de una búsqueda consciente de una determinada calidad estética o ambiental. Esos paisajes son la consecuencia de mucha experiencia y de continuas mejoras para aumentar su eficacia a medida que se conocía mejor la complejidad del medio natural.

De esos fracasos podemos aprender mucho: un río trenzado que es el resultado de un devastador proceso erosivo en las laderas; un cono de deyección cuyo origen coincide con el comienzo de la deforestación en una cuenca; unos movimientos en masa superficiales que están estrechamente relacionados con la eliminación del bosque; unas laderas que aparecen recubiertas de un enlosado de piedras después de que el suelo haya sido erosionado; los restos de muros de piedras entre campos de cultivo, que muestran el deterioro de un viejo paisaje. La naturaleza es pródiga en mostrarnos multitud de ejemplos positivos y negativos de la forma en que los grupos humanos han percibido su forma de relacionarse con la naturaleza, de aprovechar sus recursos y también de considerar la trascendencia de cualquier transformación del paisaje, que debe exceder a la duración de unas pocas generaciones. De todas estas cuestiones trata este trabajo aplicado al Pirineo aragonés, comprendido entre los valles de Ansó y la Ribagorza aragonesa (Figura 1). El objetivo es mostrar algunos de los rasgos que mejor identifican a la construcción de los paisajes culturales y también a su proceso reciente de deconstrucción o desplome. Trataremos de proporcionar una visión global e integradora, a la vez que generalista, sin dejar de lado la referencia a ejemplos concretos.

\section{La importancia de una perspectiva global: nada hay independiente}

Las sociedades que a lo largo de la historia han ido transformando el paisaje y adaptándolo a sus necesidades y a otras muchas circunstancias, supieron captar muy pronto que en las zonas de montaña no hay muchas alternativas ni puntos medios: cuando se crea el espacio agrícola y se expanden las áreas de pastos, o conservas o destruyes. Conservar significa principalmente controlar la escorrentía superficial y retener el suelo. Ambas cuestiones están íntimamente relacionadas y constituyen un punto crítico de la sostenibilidad que condiciona la estructura del paisaje y también su funcionalidad hidromorfológica. Que las cosas se hagan bien o mal dependerá de muchos factores, todos ellos de mucho peso, aunque cambiantes a 

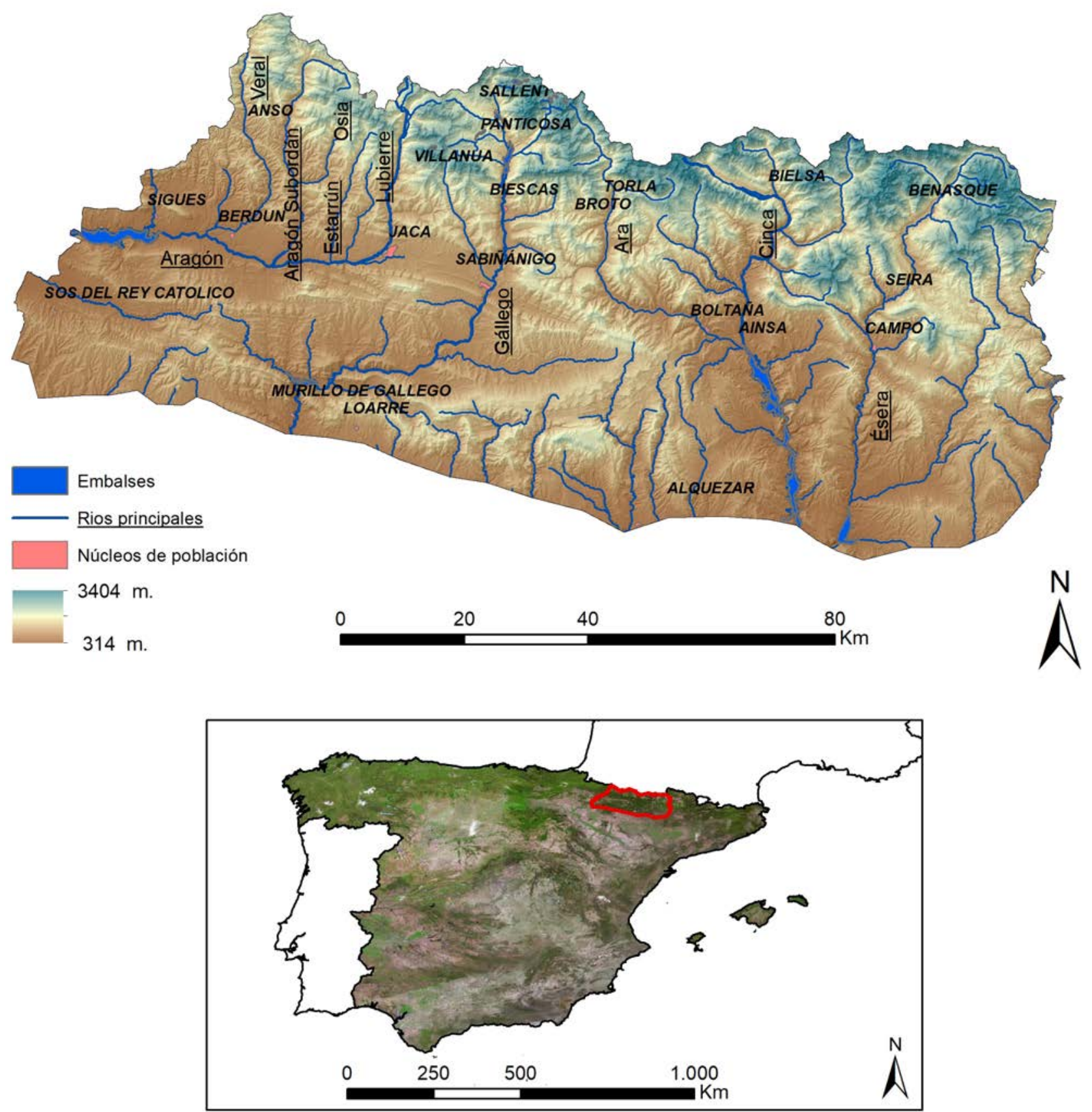

Figura 1: Área de estudio, con la localización de los núcleos de población más importantes y de la red fluvial principal.

Figure 1: Study area, with the location of major human settlements and the main fluvial network.

lo largo de la historia. En todo caso, el éxito o fracaso iniciales dependieron de la capacidad de interpretación del medio que tenían las poblaciones humanas. Es cierto que al principio las necesidades (de pastos o de campos de cultivo) serían pocas y que las posibilidades de error estarían lógicamente muy reducidas, pero un uso excesivo o erróneo del fuego (que fue, sin duda, el principal mecanismo de "apropiación" del territorio, seguido de laboreo recurrente con arado: Pavelka et al., 2017) pudo contribuir a destrozos innecesarios que también ayudaron a aprender sobre la forma en que el agua discurre por las laderas y su capacidad erosiva, o sobre la importancia de quemar en determinados momentos y no en otros para reducir el riesgo erosivo, o cómo las laderas pendientes, una vez desbrozadas y preparadas para el cultivo, conducen a una rápida pérdida de suelo. En las primeras etapas de esa "apropiación" es seguro que hubo muchos errores, pero sirvieron para sentar las bases del conocimiento de agricultores y ganaderos y para mejorar su dominio del medio. 
La acumulación de información después de varias generaciones permitió, de esto no cabe duda, profundizar en las oportunidades que ofrece la heterogeneidad topográfica, relacionar la organización espacial de la fertilidad del suelo con la distribución de determinadas plantas y con la proximidad de ríos y conos aluviales; la necesidad de dominar el drenaje de las aguas de lluvia y el excedente hídrico de los campos de cultivo, como sucedió en el pueblo de Gistaín, asentado en la parte alta de un gran deslizamiento profundo, donde se abrieron drenajes que evitaban la excesiva infiltración de las aguas de lluvia y de fusión (Martí Bono \& Puigdefábregas, 1983). También el descubrimiento de lo que hoy llamamos topoclimas, áreas relacionadas con la mayor o menor insolación, cuya comprensión ayudó a optimizar el aprovechamiento agrícola o la ubicación de casetas de pastores, pueblos y lugares de redileo. La ocupación de espacios más marginales debido a su pendiente debió aconsejar la construcción de terrazas, puesto que muy pronto se comprenderían las relaciones entre pendiente, infiltración, intensidad de lluvia y erosión. Puede parecer sorprendente, pero la presencia de terrazas es más frecuente hacia el este en el Pirineo Central que hacia el oeste, con una marcada separación en la divisoria entre los valles del Aragón y del Gállego. Del Aragón hacia el oeste predominaron más los campos en pendiente (matizados por la presencia de pequeños muros en la parte inferior de cada parcela para suavizar algo la pendiente y favorecer la retención de suelo). No obstante, hay también algunas terrazas en el sector occidental, pero estas últimas están más presentes en numerosas laderas entre los valles del Gállego y del Noguera Ribagorzana. Sin duda, la necesidad de favorecer la infiltración en las áreas de influencia más mediterránea fue un factor decisivo en este caso, mientras que hacia el oeste un mayor volumen de precipitaciones sugeriría la necesidad de favorecer el drenaje. A veces, nos hemos preguntado si no hay algo cultural en esta distribución espacial de las terrazas, aunque carecemos de respuesta. En todo caso, es significativo el cambio tan brusco en la tipología dominante de campos de cultivo al este y al oeste de la citada divisoria (Balcells, 1976).

De lo que podemos deducir acerca de la construcción histórica de los paisajes humanizados, lo más importante es que tales paisajes son la consecuencia de una iniciativa colectiva (Fernández Mier \& Quirós Castillo, 2015) que requirió diversas aproximaciones de escala y que responden, como no podía ser de otra forma, a una determinada cultura, es decir, a una manera de percibir la naturaleza y de aprovecharla de forma óptima, mediante aprendizaje in situ o en otros lugares (Palang et al., 2005). Obra colectiva fue, por ejemplo, la organización espacial de la gestión del territorio, basada en primer lugar en el escalonamiento altitudinal de la vegetación, los procesos geomorfológicos, la temperatura, las precipitaciones y las posibilidades productivas. De ahí la distribución de cultivos, bosques y pastos de verano, e incluso la organización de un sistema, como la trashumancia, que necesita una perspectiva muy amplia y unas condiciones sociopolíticas muy determinadas. Esa organización espacial solo es po- sible en un colectivo bastante cohesionado, que además establece normas de aprovechamiento de pastos (fecha de apertura de puertos de verano, por ejemplo), pactos con comunidades próximas para la utilización del bosque y los pastos más alejados, normas obligatorias de aprovechamiento de leña, de rotaciones de cultivo, distribución del barbecho y sus alternancias con las áreas de cultivo y de pastoreo en los rastrojos, entre otras muchas y muy complejas normativas. Incluso los bosques parecen ocupar el lugar más adecuado entre los pastos de verano y las áreas de cultivo, contribuyendo a controlar los ciclos hídricos y químicos, sobre todo durante el periodo de fusión de nieve (Puigdefábregas \& Fillat, 1986). La importancia de los bosques desde muchos puntos de vista se ha puesto históricamente de manifiesto con las regulaciones de tala, que decidían qué lugares se convertían en reservas forestales para la explotación ordenada de la madera, qué árboles podían cortarse y en qué condiciones podían efectuarse roturaciones para cultivo.

Por supuesto, la construcción de laderas aterrazadas fue también una obra colectiva, como no podía ser de otra forma, al tratarse de un esfuerzo ingente para el que se necesitaba una organización que permitiera crear ordenadamente los bancales, siguiendo unas leyes naturales que atendieran a la optimización del tamaño de las parcelas en relación con la pendiente, y también a la creación de sistemas de drenaje que desviasen las aguas de lluvia y limitasen el riesgo de erosión. En el Pirineo Central las terrazas representaron el esfuerzo colectivo más importante de humanización del paisaje para asegurar la existencia y sostenibilidad del espacio cultivado en condiciones muy limitantes. Eso incluyó no solo el diseño de los campos, caminos y canales de drenaje, y el cuidado de las zonas próximas a los barrancos, que generalmente se protegían con una densa cubierta de arbustos y árboles; también el acarreo de enormes cantidades de suelo y material aluvial y coluvial desde otras laderas próximas o desde los fondos de valle. Solo así se explica la existencia de bancales con saltos de más de 2 metros de altura, en general protegidos por un muro de piedra seca (a veces también hierba, árboles y arbustos) para evitar la rápida pérdida de suelo en una posición inestable. Así pues, respecto a la construcción del paisaje poco margen se dejó a las decisiones individuales, excepto durante la reconquista del Prepirineo, cuando grandes propietarios y monasterios se hicieron con extensas fincas cuyo paisaje y explotación pudieron organizar a la medida de sus posibilidades.

\section{Factores en la construcción de los paisajes de montaña: el caso pirenaico}

Un paisaje se construye a partir de la compleja interacción de (i) las dificultades del medio; (ii) la diferente presión demográfica a lo largo de la historia; (iii) la ocurrencia de conflictos bélicos y/o políticos; y (iv) la influencia del mercado. Puede añadirse también la organización social, pero en el caso del Pirineo aragonés esta 
última ha evolucionado conjuntamente con la propia construcción del paisaje y como consecuencia de los modos de gestión del territorio. Nos referiremos a ella brevemente al explicar el segundo de los factores.

\subsection{Las dificultades del medio natural}

Como se ha señalado más arriba, el paisaje cultural implica un estrecho conocimiento de las características del medio natural con el fin de optimizar la productividad agroganadera en un contexto de sostenibilidad. Ese conocimiento es aún más importante cuando aumenta la población y se ocupan áreas más pendientes o menos estables. Es entonces cuando las sociedades rurales necesitan de una perspectiva global sobre el medio en el que viven y a la vez colectiva, para poder transformar el bosque en campos de cultivo o en pastos, representando el interés del conjunto del grupo. Si no se actúa así, los sucesivos fracasos conducen al deterioro del paisaje y de sus componentes y a la pauperización de la sociedad. Esta idea de adaptación al medio a través del conocimiento que procede de la experiencia es particularmente importante en las áreas de montaña debido a que pueden definirse como áreas de alta energía: los fuertes desniveles favorecen una rápida respuesta del medio natural en forma de avenidas súbitas, deslizamientos, avalanchas de rocas, aludes de nieve y erosión del suelo (Figura 2). Un error de cálculo en la deforestación de una ladera puede conducir en poco tiempo a un deterioro irreversible a escala de generaciones. De ahí la importancia de los trabajos dirigidos a proteger el suelo y a controlar la escorrentía. Además las áreas de montaña presentan grandes limitaciones a los cultivos. Estos son algunos de los problemas que han

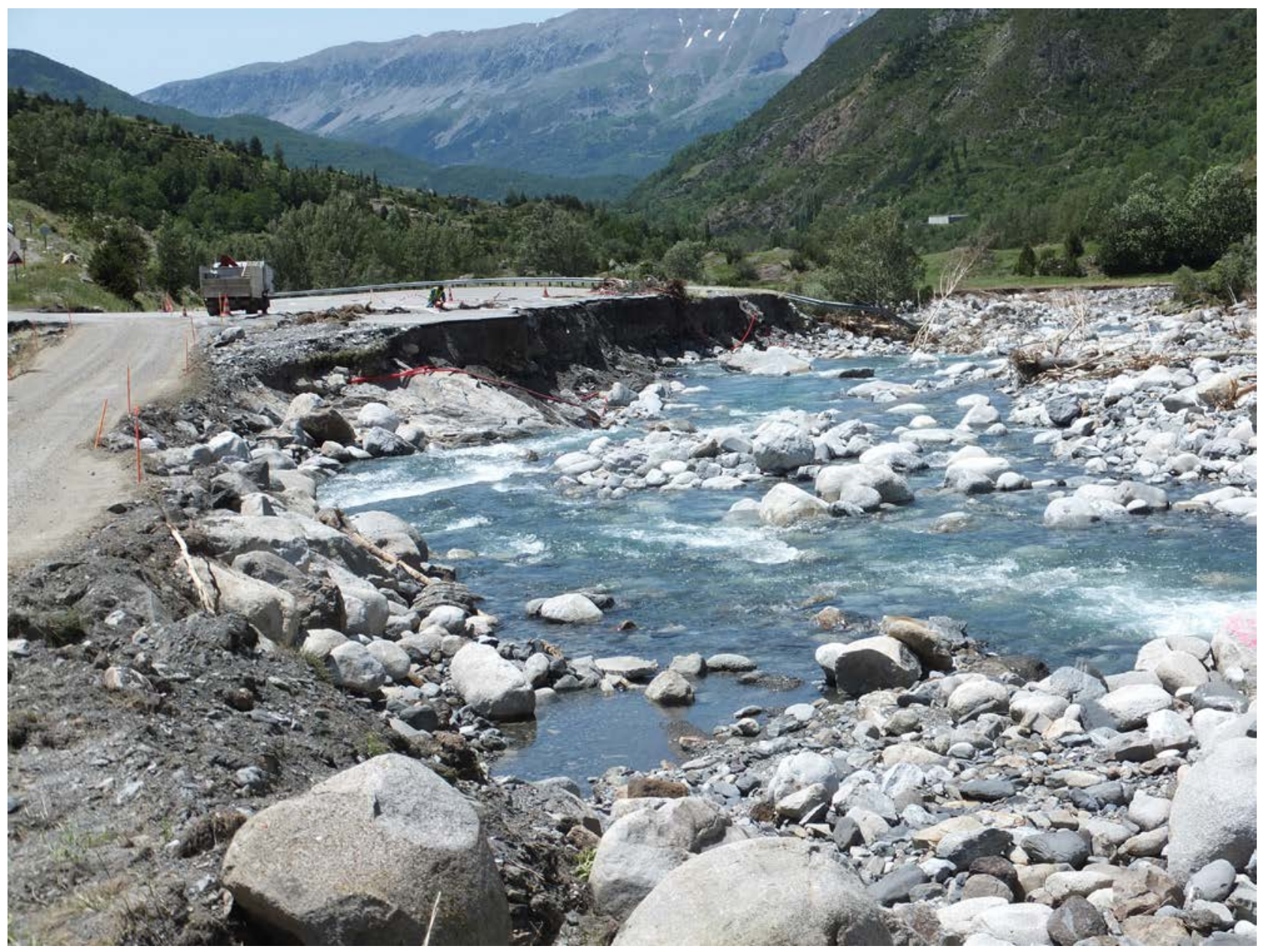

Figura 2: La avenida del río Ésera en junio de 2014 alteró profundamente el cauce fluvial y destruyó tramos de carretera, reflejando la ocurrencia de eventos hidrológicos con elevado riesgo para la población e infraestructuras. El arrastre de grandes bloques, la mayor parte de origen morrénico, es un buen indicador de la capacidad de erosión y transporte de los ríos pirenaicos, caracterizados por avenidas súbitas y fuertes pendientes. Foto: J.M.G.R.

Figure 2: The flood of the Ésera River in June 2014 deeply disturbed the fluvial channel and destroyed some road stretches, confirming the occurrence of extreme hydrological events with high risks for population and infrastructures. The transport of big boulders, most of them of morainic origin, is a good indicator of the capacity of erosion and transport by the Pyrenean rivers, which are characterized by sudden floods and strong gradients. Photo: J.M.G.R. 
condicionado la construcción y transformación del paisaje en el Pirineo aragonés:

(i) La accidentada topografía reduce notablemente la superficie ocupada por los espacios llanos o suavemente pendientes. Las áreas más extensas se localizan en las depresiones margosas de la Depresión Interior Altoaragonesa, sobre terrazas fluviales y glacis: La canal de Berdún, la Val Ancha, la zona de Aínsa-Tierrantona y la depresión de Campo. Es ahí donde pueden encontrarse los campos de mayores dimensiones, con escasa pendiente y suelos profundos, a veces amenazados por la formación de cárcavas en los escarpes de glacis y terrazas, lo que conduce a una fragmentación progresiva de los espacios cultivables (Nadal-Romero \& Regüés, 2010). Los campos llanos también aparecen en rellanos de obturación glaciar, colgados unos 300-400 m sobre el fondo del valle. El más extenso es el de Linás de Broto, en la cabecera del Valle del Ara; normalmente son de pequeñas dimensiones (por ejemplo, en la margen izquierda del Valle de Aísa, en Villanúa en el Valle del Aragón, y en Escuer en el Valle del Gállego). Los fondos de valle no son especialmente propicios para la presencia de grandes espacios llanos, dada la estrechez de los valles por encajamiento al atravesar afloramientos de rocas duras, pero en algunos casos son especialmente importantes para la organización del paisaje y su gestión: entre Hecho y Siresa, la cubeta de Villanúa-Castiello de Jaca (Valle del Aragón), la Ribera de Biescas (Valle del Gállego), la Ribera de Fiscal (Valle del Ara), coincidiendo en general con el paso de ríos importantes a través del flysch eoceno surpirenaico y a veces con la formación de artesas glaciares a su paso por afloramientos rocosos de resistencia

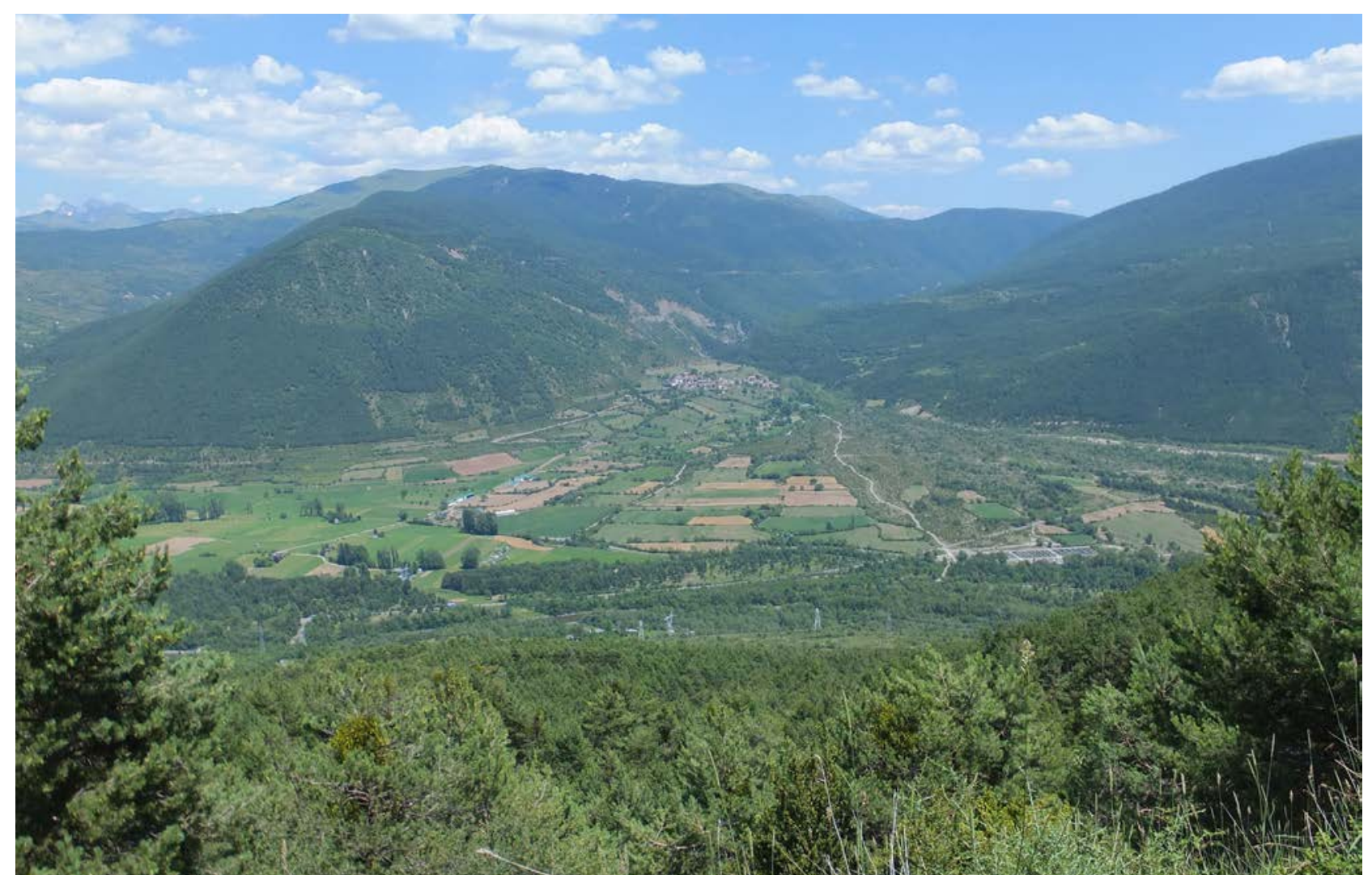

Figura 3: Cono de Orós, en la Ribera de Biescas, Valle del Gállego. El pueblo de Orós está situado en el ápice de un cono de deyección, sobreelevado sobre el cauce y protegido de las avenidas que caracterizan a estos cursos torrenciales. El cono se encuentra parcialmente cultivado, con presencia de setos que refuerzan el sentido de la propiedad, tanto más cuanto más cerca del pueblo. Sin embargo, parte del cono está sin cultivar, ocupado por una formación densa de matorral y arbolado que sugiere la abundante pedregosidad del suelo y el riesgo de ocurrencia de avenidas. El torrente atraviesa la morrena lateral del Valle del Gállego que es ahora la principal fuente de sedimento, después de que las laderas hayan sido recolonizadas por el bosque. Foto: J.M.G.R.

Figure 3: Orós alluvial fan, Ribera de Biescas, Gállego Valley. The village of Orós is located in the apex of an alluvial fan, protected from the floods that affect these torrential ravines. The fan is partially cultivated, with the presence of hedgerows that reinforce the property. Nevertheless, part of the alluvial fan is not cultivated, occupied by a dense formation of shrubs and trees, suggesting the presence of stoniness in the soil and the occurrence of floods. The ravine crosses the lateral moraine of the Gállego Valley and now is the main sediment source, after the hillslopes have been recolonized with the forest. Photo: J.M.G.R. 
variable. Los valles son particularmente estrechos en Ansó-Fago, alto Cinca, Cinqueta y Baliera (Castanesa), condicionando la organización del espacio y los modos de gestión. Algunos conos de deyección han tenido también una gran importancia, sobre todo en la Ribera de Biescas (conos de La Sía, Orós y Oliván) (Figura 3), con algunos sectores todavía no muy estabilizados. En el Prepirineo la topografía está muy fragmentada en frentes de cuesta y reversos, con la presencia de pequeñas depresiones subsecuentes que no han podido favorecer el desarrollo de amplios espacios de cultivo (Rasal, Bara, Nocito, Osia, Javierrelatre, la Val d'Onsella).

(ii) Las fuertes pendientes han obligado a realizar grandes esfuerzos de conservación del suelo y de control de la escorrentía en las laderas. De ahí la construcción de terrazas o bancales y el trazado de drenajes alternativos para derivar las aguas de lluvia. La influencia de las fuertes pendientes se deja ver sobre todo en el entorno del Parque Nacional de Ordesa y Monte Perdido y, en general, en gran parte de Sobrarbe, donde algunos pueblos (Revilla, Sercué) (Figura 4) cuentan con un reducidísimo espacio agrícola al pie de escarpes, sobre cañones fluviales o en pequeños rellanos estructurales. Por otro lado, la fácil conectividad entre laderas y cauces ha favorecido una rápida y voluminosa exportación de sedimento desde las áreas deforestadas hacia los ejes fluviales; esa es la principal razón de que se hayan desarrollado cauces trenzados muy

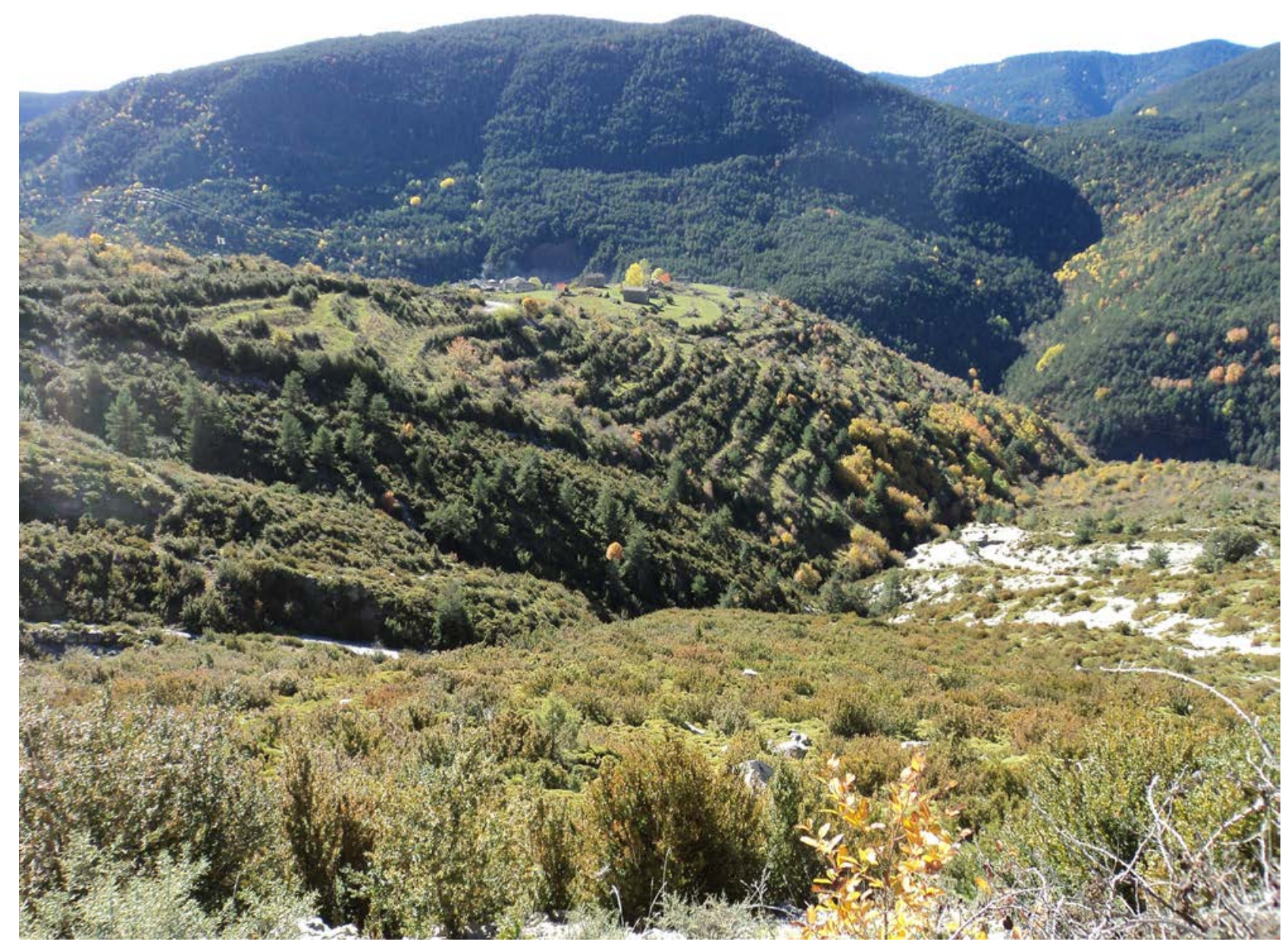

Figura 4: Sercué, Valle de Vió, en las inmediaciones del Parque Nacional de Ordesa y Monte Perdido. Las fuertes pendientes han obligado a ocupar pequeñas divisorias donde se asientan unos pocos campos llanos, y a su alrededor unos bancales muy estrechos descienden escalonadamente para aprovechar al máximo el espacio. Contraste entre la ladera solana, en primer plano, con predominio de Buxus sempervirens y Echinospartum horridum, y la umbría, al fondo, densamente poblada por un pinar de pino silvestre, con frondosas aisladas. Foto: T.L.

Figure 4: Sercué, Vió Valley, close to the Ordesa and Monte Perdido National Park. The strong gradients obligated to occupy small divides where a few flat fields can be found. Around, narrow bench-terraced fields go down to cultivate all the possible areas. There is a contrast between the south-facing slope, in the foreground, with predominance of Buxus sempervirens and Echinospartum horridum, and the north-face slope, densely populated with Pinus sylvestris and isolated deciduous trees. Photo: T. L. 
torrenciales, con escombrado de sedimento grueso y avenidas súbitas que contribuyen a cambiar la organización de la llanura aluvial amenazando campos e infraestructuras.

(iii) Por último, la altitud impuso desde el principio fuertes limitaciones a la diversidad de cultivos: nada que ver con el típico policultivo mediterráneo, salvo en la parte más meridional, donde almendros, olivos y algunos viñedos complementan el predominio cerealista y lo hacen más complejo. El Pirineo aragonés fue esencialmente un territorio cerealista y ganadero, y así ha seguido siendo hasta tiempos recientes. Además, el marcado escalonamiento altitudinal, con descenso de la temperatura media y ocurrencia de mínimas más extremas a medida que se asciende hacia las cumbres, impone mayores limitaciones y reduce la productividad del cereal, impidiendo su cultivo por encima de $1600 \mathrm{~m}$ s.n.m. (hasta $1800 \mathrm{~m}$ en la parte más oriental del Pirineo aragonés), altitud a partir de la cual la integral térmica ya no permite el cultivo del cereal, coincidiendo aproximadamente con la ubicación de la isoterma de $0^{\circ}$ en invierno (Del Barrio et al., 1990). Claro está, la insolación, que contribuye directamente a esa integral térmica, explica que los cultivos estén ligados a las laderas solanas (y a los fondos de valle) y casi nunca a las umbrías, donde sólo excepcionalmente se han abierto campos de cultivo en pendientes relativamente suaves.

Las dificultades del medio natural podían provocar situaciones críticas relacionadas sobre todo con lluvias excepcionales o años especialmente secos o fríos, que implicaban un descenso de la producción de cereales o limitaciones al pastoreo en el piso subalpino. No obstante, la población pirenaica podía defenderse de esos eventos mediante la venta parcial de los rebaños (lo que resolvía el problema a escala individual) o mediante la venta de madera de montes comunales (Puigdefábregas \& Fillat, 1986).

\subsection{El peso determinante de la demografia}

Uno de los factores más importantes en la progresiva construcción de un paisaje es la demografía. Inicialmente, los grupos humanos que se instalan en un determinado territorio montañoso son muy pocos y su número crece lentamente, haciendo también que el proceso de transformación de un paisaje sea lento. Eso da tiempo a entender la heterogeneidad del relieve de la montaña y a descubrir las interacciones entre el relieve, la circulación del agua y la distribución de la vegetación. De esas interacciones se aprende mucho: se reconocen las áreas con tendencia a la saturación, las laderas más aptas para determinados cultivos, las pendientes con más y menos problemas para la implantación de campos de cultivo, las zonas con mayor riesgo de caídas de piedras o de inundaciones, los torrentes más activos o la presencia de suelos profundos, bien drenados y aparentemente más productivos. Las personas que tenían intención de transformar el paisaje para cultivar o para pastorear con ovejas y cabras tenían que conocer todo eso, es decir, las limitaciones a las que se enfrentaban. Y también quienes les sucedieron en el tiempo y necesitaron acceder a más recursos agrícolas y pastorales a medida que crecía la población. Se basaron en la observación y en la deducción y ese fue el inicio de la experiencia. También pudieron deducir que los recursos en zonas con fuertes contrastes estacionales, como es el caso de la montaña, son cambiantes en el tiempo y que su aprovechamiento requiere de una compleja organización social. La montaña es, en este sentido, un laboratorio muy especial, porque en un espacio muy reducido permite la presencia de distintos pisos escalonados, que se activan a partir de la primavera en los fondos de valle y culminan en verano en el piso subalpino y alpino, ofreciendo variados recursos en momentos diferentes. Para los ganaderos de la montaña esto era una gran oportunidad para aprovechar los pastos escalonadamente, hasta alcanzar el piso subalpino y permanecer allí durante el verano. Esta trasterminancia fue probablemente suficiente para los ganaderos pirenaicos, pues los pequeños rebaños podrían pastar durante el invierno en los barbechos o en zonas próximas. Hay incluso autores que sugieren la existencia de rutas de trashumancia ya desde el Neolítico o poco posterior (Higgs, 1976; Blondel, 2006), aprovechando la tradición de seguir a los herbívoros en sus movimientos estacionales. De hecho, algún autor se pregunta por la complejidad y movimientos de la ganadería antes del siglo $\mathrm{X}$, es decir, si hubo verdadera trashumancia de largo alcance y cómo fue posible en un territorio tan fragmentado política y territorialmente (Escalona Monge, 2001). Galán Domingo \& Ruiz-Gálvez (2001) dudan de que hubiera movimientos trashumantes largos en la Península Ibérica durante las edades del Bronce y del Hierro, y que sólo cabría hablar de trasterminancia de corto recorrido entre los asentamientos de los fondos de valle y los pastos de verano, y que la trashumancia sólo sería realmente posible cuando existiera una cierta unidad política, es decir, en época romana o tras la Reconquista. Aunque las rutas trashumantes tradicionales cuentan con numerosos ejemplos de restos de manufacturas líticas del Neolítico y la Edad del Bronce, quizás pertenecientes a pastores que subían a aprovechar los pastos de verano, esta información suele tomarse con cautela (Davidson, 1980). En todo caso, los numerosos túmulos y dólmenes que pueden encontrarse en el piso subalpino en cualquier valle pirenaico son la prueba de que el pastoreo nómada, ligado a la estacionalidad de los recursos, estaba ya presente desde muy temprano (Montes Ramírez et al., 2016) (Figura 5), aunque probablemente se limitaba a poblaciones locales que practicaban una trasterminancia limitada. También los pequeños restos de carbones presentes en muchos suelos del piso subalpino son un buen ejemplo del proceso de deforestación con la intención de ampliar la superficie de pastos de aprovechamiento estival, como se ha confirma- 


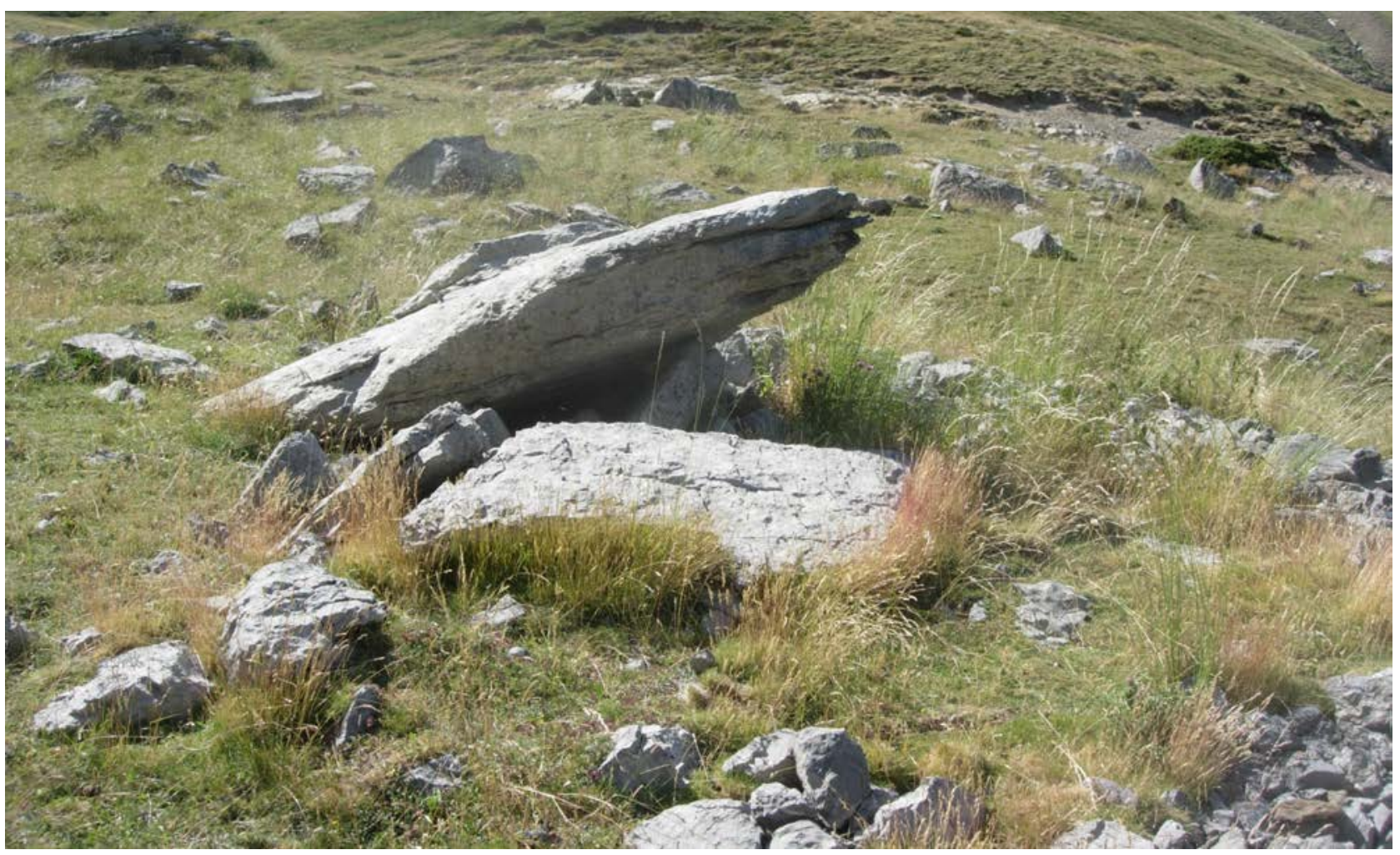

Figura 5: Dolmen de Napazal, junto a una vía ganadera típica entre los valles de Aragüés y de Aísa, cerca del Puerto del Bozo, en pleno piso subalpino. Los monumentos megalíticos son muy abundantes en el Pirineo aragonés donde, con alguna excepción, tienden a localizarse en el piso subalpino, como expresión de la presencia de pastores durante el verano desde al menos la Edad del

Bronce. Son también indicadores de incendios tempranos que facilitaron el pastoreo y la defensa frente a grandes carnívoros competidores. Foto: J.M.G.R.

Figure 5: Dolmen of Napazal, near to a typical livestock path between the Aragüés and Aisa valleys, close to the Bozo Pass in the subalpine belt. Megalithic monuments are very abundant in the Aragón Pyrenees, where they tend to locate in the subalpine belt, as a result of the presence of shepherds since at least the Bronze Age. They are also indicators of early wildfires that facilitated grazing and protection against large competing carnivores. Photo: J.M.G.R.

do en la Sierra de Urbión, Sistema Ibérico, donde el inicio de la deforestación del piso subalpino data al menos de mediados del Neolítico y se prolongó durante el Calcolítico, la Edad del Bronce, el periodo romano y la Edad Media (García-Ruiz et al., 2016a, 2016b).

El conocimiento de la heterogeneidad espacial y temporal dio paso a las rutinas en la gestión del territorio. Se ocuparon fondos de valle, partes de conos de deyección, pies de vertiente con buenos suelos y rellanos colgados (generalmente relacionados con obturaciones glaciares rellenas de sedimento). Y si estos recursos no estaban siempre disponibles se procedía a aterrazar las vertientes para retener el suelo, que a veces se subía desde el fondo del valle o de otras laderas más marginales. En el Pirineo aragonés las primeras actividades deforestadoras con marcada intencionalidad agrícola tuvieron lugar durante las edades del Bronce y del Hierro, cuando aparecen los primeros signos de agricultura sedentaria (GonzálezSampériz et al., 2017). La expansión agropecuaria se manifestó más claramente en el periodo Ibero-Romano y en las Edades Oscuras (Dark Ages), con presencia de polen de Olea y Vitis en torno al lago de Estaña y progresivo aumento de Cerealia (Morellón et al., 2011) y un progresivo descenso en la proporción de polen arbóreo en secuencias lacustres tanto de tierras bajas (lago de Estaña) como altas (lagos de Tramacastilla y Basa de la Mora: Montserrat, 1992; Pérez-Sanz et al., 2013). Riera et al. (2004) comprobaron una expansión del cultivo de cereales y olivo en torno al lago de Estaña en periodo romano, en un ambiente prepirenaico. Esas secuencias muestran también que durante la Anomalía Climática Medieval (900-1300 AD) aumentan notablemente las evidencias de actividades humanas.

Las terrazas fueron un descubrimiento posiblemente fechado en la Edad del Bronce (Asins, 2006) y desarrollado hasta mediados del siglo XIX en función de muchas circunstancias. Según Agnoletti et al. (2015), el impulso tecnológico aportado por los árabes en la Alta Edad Media dio lugar a un nuevo desarrollo de la agricultura en terrazas, con máxima expansión durante el Renacimiento. Después, la creación de nuevas terrazas estaría en consonancia con las fluctuaciones demográficas. Estudios recientes con datación mediante OSL han fechado terrazas de cultivo en Cataluña entre los siglos XIII y XVIII (Kin- 
naird et al., 2017) y entre los siglos XV y XIX (Turner et al., 2017). Excavaciones en terrazas de Salvatierra (Álava) han proporcionado edades entre los siglos VI y XIII (Quirós Castillo, 2011), reflejando un continuum que parece muy probablemente relacionado con la necesidad de ampliar la superficie cultivada. No faltan autores, sin embargo, que sitúan la construcción de la mayoría de las terrazas en los siglos XVIII y XIX (Grove \& Rackham, 2001). Es evidente, no obstante, que en el Pirineo aragonés muchas de esas terrazas se establecieron desde los primeros tiempos de ocupación agrícola del territorio y de los asentamientos humanos, porque ¿cómo desligar el origen de muchos pueblos pirenaicos (Bestué, Puértolas, Laspuña, Tella, Panillo, Otal, Berroy, San Vicente de Labuerda, Muro de Bellos, Saravillo, Yeba, Ceresuela y el Valle de la Solana, en el valle del Ara, entre muchos otros) del de la construcción de terrazas de las que han dependido para la obtención de alimentos? Permitieron cultivar sin grandes riesgos laderas muy pendientes que, de otra forma, se hubieran erosionado muy rápidamente (Figuras 6 y 7). A la vez se desviaron las aguas de escorrentía superficial de manera que las terrazas estuvieran bien drenadas y además protegidas. No debe olvidarse que si en ambientes mediterráneos las terrazas favorecen la infiltración del agua como recurso escaso, en áreas de montaña un exceso de humedad o la saturación estacional de las terrazas impide el desarrollo del cereal y favorece la formación de movimientos en masa, con la consiguiente necesidad de reparación (Blondel, 2006; Lasanta et al., 2013a; Tarolli et al., 2014). En el paisaje se observa que las terrazas no son homogéneas: Lasanta (1997) comprobó que los mejores bancales, es decir, los que requerían

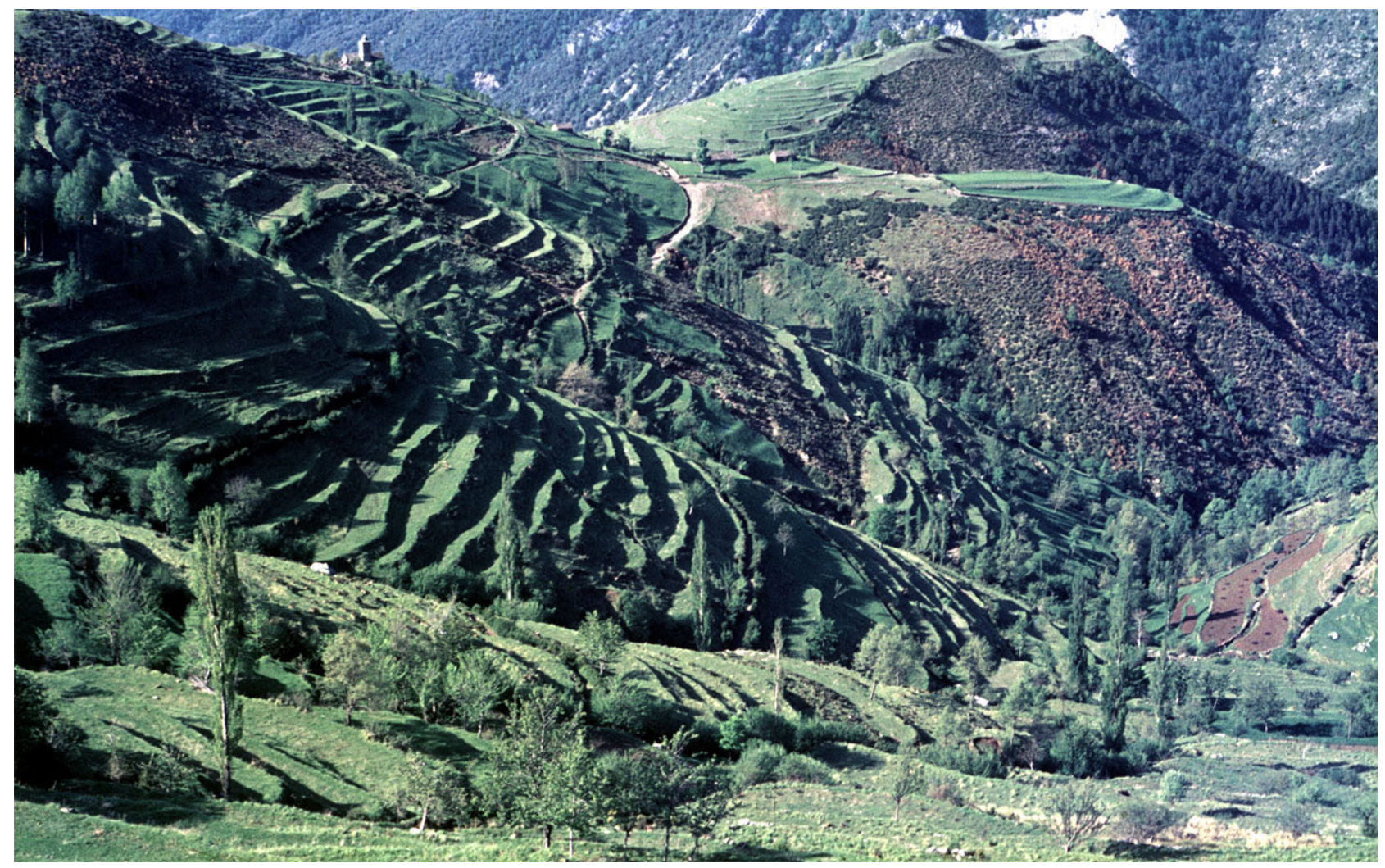

Figura 6. Bancales en Bestué, cerca del Parque Nacional de Ordesa y Monte Perdido. Muchos de los pueblos de Sobrarbe se asientan sobre estrechas divisorias, mientras los campos de cultivo se precipitan por laderas muy pendientes, formando complejos sistemas abancalados que sugieren un intenso y sofisticado trabajo colectivo. Aquí los bancales forman estrechas fajas separadas por saltos de casi $2 \mathrm{~m}$ de altura. Hoy están completamente abandonados dada la imposibilidad de mecanización. Obsérvese que algunos sectores

de la ladera carecen de bancales como consecuencia, muy probablemente, de procesos erosivos por movimientos en masa superficiales. La foto está tomada en 1973, cuando los campos originalmente cerealistas habían pasado a prados de diente. En la actualidad arbustos y árboles han colonizado los saltos entre bancales y comienzan a cubrir el espacio cultivado. Foto: J.M.G.R.

Figure 6. Terraces around Bestué, close to the Ordesa and Monte Perdido National Park. Many of the villages in the Sobrarbe

County are located on narrow divides, whereas the cultivated fields occupy very steep gradients, forming complex terraced systems that suggest an intense and sophisticated collective work. Here, terraces form narrow strips separated by an unevenness of $2 \mathrm{~m}$.

Today they are completely abandoned due to the impossibility of mechanization. Observe that some sectors of the slope lack terraces, most likely as a consequence of erosive processes through shallow landslides. The photo was taken in 1973, when cereal fields were substituted by grazing meadows. At present, shrubs and trees have colonized the steps between terraces and start to cover the old cultivated fields. Photo: J.M.G.R. 


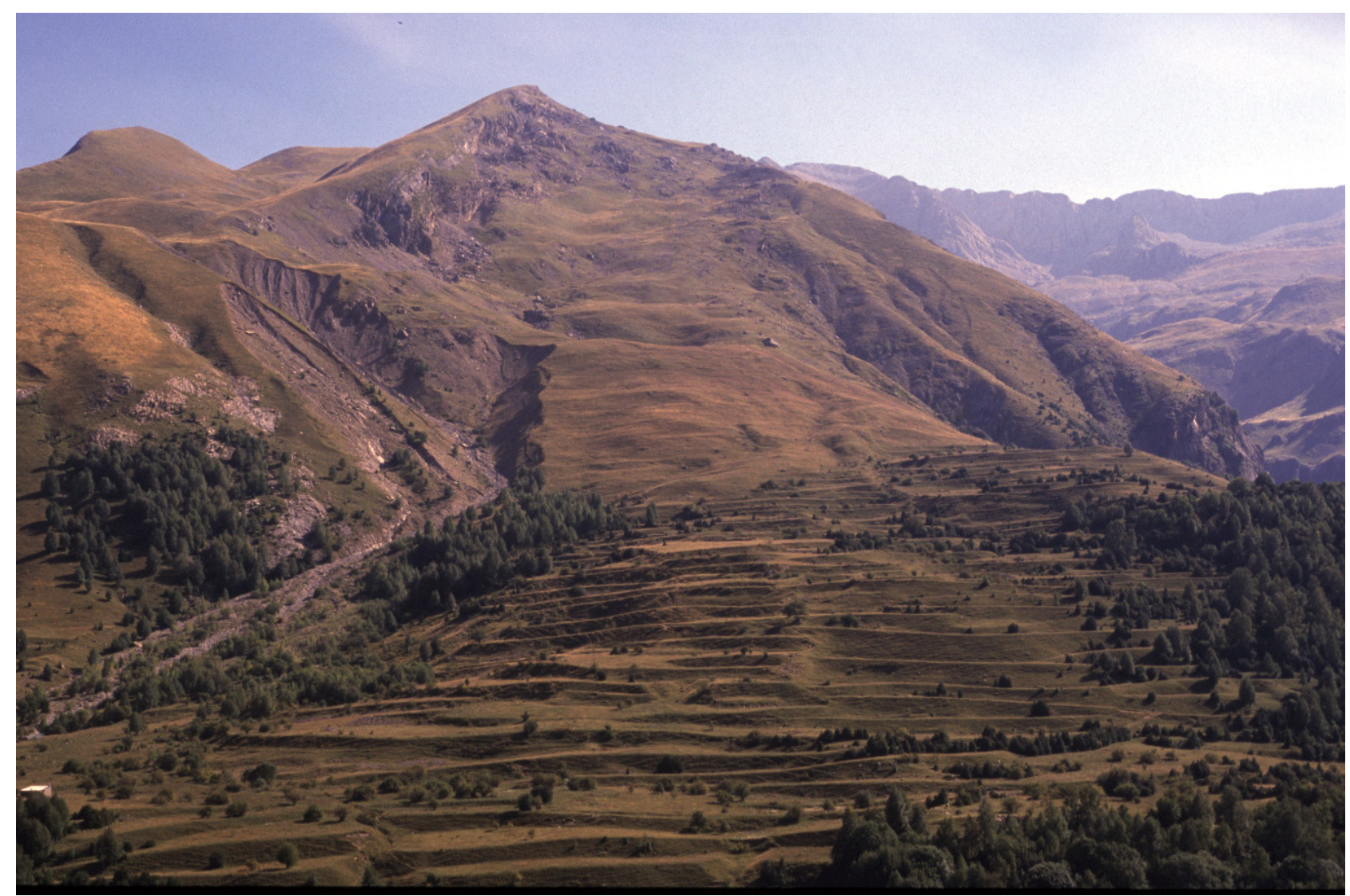

Figura 7: Bancales de Faceras, en la base de la ladera que desciende desde el Pico del Verde, en el municipio de Panticosa. La ladera corresponde a un gran deslizamiento profundo cuya raíz o cicatriz se localiza cerca de la cumbre, afectando a areniscas y pizarras paleozoicas y a la morrena lateral izquierda del Barranco Ripera. En su frente el deslizamiento adopta forma de espátula, donde se construyeron bancales separados por saltos cubiertos de hierba o espuenas. Lateralmente se evitó el cultivo para favorecer la presencia de bosque con el fin de frenar en lo posible la erosión. Foto: J.M.G.R.

Figure 7: Terraces of Faceras, at the lowest part of the slope that descends from the Verde Peak, in the community of Panticosa. The slope corresponds to a large deep-seated landslide whose scar is located close to the Peak, affecting paleozoic sandstone and shale and to the lateral moraine of the Ripera tributary valley. At the front of the landslide the farmers constructed terraces separated by a steep versant covered with grass. The presence of trees in both margins of the landslide reduced the erosion risk. Photo: J.M.G.R.

mayor inversión de trabajo, tendían a localizarse en las proximidades de los pueblos o en suelos más fértiles, mientras que su calidad se reducía a medida que se alejaban de los asentamientos. Una visita al pueblo abandonado de Otal refleja la transición desde los mejores bancales hasta los que se difuminan en la parte alta del espacio agrícola, donde casi se confunden con el inicio de las áreas de pastos de verano.

Lo que está claro es que el crecimiento demográfico ha sido un factor decisivo en la progresiva construcción y transformación de los paisajes (Lasanta et al., 2017a). En numerosos trabajos se ha reconocido que la máxima expansión de la superficie agrícola en el Pirineo (y en otras montañas del centro y norte de España) tuvo lugar a mediados del siglo XIX, coincidiendo con el momento de mayor densidad demográfica (Ortega Valcárcel, 1974; Díaz Muñoz, 1984; Rodríguez Gutiérrez, 1989; SanchoReinoso, 2013), si bien el momento de máxima deforestación pudo ser anterior, hacia el siglo XIV, como en otras regiones europeas (Kaplan et al., 2009). El crecimiento del número de habitantes indujo a una constante ampliación de la superficie cultivada. De los mejores terrenos ocupados en el comienzo de la instalación de asentamientos se fue pasando al cultivo de laderas más pendientes (Figura 8) e incluso a la adopción de sistemas de cultivo nómadas (artigueo, shifting agriculture) que consistían en el desbroce de una parte de la ladera, la quema lenta de los productos de la roturación (fornigueros) y la utilización de las cenizas como único abono (Lasanta, 1989) para cultivar trigo, cebada, avena o patatas (Daumas, 1976), aunque existen referencias a las articas desde la Baja Edad Media, por ejemplo en el Valle de Bielsa (Bielza de Ory et al., 1986). La práctica de este sistema en ciclos muy largos (cultivo durante dos o tres años y 25 o 30 años de abandono hasta una nueva roturación) produjo daños irreparables en el suelo, que fue rápidamente erosionado. Su actividad se mantuvo hasta las década de 1940 e incluso más en el Pirineo aragonés oriental (en 


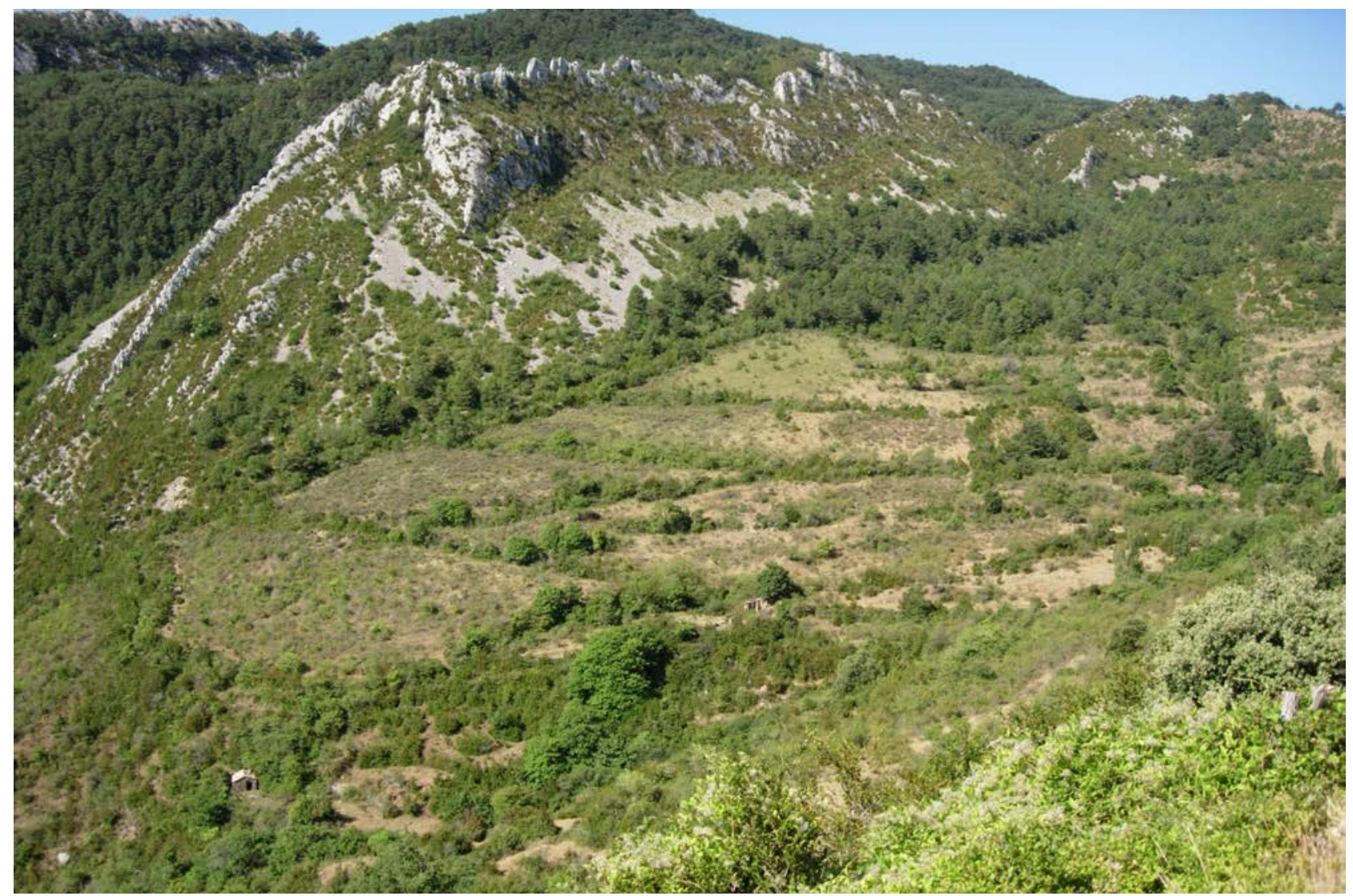

Figura 8: La ampliación del espacio cultivado a medida que aumentaba la población dio lugar a la ocupación de laderas más pendientes. Campos de cultivo ya abandonados en Salinas Viejo, Prepirineo. Foto: J.M.G.R.

Figure 8: The enlargement of the cultivated area as population increased resulted in cultivation of steeper slopes. Abandoned fields in Salinas Viejo. Photo: J.M.G.R.

Bonansa y Calasanz), especialmente entre los agricultores más modestos (Daumas, 1976). Hoy vemos las consecuencias en algunas laderas pendientes, donde el suelo ha sido casi completamente sustituido por acumulaciones de piedras en las que la colonización vegetal avanza muy lentamente (Lasanta et al., 2006 y 2017b) (Figura 9). Esta agricultura nómada coincidió además en el tiempo con la crisis de muchas industrias artesanales y de actividades mineras en el Pirineo, lo que creó una mano de obra excedentaria que sólo pudo acceder a la tierra mediante este sistema tan poco conservador. De manera aún más acusada ocurrió también en las montañas riojanas cuando, además de la crisis de la trashumancia, anunciada desde finales del siglo XVIII, se asistió al rápido desmoronamiento de la industria textil: el resultado fue la ocupación generalizada de las laderas hasta pendientes inverosímiles (Gómez Urdáñez y Moreno Fernández, 1997; García-Ruiz et al., 2017). El paisaje actual guarda muchos testimonios de esa fiebre desbrozadora, tanto en el Pirineo como en La Rioja. Digamos, en consecuencia, que, a pesar de las dificultades del clima y la topografía, las cosas pudieron ir relativamente bien en el Pirineo hasta que se superó un umbral demográfico que obligó a ocupar laderas cada vez más pendientes y menos productivas, hasta cultivar áreas inimaginables en aras de una supervivencia a corto plazo. Los siglos XVIII y XIX coincidieron con el momento de máxima presión demográfica, cuando todavía la industrialización en los centros urbanos era muy incipiente e incapaz de absorber los excedentes demográficos del medio rural; de ahí que se asistiera en todo Aragón, incluyendo particularmente las áreas montañosas, a la roturación de tierras cada vez más marginales (Faus Pujol \& Rubio Gracia, 1984).

La principal consecuencia de esa evolución demográfica ha sido, por lo tanto, la progresiva transformación de los bosques en zonas de cultivo y de pastos, ampliándose también el espacio ocupado por matorrales en la montaña media y baja. Es importante tener en cuenta que la creación del espacio cultivado tuvo características muy diferentes en la mitad oriental y la occidental del Pirineo aragonés. Algunos datos son bien expresivos de estas diferencias a un lado y al otro del Valle del Gállego. Así, los bancales han predominado en los valles pirenaicos orientales (Broto, Bestué-Puértolas, por ejemplo) (Figura 10), llegando a ocupar el 70\% del espacio cultivado, mientras que en los valles pirenaicos occidentales (Hecho, Aragüés, Aísa) representaron menos del 10\% de la superficie cultivada. Por el contrario, las articas llegaron a 


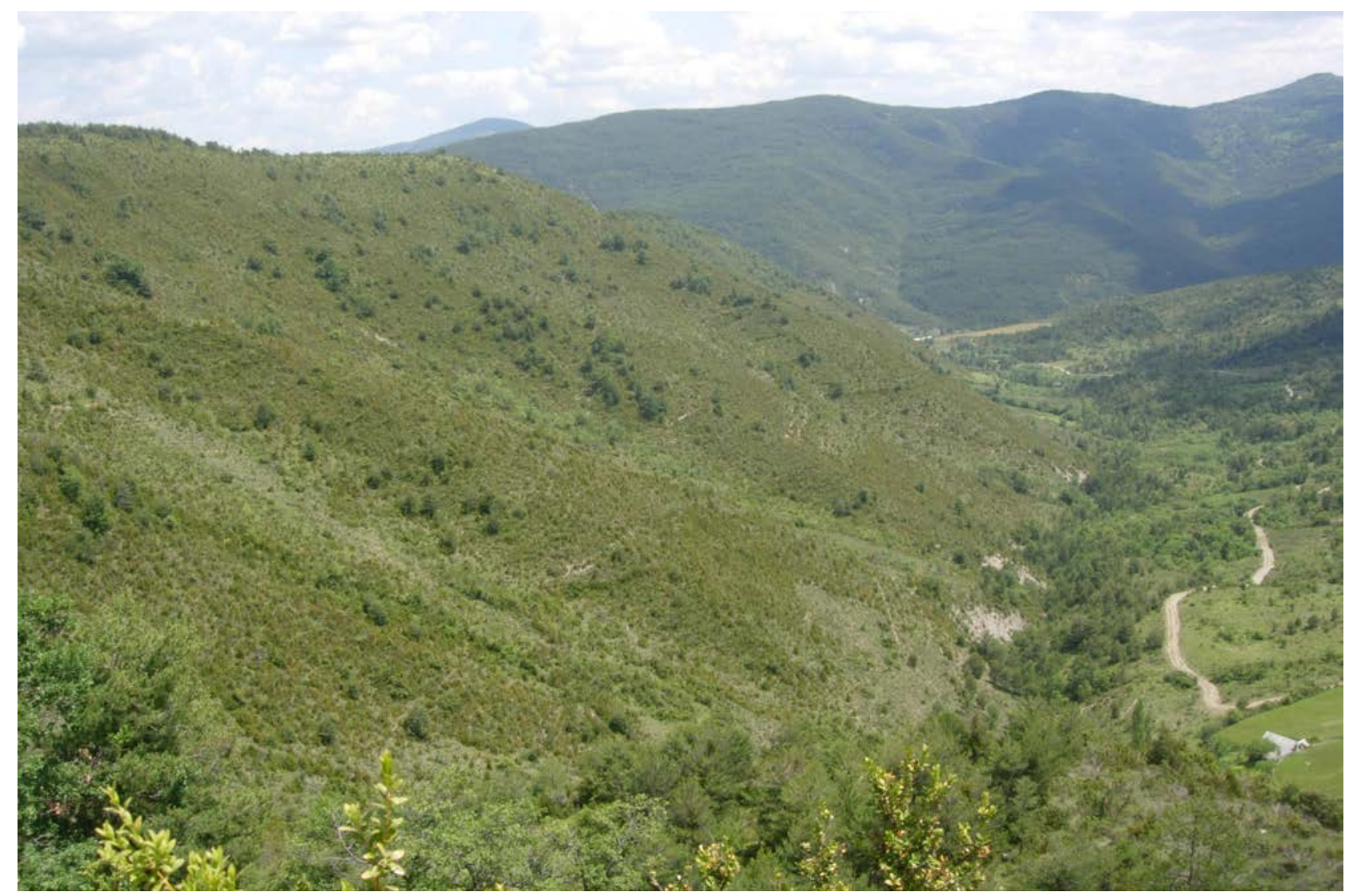

Figura 9: Ladera solana en la cuenca de Arnás, Valle de Borau. Esta ladera se cultivó siguiendo procedimientos de agricultura nómada y fue abandonada a principios del siglo XX, cuando se relajó algo la presión demográfica. Ahora aparece cubierta por un matorral bastante denso y presencia creciente de arbolado, aunque la recuperación del bosque sigue un proceso muy lento debido a la degradación que experimentó el suelo. Foto: J.M.G.R.

Figure 9: South-facing slope in the Arnás catchment, Borau Valley. This hillslope was cultivated following the procedures of shifting agriculture and was abandoned at the beginning of the 20th century, when demographic pressure decreased. Now it is covered by relatively dense shrubs and the increasing presence of trees, although the recovery of forest structure is a very slow process due to soil degradation. Photo: J.M.G.R.

representar el $42 \%$ en los valles occidentales, el 17,6\% en el Valle del Gállego y sólo el 2,7\% en los valles orientales (Lasanta Martínez et al., 1994). Esta distribución indica que en el sector occidental las estructuras agrarias eran más provisionales, sugiriendo que la expansión de la agricultura era un remedio casi coyuntural ante la presión demográfica. En cambio, hacia el este, el carácter más perenne de los campos aterrazados refleja una cultura más intrínsecamente agrícola.

A comienzos del siglo XX, después de alcanzada la máxima presión demográfica de la historia, el Pirineo aparecía muy deforestado, con una extensa superficie de campos cultivados a los que se sumaban los que habían empezado a abandonarse por degradación o simplemente porque había comenzado el retroceso demográfico. Este último alcanza su máxima expresión desde mediados del siglo XX y representa el abandono general de los cultivos en laderas, incluyendo los bancales y los campos en pendiente (Lasanta, 1989). Se aludirá más adelante a este asunto, tanto por su extraordinaria im- portancia paisajística como desde el punto de vista de la gestión del territorio.

Una cuestión que no debe pasarse por alto y que tiene su respuesta paisajística es la acomodación de la organización social frente al crecimiento demográfico y la sostenibilidad del sistema agroganadero. Es bien sabido que la organización social pirenaica descansaba sobre la institución de la casa transmitida de generación en generación a través del heredero único. Este último heredaba más una institución que una propiedad, que debía pasar en igualdad de condiciones o mejorada a su heredero. Esta fue la manera de evitar el desmembramiento de la propiedad (tanto tierras como ganado) y de asegurar la estabilidad de las explotaciones. Este sistema aseguraba al propietario la existencia de mano de obra abundante y muy barata (los hermanos del heredero, es decir, los llamados tiones, y criados procedentes de familias de pequeños propietarios) que contribuía así al sostenimiento de la casa mediante una organización muy patriarcal (Puigdefábregas \& Balcells, 1970; Esteva Fabregat, 1971; Puja- 
das \& Comas, 1975; Daumas, 1976; García-Ruiz, 1976). Esta población se independizaba con frecuencia, recibiendo alguna parcela y necesitando aumentar su propiedad mediante la ocupación de parte del monte, pero nunca dividiendo el tamaño del parcelario. Otros hijos no herederos contribuyeron a la milicia y a las órdenes monásticas y clero regular, así como al peonaje y trabajos domésticos en los centros urbanos de la Depresión del Ebro, relajando tímidamente la presión sobre el territorio. En algunos valles hay además constancia de migración de tiones a América del Norte y de migraciones temporales a Francia (Balcells, 1984, 1985; Calvo Eito et al., 2015) y de notables actividades contrabandistas (Balcells, 1985). De hecho, Moreno Fernández (2002) señala que el régimen de heredero único contaba con importantes ventajas, al ser un mecanismo eficaz de expulsión de la población y de fomento del celibato para reducir la presión demográfica.

Con muy pocas excepciones, si es que hubo alguna, el entramado de pueblos y aldeas estaba ya definitivamente configurado durante la Edad Media, después de que algunos pequeños asentamientos se abandonasen en ese periodo (los llamados posteriormente villares: García-Ruiz, 1976), quizás como consecuencia de la repoblación de tierras reconquistadas. Debido a su posición fronteriza (de manera más notable que en los altos valles), los núcleos de población en el Prepirineo se instalaron en posiciones defensivas o de vigilancia, en torno a pequeños cerros o escarpes dominados en su parte alta por un castillo, organizados en varias líneas defensivas, destacando Abizanda, Samitier, Murillo de Monclús, Aínsa y Boltaña (Biarge, 2011). La presencia de casas fuertes acompañadas de torres defensivas (Guaso, Arasanz, Ligüerre de Cinca, Oto) contribuye también a esa imagen del Prepirineo como territorio fronterizo. El espacio agrícola se organizaba, en general, alrededor de los pueblos, que solían ocupar pequeñas divisorias desde las que descendían las terrazas de cultivo formando fajas alineadas y ordenadas que sugerían un diseño y un esfuerzo comunes. Ya en la Edad Media estaban ocupados todos los llanos posibles,

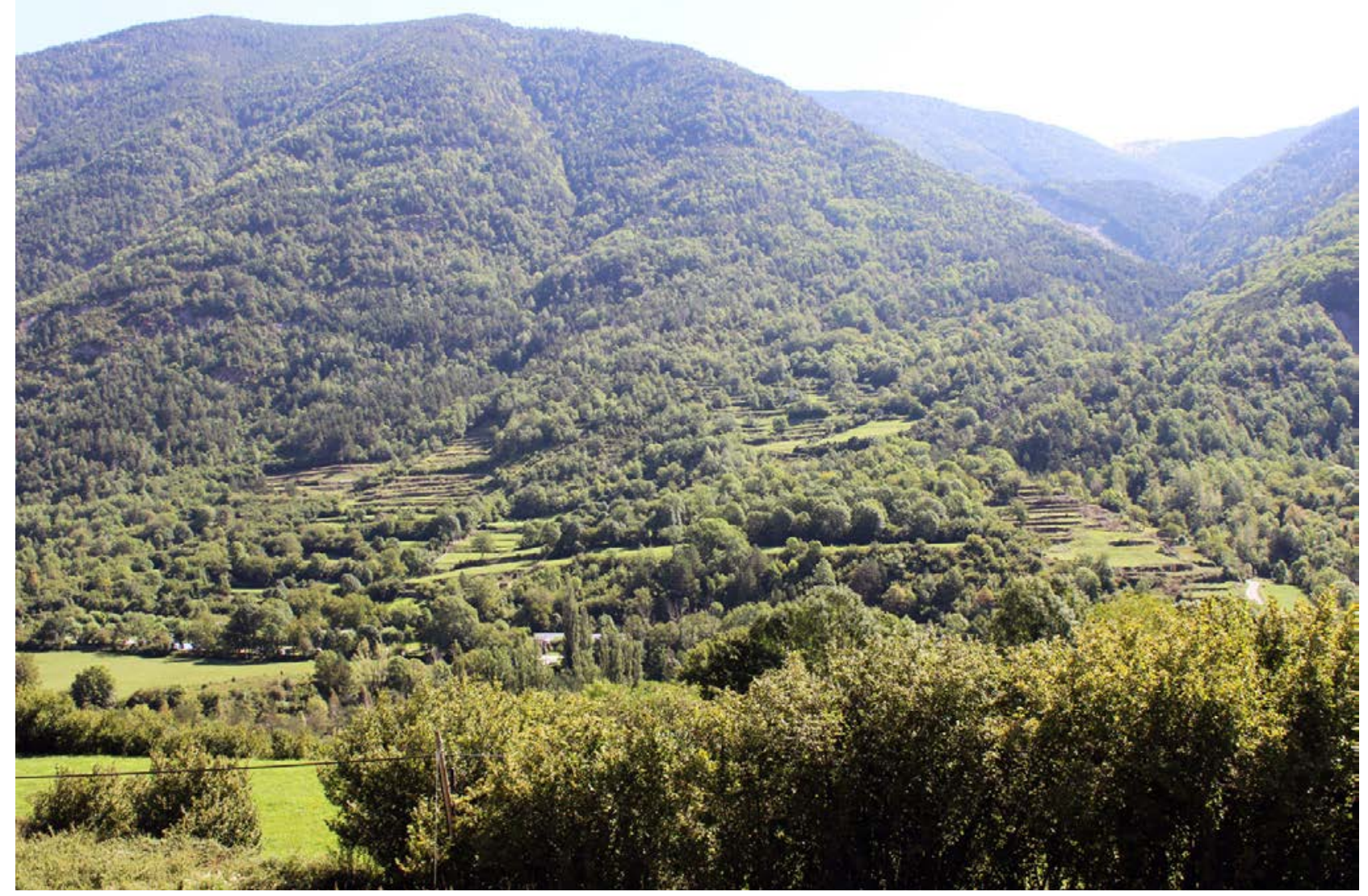

Figura 10: Bancales en el Valle de Broto. La mayor parte de los bancales en el Pirineo aragonés se sitúa al este del Valle del Gállego. El Valle de Broto se caracteriza precisamente por el predominio de bancales, de los que solo se conservan los localizados en los pies de vertiente, donde se acumula suelo y nutrientes y se dispone de mayor humedad. Las laderas aparecen ahora cubiertas de un bosque muy denso, aunque muchas de ellas guardan restos de primitivos bancales. Foto: T.L.

Figure 10: Terraces in the Broto Valley. Most of terraces in the Aragón Pyrenees are located eastwards from the Gállego Valley. The Broto Valley is characterized by the predominance of terraces, although only those located at the foot of hillslopes have been preserved thanks to water, soil and nutrient accumulation. The slopes appear to be covered with a dense forest, although most of them hold remnants of the old terraces. Photo: T.L. 
en depresiones subsecuentes entre relieves en cuesta, permitiendo el crecimiento de un poblamiento disperso en pequeñas aldeas y pardinas en condiciones muy duras y deforestación general; esas aldeas crecieron muy limitadamente y, durante la crisis del siglo XX, se enfrentaron a graves problemas de supervivencia. Hoy el Prepirineo es el territorio donde existe un mayor número de pueblos abandonados (García-Ruiz, 1976; Acín Fanlo, 1997), debido a la debilidad de la red de comunicaciones, la ausencia de centros urbanos organizadores de la actividad económica, los bajos rendimientos del tradicional monocultivo cerealista, la escasez de pastos de calidad bien distribuidos en el tiempo y en el espacio, y las pequeñas dimensiones del espacio cultivable. Pero también es el territorio pirenaico donde, en general, las propiedades son de mayores dimensiones (por ejemplo, en Laguarta, ribera de Fiscal y áreas en torno a Graus y Benabarre: Daumas, 1976), como consecuencia del reparto de tierras durante la Reconquista en un territorio fronterizo poco poblado.
En la Depresión Interior Altoaragonesa los asentamientos se localizaron preferentemente en la ladera que mira al sur, casi siempre en el contacto entre los glacis y las laderas meridionales del flysch. Estos pueblos vivieron de la explotación agrícola de glacis y terrazas fluviales con suelos profundos muy productivos y del aprovechamiento de las laderas meridionales del flysch, especialmente en los momentos de mayor presión demográfica (Figura 11); tales laderas muestran hoy los límites de antiguos campos de cultivo ya abandonados, una evidencia de las dificultades a que tuvieron que enfrentarse incluso los pueblos que disponían de las mejores tierras llanas. La presencia próxima de capitales comarcales (Jaca, Boltaña, Aínsa, Graus y Campo en mucha menor medida) facilitó durante siglos el establecimiento de relaciones sociales y económicas a la sombra de ferias y mercados que contribuyeron a fijar población y crear riqueza (Esteva Fabregat, 1971). En cambio, la conversión de Sabiñánigo (una pequeña aldea a comienzos del siglo XX) en un centro industrial y capital comarcal contribuyó en

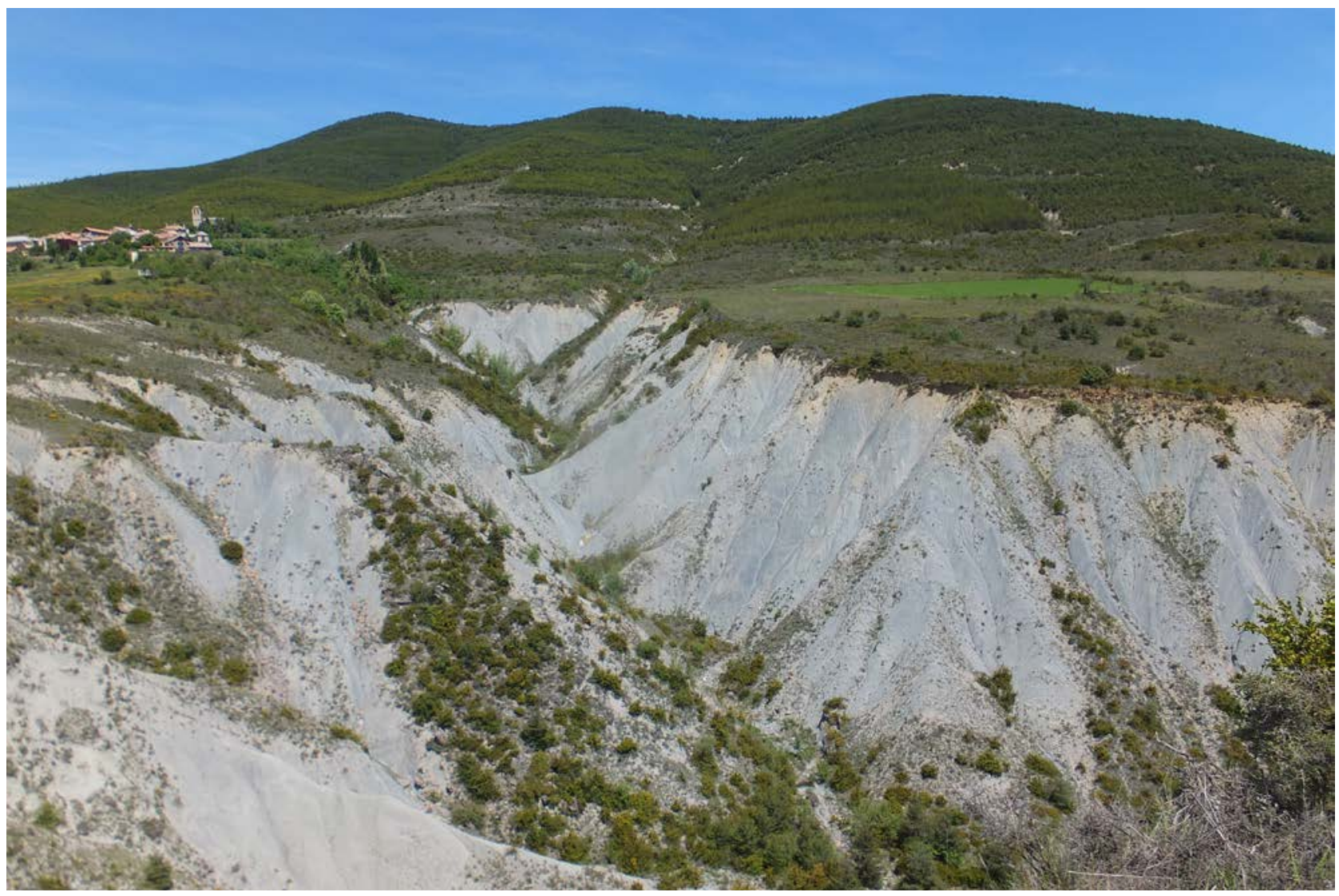

Figura 11: En la Depresión Interior Altoaragonesa los cultivos se asentaron sobre glacis y terrazas, aunque la erosión de las margas amenaza en algunos lugares con recortar la superficie de cultivo. En la foto, campos y gran cárcava junto a Araguás del Solano. Al

fondo, ladera modelada en flysch, actualmente cubierta por repoblaciones de pino laricio y silvestre, ocultando la presencia de antiguos campos cultivados, con bancales precarios. Todo parecía poco para obtener una pobre cosecha de cereales. Foto: J.M.G.R. Figure 11: In the Pyrenean Inner Depression, cultivated fields were located on pediments and fluvial terraces, although erosion in the marl outcrops threats the cultivated area. In the photo, fields and large badlands near Araguás del Solano. In the background, a hillslope on flysch, currently covered with Pinus sylvestris and Pinus nigra afforestations, hiding the presence of old cultivated fields with precarious terraces. Everything seemed necessary for obtaining a poor cereal crop. Photo: J.M.G.R. 
buena parte al vaciado demográfico del Prepirineo (García-Ruiz, 1976), porque el tiempo de creación de nuevas redes de relaciones intracomarcales ya había pasado.

En la parte septentrional del Pirineo aragonés, en los llamados valles altopirenaicos, los asentamientos se distribuyeron entre los fondos de valle y las laderas. Los núcleos principales aprovechan las mejores zonas próximas a los ríos y conos aluviales que pueden no estar estabilizados del todo, mientras las laderas y pequeños valles laterales se ocuparon con aldeas que aprovechan pequeños rellanos (morrenas laterales, obturaciones glaciares, como en Hoz de Jaca, Escuer, Fragén, Buesa, Espierba, Cerler) y laderas muy pendientes cuando creció la población (Valle de la Garcipollera en la cuenca superior del río Aragón, y Valle de la Solana en el Valle del Ara). Es interesante señalar, no obstante, que los núcleos de población se localizan a mayor altitud hacia el este, llegando a superar en Cerler los 1500 m s.n.m., mientras que en los valles occidentales zonas relativamente llanas (Zuriza, Guarrinza), entre 1100 y 1300 m s.n.m., no han contado nunca con poblamiento estable (Creus-Novau \& Balcells, 1986) (Figura 12). Los campos de cultivo, salvo contadísimas excepciones siempre en laderas solanas, ascendieron hasta su límite máximo posible, sobre todo en el sector más oriental del Pirineo Aragonés (en Biadós, La Poma de Gistaín, Cerler, Castanesa, Sahún, Bono, El Chordal y Feneplán en Serveto, Estigüés en San Juan de Plan, Diazas en Torla, Toronzué en la cabecera del río Sorrosal, por ejemplo), donde algunas parcelas abancaladas llegan a conectar con los pastos más bajos del piso subalpino, entre 1500 y 1800 m s.n.m.; son los llamados panares, campos aterrazados separados por taludes herbosos, general-

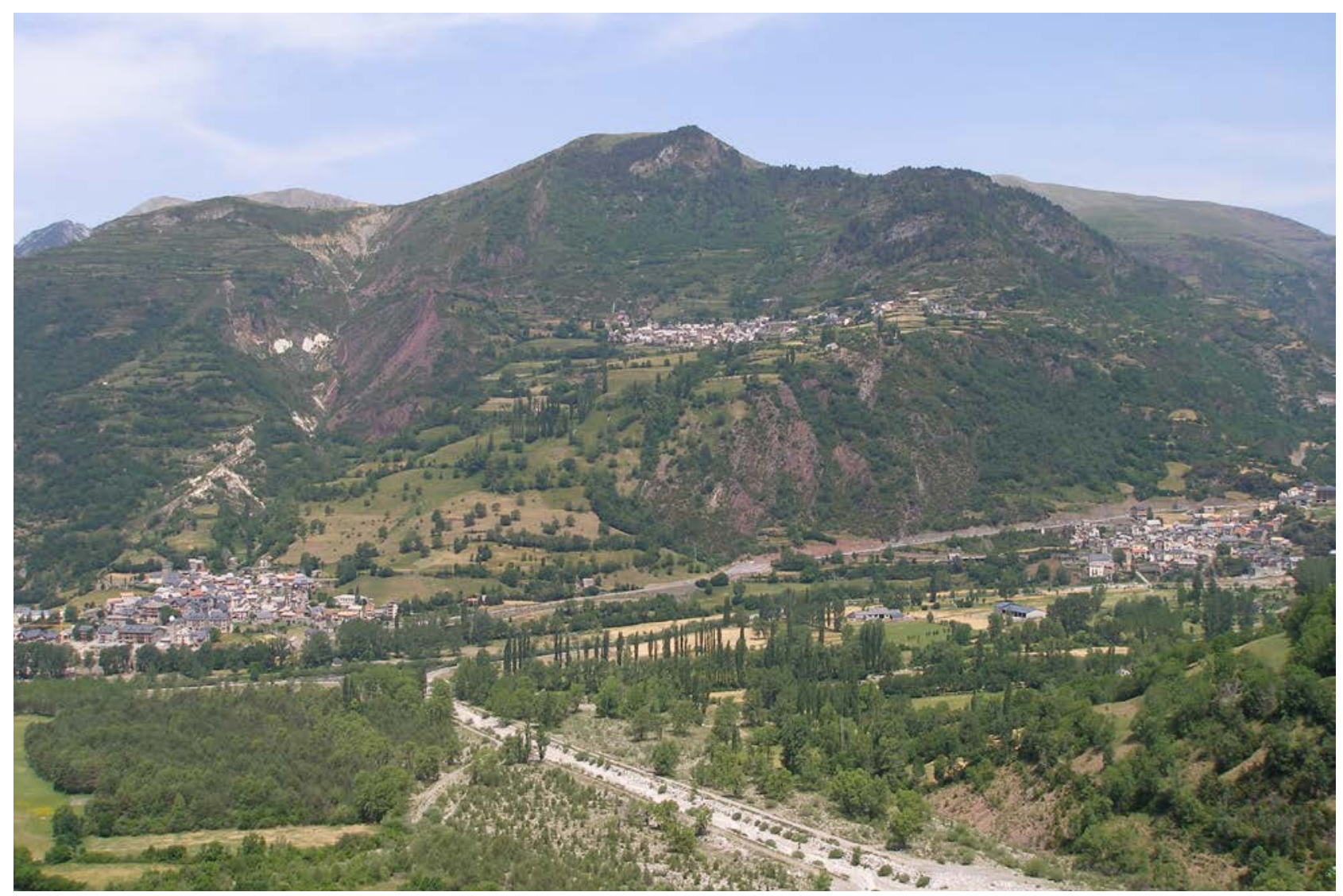

Figura 12: Esta imagen refleja muy bien algunos de los principales rasgos de la organización del espacio en el Pirineo. Gistaín aparece a media ladera, mientras Plan y San Juan de Plan ocupan el fondo del valle. Se ha cultivado todo lo posible. Gistaín se sitúa en la parte alta de un gran deslizamiento profundo, cuya cicatriz, con bosque y campos de cultivo, es bien visible. La lengua del

deslizamiento está completamente cultivada con campos en pendiente, quizás porque algunos movimientos superficiales desestabilizarían a los saltos entre bancales. Hacia la izquierda, los campos de cultivo, ya convertidos en prados de diente cerrados que se degradan hacia la parte alta, escalan una ladera de fuerte pendiente. El fondo del valle está ocupado al máximo. Foto: J.M.G.R.

Figure 12: This image represents some of the main features of the spatial organization in the Pyrenees. The village of Gistain appears at the mid-hillslope, whereas Plan and San Juan de Plan are located in the valley bottom. Most of the territory has been cultivated. Gistain is located in the upper part of a deep-seated landslide, whose scar, with forest and cultivated fields, is visible. The tongue of the landslide is completely cultivated with sloping fields, perhaps because some surface movements should destabilize the walls between terraces. On the left, the cultivated fields have been transformed into closed grazing meadows in a steep slope. Photo: J.M.G.R. 
mente sobre morrenas laterales y rellanos de obturación glaciar, donde se cultivó centeno en ciclos de 13 meses, en una prueba más de la importancia de la presión demográfica en la transformación del paisaje. De hecho, el nombre de panares alude a que eran lugares en que se cultivaba centeno para la producción de pan (Biarge, 2009) (Figuras 13 y 14). Aunque no se dispone de información acerca del momento en que fueron creados esos campos tan peculiares en el límite altitudinal de los cultivos, Daumas (1976) sugiere que su construcción correspondería al siglo XIX y mantuvieron un sistema mixto, espacialmente organizado, de campos de cultivo y barbecho de manera que pudieran pastarse parcialmente. De hecho lo habitual es que los panares formasen dos conjuntos separados en cada municipio, de manera que se cultivaban alternativamente un año sí y otro no para permitir el pastoreo y el abonado de los campos con ganado ovino durante los periodos de tránsito (mayo-junio y sep- tiembre-octubre) (Fernández Piñar, 2019). Según este autor, algunos documentos sugieren la presencia de los $p a-$ nares de Biadós desde al menos el siglo XVI, aunque probablemente la superficie de panares aumentaría en las últimas décadas del siglo XIX y la primera parte del XX, cuando el clima se hizo más benigno tras la Pequeña Edad del Hielo. Lo normal es que los panares aparezcan salpicados de numerosas bordas que podían servir para henificar la hierba, almacenar el grano o como vivienda temporal mientras se realizaban las labores de siembra y cosecha. Los mejores ejemplos se localizan en las cabeceras de los valles de Gistaín (Bordas de Biadós) y de Castanesa (Bordas de Posinqueso). En la actualidad se han convertido en pastos mixtos de siega y diente que se aprovechan sobre todo cuando el ganado inicia su transición hacia el fondo del valle desde mediados de septiembre. Las umbrías, especialmente por encima de 13001400 m s.n.m., mantuvieron amplias superficies forestales

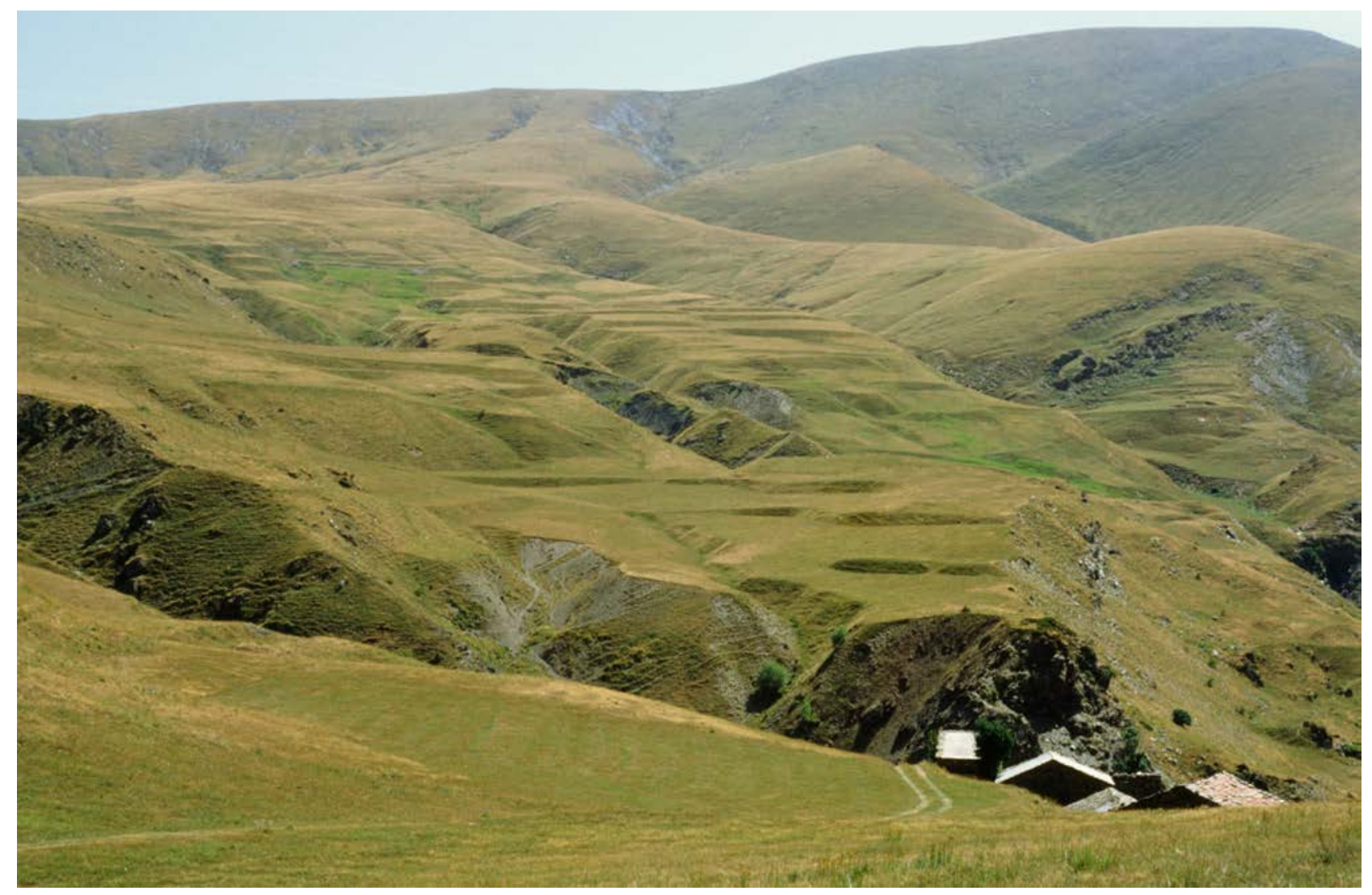

Figura 13: Panares de Posinqueso en la cabecera del Valle de Castanesa. Los panares son campos de cultivo creados en el límite entre el piso montano y el subalpino, donde solo podía cultivarse centeno en ciclos de trece meses, dada la baja integral térmica. En muchos casos se localizan sobre depósitos morrénicos, siempre mediante campos abancalados con saltos cubiertos de hierba

(espuenas). No se cultivaban todos los años y estaban sujetos a una regulación estricta para favorecer el pastoreo con ganado lanar.

Actualmente están todos abandonados, aunque se mantiene un pastoreo muy extensivo y, en ocasiones, un dallado anual para almacenar hierba de cara al invierno. Foto: J.M.G.R.

Figure 13: Panares of Posinqueso, in the headwaters of the Castanesa Valley. Panares are cultivated fields created in the limit between the montane and the subalpine belts, where farmers cultivated rye in a 13-month cycle. In most cases they were located on morainic deposits, forming a series of bench-terraced fields with steps covered with grasses (espuenas). They were not cultivated every year and were subject to strict regulations in order to favour grazing with sheep flocks. At present they are abandoned, although extensive grazing occurs and occasionally they are mowed to store hay for winter. Photo: J.M.G.R. 


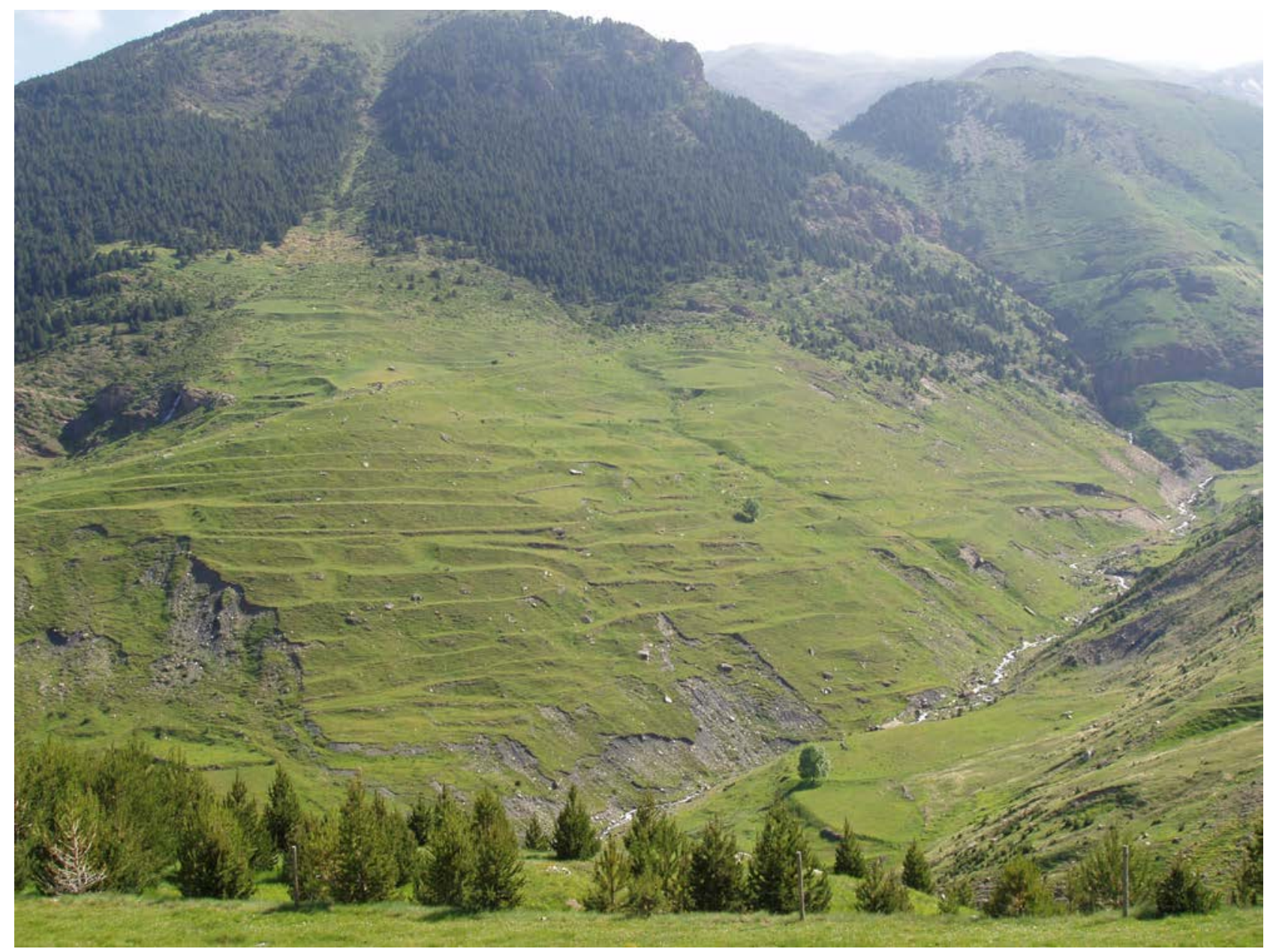

Figura 14: Panares en Cerler, junto al Barranco de Remáscaro. Pequeños bancales en ladera muy pendiente, sobre depósitos morrénicos muy inestables afectados por deslizamientos. El tamaño de las parcelas y la elevada altitud indican que estos campos se construyeron en una situación límite, quizás para favorecer también el pastoreo de los rebaños cuando ascendían a los puertos de verano o descendían a la invernada trashumante. Foto: T.L.

Figure 14: Panares at Cerler, close to the Remáscaro ravine. Small bench-terraced fields in a steep slope, on instable morainic deposits affected by shallow landslides. The size of the plots and the high altitude suggest that these fields were constructed under extreme conditions, maybe to favour grazing when the sheep flocks climbed up to the summer grasslands or descended towards the areas of winter transhumance. Photo: T. L.

que han llegado hasta hoy como reservas de madera y leña, explotadas mediante normas estrictas, dado que no tenían ninguna utilidad agrícola.

\subsection{Acontecimientos históricos con influencia en la evolución del paisaje}

No hay informaciones directas que muestren las relaciones entre los conflictos de época preindustrial que han sacudido al Pirineo Central a diferentes escalas espaciales (regional y nacional) y la construcción de su paisaje. En términos generales, parece evidente que cualquier evento de cierta duración ha debido tener influencia en la forma e intensidad con que se ha venido transformando el paisaje. Pero las evidencias directas son pocas: no sabemos cómo afectó la romanización al paisaje pirenaico, y no conocemos la existencia de colonias para asentar a veteranos licenciados de las legiones. Es bien conocido que el Pirineo aragonés fue lugar de paso, especialmente a través del Puerto de Somport (Valle del Aragón) y de otras vías mucho más secundarias (Puerto de Palo, en la cabecera del Valle de Hecho: Moreno Gallo, 2006), lo que sin duda tendría algún efecto en el poblamiento y en la transformación, siquiera modesta, del paisaje. En otros lugares de la Península Ibérica (por ejemplo, en la Cantábrica asturiana) el territorio estaba ya ampliamente deforestado en época romana, seguramente con finalidad ganadera (Fernández Mier et al., 2013). La información sobre los efectos de la dominación visigoda es aún más fragmentaria, aunque su influencia se deja sentir en algunos edificios (por ejemplo, el Monasterio de San Urbez, cerca de Noci- 
to). Y sólo podemos intuir las consecuencias de la invasión musulmana, con el consiguiente desplazamiento de godos notables y clérigos que se refugiaron en las tierras altas pirenaicas, especialmente en el primitivo Aragón (en torno a Jaca) y en la Ribagorza, donde los musulmanes no llegaron a ejercer un control total gracias a la penetración carolingia. En Sobrarbe, en cambio, los musulmanes se instalaron en puntos estratégicos (Boltaña, Aínsa, Roda) (Bielza de Ory et al., 1986), con efectos aún desconocidos sobre el paisaje. En torno a nuevos monasterios (por ejemplo, Siresa, San Martín de Cercito, San Victorián, Obarra, Alaón y varios más, desde el siglo IX) hubo sin duda una expansión del espacio cultivado para atender a las necesidades del aumento de población. Es conocido el caso del Monasterio de San Adrián de Sasave en el valle de Borau. Fundado en el siglo IX, y sede del primer obispo de Aragón, a su alrededor se eliminó gran parte del bosque para cultivar casi todas las laderas, muchas de ellas con bancales. Esa deforestación en coincidencia con tormentas de elevada intensidad tuvieron severos efectos erosivos, con el arrastre de grandes cantidades de sedimento hasta enterrar parcialmente al Monasterio durante el siglo XII, y casi ocultarlo del todo durante el siglo XVIII (Martí et al., 1997). Hoy es inimaginable que esto pudiera ocurrir dado el denso cubrimiento forestal de las laderas, pero durante buena parte de las edades Media y Moderna la cuenca que drena hacia el Monasterio estaba cultivada, incluso en pendientes muy fuertes, como lo muestran los restos de los límites de antiguos campos cultivados y, especialmente, los numerosos muros de bancales. Es muy probable, por lo tanto, que los altos valles pirenaicos, desde la Depresión Interior hacia el norte experimentaran notables cambios paisajísticos hasta comienzos del siglo XII, cuando se reconquista buena parte de la Depresión del Ebro, hasta más al sur de Zaragoza. La llegada de un número no conocido de nobles visigodos y clérigos, debió de favorecer la deforestación y la expansión de la superficie cultivada. Durante este largo periodo, el paisaje estaría dominado por pequeños espacios cultivados de cereales, así como viñas, que llegan hasta el Monasterio de Siresa, aprovechando las bondades de la Anomalía Climática Medieval (Moreno et al., 2012), y también en el Valle de Broto, en Boltaña, Puértolas y La Fueva, con especial abundancia de citas durante los siglos X y XI (Azcárate Luxán, 1990). La ganadería, probablemente organizada en pequeños rebaños, debió de gozar de prosperidad por su facilidad de movimiento para trasladarse a lugares más seguros durante las numerosas incursiones que desde los vascones a los musulmanes asolaron a las tierras pirenaicas aragonesas.

No están claros los detalles de la ubicación de la frontera cristiano-musulmana a comienzos del siglo XI, pero por razones estratégicas y orográficas, debió estabilizarse pronto en las sierras prepirenaicas, al sur de la Depresión Interior Altoaragonesa, entre el inicio de los relieves accidentados de San Juan de la Peña, Oroel, Canciás y el frente de las Sierras Exteriores (Santo Domingo, Gabardiella, Guara, Montsech) en contacto con la Depresión del Ebro. A lo largo del siglo XI la progresión hacia el sur fue relati- vamente rápida, de manera que en 1067 Sancho Ramírez había tomado ya el frente de las Sierras Exteriores (Alquézar, Santa Eulalia, Graus y Barbastro por ejemplo), y en 1088 se inició la fortificación de Montearagón, junto a Huesca (Buesa Conde, 1978). Hasta entonces las sierras prepirenaicas debieron de funcionar como tierra de nadie, con asentamientos muy pequeños y espacios vacíos con escaso control por ambas partes. Se conquistaron definitivamente muy pronto, a lo largo del siglo XI, y se repoblaron de manera muy modesta, con pueblos ocupando rellanos locales de carácter más arcilloso entre escarpes de areniscas, a modo de depresiones subsecuentes. Además de las pequeñas propiedades unidas a los pueblos, la Reconquista dio lugar a explotaciones mayores, repartidas como dote entre los conquistadores o como donaciones a los Monasterios; esas explotaciones fueron origen de las futuras pardinas y masías (Figura 15). Todas ellas, con edificios de cierta entidad, se convirtieron en explotaciones aisladas en el monte, que cultivaban cereal en pequeñas depresiones y además mantenían rebaños de ovejas. Han pervivido hasta la actualidad, aunque con muy pocas excepciones se encuentran ya abandonadas. Su superficie superaba, en general, las 150 ha y podía sobrepasar excepcionalmente las 1000 ha. Eran particularmente numerosas al sur de San Juan de la Peña y Oroel y en el Prepirineo del Alto Aragón Oriental, y definen un tipo de paisaje peculiar con frentes y reversos de cuesta, depresiones subsecuentes, campos de cultivo permanentes en estas últimas y ocupación agrícola casi general de los reversos de cuesta, alternando con bosques que llegaron muy reducidos en extensión a comienzos del siglo XX. Estas pardinas también sirvieron como áreas de pasto para los rebaños trashumantes que ascendían a los puertos de verano en mayo y los que descendían a la Depresión del Ebro en octubre. Se conocían como aborrales. También, aunque desconocemos su alcance temporal, sirvieron para pasto invernal (entre noviembre y mayo) de ganaderías vacunas trashumantes procedentes de los valles de Ansó y Hecho (García-Ruiz $\&$ Balcells, 1978). Los numerosos acuerdos entre municipios fronterizos de España y Francia (facerías o pacerías, por ejemplo entre los valles de Ossau y Canfranc a finales del siglo XIII) para aprovechar los pastos más alejados son una prueba más de la delicada organización del aprovechamiento de los pastos (Utrilla Utrilla et al., 2005). Lo que parece evidente es que la evolución de la trashumancia estuvo estrechamente vinculada a la evolución del reino de Aragón, de manera que las principales rutas de la trashumancia se vertebran entre 1170 y 1230 (Bielza de Ory et al., 1986), muy probablemente siguiendo rutas ya establecidas en épocas anteriores.

Es interesante señalar que en los altos valles pirenaicos los términos municipales no siempre coinciden con los límites impuestos por la topografía, debido a concesiones de origen medieval. Así, la Mancomunidad de Ansó-Fago no se limita al territorio drenado por los ríos Veral y Fago, sino que por la parte más elevada se extiende hacia el este, apropiándose de las cabeceras de los ríos Aragón Subordán (que corresponde al Valle de Hecho), Osia (que corresponde al Valle de Aragüés) y Estarrún (en 


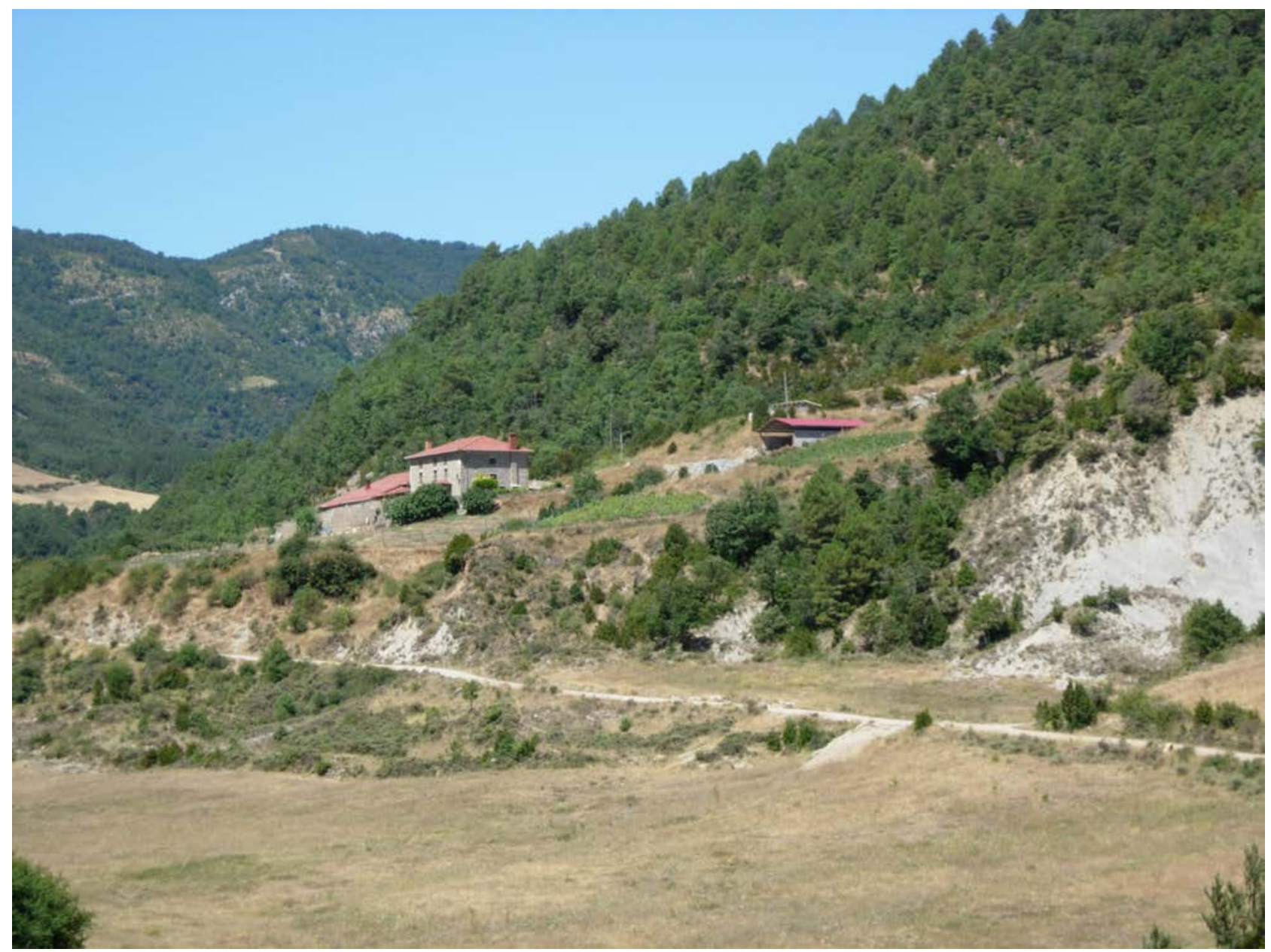

Figura 15: Pardina de Ferrera, cerca de Salinas de Jaca y Villalangua, en el Prepirineo aragonés. Las pardinas son grandes fincas, localizadas especialmente en el Prepirineo, de origen medieval, muy relacionadas con el proceso de Reconquista y, más tarde, con la Desamortización. Constituyen un ejemplo de hábitat disperso con explotación agrícola, ganadera y forestal. En la segunda mitad del siglo XX se abandonaron de manera general y se han visto favorecidas por una reforestación natural o, en muchos caso, repoblaciones forestales inducidas. Tradicionalmente, las pardinas se utilizaban también durante aproximadamente un mes como pastos de tránsito por parte de los ganaderos trashumantes, especialmente cuando regresaban hacia los altos valles pirenaicos en los meses de abril y mayo. Más recientemente, algunas pardinas se han utilizado como lugares de invernada de ganado vacuno.

Foto: J.M.G.R.

Figure 15: Pardina of Ferrera, close to Salinas de Jaca and Villalangua, in the Aragón Pre-Pyrenees. Pardinas are large properties, particularly located in the Pre-Pyrenees. They have a medieval origin and were related to the Reconquista process and, lately, with the Desamortización. They are the example of scattered habitat with agricultural, stockbreeding and forest exploitation. They were

abandoned during the second half of the 20th century and have been favoured by natural reforestation or human-induced afforestation. Traditionally, pardinas were also used during one month as intermediate grasslands when the transhumant sheep flocks came back to the high Pyrenean valleys in April and May. Recently, some pardinas have been used as areas for transhumant cows in winter Photo: J.M.G.R.

el Valle de Aísa), ampliando mucho la superficie ocupada por pastos estivales y creando un fuerte desequilibrio entre recursos pastorales de verano e invierno que explica la tradicional importancia de la trashumancia en el valle de Ansó. En compensación, el Valle de Hecho penetra por el sur en el Valle de Ansó (Bordas de Santa Lucía, que llegaron a estar pobladas) en una zona de predominante aprovechamiento agrícola. Además, el Valle de Aísa penetra en la cabecera del Valle del Aragón, donde cuenta con los pastos de Candanchú. Igualmente, la ciudad de Jaca dis- pone del enclave altimontano de Astún y La Raca (Balcells, 1985). De la importancia de los pastos de verano hablan muchos documentos, reflejando el interés de distintos pueblos por acceder a ellos mediante concesiones reales, así como los derechos obtenidos por la Casa de Ganaderos de Zaragoza para pastar en la cabecera de los valles de Ansó al Gállego (Utrilla Utrilla et al., 2005).

Otro fenómeno político de gran trascendencia paisajística en toda España fue la Desamortización de Mendizábal en 1835-36, seguida por la de Madoz en 1855, 
aunque ya había habido precedentes desde finales del siglo XVIII (Tomás y Valiente, 1972). Estas desamortizaciones consistieron en la expropiación por el Estado y la consiguiente venta pública de las tierras que no se podían enajenar por pertenecer a la Iglesia Católica y las órdenes religiosas, así como los llamados baldíos y tierras comunales, que eran utilizadas por todos los habitantes de cada municipio, en algunos casos representando casi el $90 \%$ de la superficie del municipio. No obstante, la mayor parte de los montes comunales expropiados fueron puestos a disposición de los municipios como bienes de propios, tal como sucedió también en valles pirenaicos catalanes (Beltrán \& Vaccaro, 2017). Las tierras que pudieron venderse fueron adquiridas por otros grandes propietarios y la burguesía urbana. Así debió suceder en el Prepirineo aragonés, donde algunos monasterios eran grandes propietarios de tierras, aunque difícilmente pasaron a manos de los lugareños. Muchos de los bosques que habían sobrevivido hasta el siglo XIX fueron rápidamente eliminados para la extracción de madera o la fabricación de carbón vegetal. En cambio, los habitantes locales se activaron para formar sociedades capaces de comprar sus antiguos bienes comunales, de manera que pudieran seguir siendo explotados por sus antiguos usufructuarios. Esas sociedades (en Nocito, Longás, Laguarta, Sarsa de Surta, Castanesa, Montanuy, por ejemplo) han llegado hasta nuestros días y siguen activas a pesar del descenso de la presión demográfica. En los siglos XIX y XX contribuyeron a ayudar a la población más marginal, al permitir roturaciones temporales que se aprovechaban mediante sistemas de agricultura nómada (Daumas, 1976; García-Ruiz, 1976) y a la preservación de montes comunales que eran fundamentales para el mantenimiento de la gestión ganadera (en las sierras de Guara y Santo Domingo). No obstante, algunos bienes quedaron excluidos de la venta y continuaron como propiedades comunales o de los ayuntamientos: ese es el caso de las dehesas boyales o boalares, que estaban destinados al pastoreo del ganado de labor en un ambiente de bosque abierto.

También la Guerra Civil española tuvo notables implicaciones en la evolución del paisaje pirenaico, aunque de efectos limitados y escasa duración. Los pocos trabajos que hacen referencia a los posibles cambios se refieren a una reactivación de la agricultura nómada como consecuencia de la necesidad de forzar la producción agrícola tras la guerra por una evidente crisis de subsistencia (García-Ruiz, 1976), aunque sólo afectó a la población más marginal durante la década de 1940. También se recuperaron algunos campos abandonados, si bien solo hasta que se produjo el descenso demográfico de las décadas de 1950 y 1960.

\subsection{La influencia del mercado}

La demanda de determinados productos ejerce actualmente una gran influencia en los cambios de paisaje. De hecho, puede llegar a considerarse como el factor más importante, pues determina umbrales de rentabilidad que condicionan la toma de decisiones por parte de los agricultores. En otras áreas de montaña de la Península Ibérica (en las Cordilleras Béticas, particularmente) es el mercado el que ha incentivado el cultivo de almendros y olivos, llegando a ocupar laderas muy pendientes, con roturaciones recientes de antiguos campos abandonados. Otro tanto ha sucedido con la vid en laderas de la Cordillera CosteroCatalana, donde incluso se han creado bancales muy inestables afectados por graves problemas erosivos (MartínezCasasnovas \& Ramos, 2006; Rodrigo Comino et al., 2017). Pero, históricamente, la influencia del mercado ha sido muy limitada, aunque ocasionalmente determinante, en una zona montañosa como el Pirineo aragonés, debido a la menor plasticidad de las condiciones naturales para permitir cambios bruscos en el aprovechamiento del territorio.

Durante siglos la actividad económica en el Pirineo aragonés se ha enfocado en buena parte hacia la subsistencia, sin dejar de producir artículos con salida comercial en la misma montaña o en zonas próximas (Moreno Fernández, 2002). Con poca superficie de cultivo y bajas producciones, la venta de cereales fuera de la región debió ser solo importante en la Depresión Interior Altoaragonesa, mientras en el resto del territorio ese cultivo buscaba sobre todo el autoabastecimiento, sin conseguirlo en la mayor parte de los casos. Buil Guiral (1997) confirmó que la producción de cereales a finales del siglo XVIII fue casi siempre insuficiente para las necesidades de la población en los valles de Broto, Gistaín, Bielsa y Tena, mientras que Benasque se autoabastecía de cereal. Por eso en el momento en que la población creció durante los siglos XVIII y XIX se cultivó todo lo posible, en pendientes extremas y con escasas medidas de conservación del suelo. Eso se hacía para sobrevivir, no para vender unas cosechas muy débiles a cambio de un esfuerzo enorme. Los ingresos procedentes de la venta de cereal serían, pues, muy reducidos, siendo la madera, la venta de ganado de trabajo y la producción de lana las que generarían mayores ingresos y permitirían comprar productos del Somontano (aceite y vino, sobre todo, especialmente durante la Pequeña Edad del Hielo, que debió desplazar a muchos viñedos fuera de la Depresión Interior y de los altos valles). La explotación forestal fue muy importante y estuvo muy controlada mediante complejas ordenanzas, con el fin de mantener un comercio con Barcelona, Valencia y Zaragoza (Bielza de Ory et al., 1986). La artesanía textil debió ser importante en el Pirineo aragonés, aprovechando la gran producción lanera relacionada con la trashumancia, aunque se dispone todavía de escasa información. Según Moreno Fernández (2002), tuvo especial relevancia en Jaca y Biescas, así como en los valles de Tena y Broto. Otros ingresos procedían, sin duda, de las migraciones temporales al sur de Francia o al centro de la Depresión del Ebro. En todo caso, la importancia de la demanda de productos ganaderos es lo que explica la definitiva expansión de los pastos estivales en el piso subalpino, como sugiere Montserrat (1992) a partir de la presencia de un marcado nivel de cenizas en los sedimentos del lago de Tramacastilla, alto Valle del Gállego, en torno 
a $1700 \mathrm{~m}$ de altitud, reflejando un momento de intensa deforestación a partir del año 1000. La actividad minera pudo ser también localmente importante y favorecer una deforestación temprana; así, destacaron las minas de plata, hierro y plomo de Benasque, Bielsa, Gistaín y el Valle del Gállego, donde más tardíamente hubo extracción de carbón hasta el último tercio del siglo XX (Utrilla Utrilla et al., 2005).

Otros cambios paisajísticos son más recientes y están relacionados sobre todo con la despoblación desde mediados del siglo XX. A ellos nos referiremos más adelante. Un cambio de uso relativamente reciente con trascendencias paisajísticas es la expansión de los prados y cultivos forrajeros, que históricamente han sido minoría frente a la mayor superficie ocupada por los cereales. Es cierto que estos últimos siguen siendo mayoritarios en el Prepirineo y en la Depresión Interior Altoaragonesa, debido principalmente al incremento de la producción (mayor profundidad de las labores agrícolas y uso de fertilizantes incluso por encima de lo necesario), a la escasez de mano de obra $\mathrm{y}$ al hecho de que el número de ganaderos ha descendido y no necesitan producción de forraje. Pero en los altos valles pirenaicos el cereal ha sido sustituido de forma general por prados de diente y de siega, así como por cultivos forrajeros que se cortan dos o tres veces desde mayo a septiembre. No era así hasta hace unos 50 años, pues los prados ocupaban pequeñas extensiones en campos sobre conos de deyección, en pies de vertiente o en algún rellano colgado de origen glaciar, próximo a fuentes. Servían para obtener hierba con la que alimentar a animales más débiles o a ganado vacuno en régimen estabulado o semiestabulado. En el resto de los campos tenía preferencia el cereal incluso hasta altitudes muy elevadas, en torno a 1600 m s.n.m. Sin embargo, hay varios hechos que han fomentado la sustitución de los campos de cereal por prados de diente o de siega: (i) El innecesario cultivo de cereales para el autoconsumo en un mercado abierto y fáciles comunicaciones. (ii) La casi total desaparición de la trashumancia y el predominio de una ganadería trasterminante basada más en el vacuno que en el ovino, con ascenso desde mayo a los puertos de verano y regreso en octubre a los alrededores de los pueblos, pastoreando en prados y en zonas de bosque y matorral; de ahí la expansión de prados en los antiguos campos de cultivo próximos a los pueblos (García-Ruiz \& Lasanta-Martínez, 1990; García-Ruiz et al., 1996) (Figura 16). (iii) La construcción de embalses ha acelerado los cambios: los embalses ocupan los mejores fondos de valle, obligando a ganaderos a producir intensivamente hierba en los pocos campos que han quedado liberados de la inundación o en campos a media ladera; así ha ocurrido en el alto Valle del Gállego, donde la reducción de recursos pastorales de invierno ha condicionado la negativa evolución de los censos ganaderos más que en otros valles pirenaicos (García-Ruiz \& Lasanta-Martínez, 1993). Muchos de los prados actuales se asientan en antiguos campos cerealistas, donde se ha introducido recientemente un bocage que cierra las parcelas y favorece el pastoreo individual (Daumas, 1976) (Figura 17). El paso de cereal a prados ha sido relativamente fácil por en- cima de 1000 m s.n.m., pero muy problemático por debajo, a no ser que se puedan regar para superar los problemas de una corta pero limitante sequía (Puigdefábregas y Fillat, 1986). Conviene señalar que una evolución similar, si cabe más acusada, ha tenido lugar en la Cordillera Cantábrica, donde la tradicional importancia de los cereales se ha visto superada por la generalización de los prados, favoreciendo, allí sí, la extensión de un paisaje de campos cercados que está completamente subordinado a la explotación ganadera (García Fernández, 1975).

Hay también otros cambios menores ligados al mercado, aunque todavía muy incipientes. Es el caso de la implantación de viñedos, probablemente beneficiados además por el calentamiento global y sus expectativas a corto plazo. Así ocurre en Barbenuta, a unos 1180 m s.n.m., en la Ribera de Biescas, si bien las mayores extensiones de viñas se han plantado en el Prepirineo próximo a Barbastro, acogiéndose a la Denominación de Origen Somontano, siguiendo una larga tradición que se benefició de la baja altitud de pequeñas depresiones intramontanas. Probablemente veremos más ejemplos en los próximos años.

\section{La ganadería como factor de los cambios de paisaje en las áreas de montaña}

En general, la creación y transformación de los paisajes de montaña es un proceso muy lento, en el que intervienen tanto las actividades agrícolas como las ganaderas. En las últimas décadas se ha afirmado frecuentemente que la vida en la montaña y, por lo tanto, su paisaje están condicionados por los modos de explotación ganadera. Pero eso es cierto solo parcialmente, porque la necesidad de obtener alimentos para asegurar la supervivencia y autoabastecimiento de las poblaciones locales ha impulsado la ocupación de fondos y laderas para producir cereales. Pero incluso esos campos de cultivo han tenido una importante relación con la práctica de la ganadería. Se ha llegado incluso a afirmar que gran parte de la población de la montaña estaba formada por agricultores con algo de ganado (Balcells, 1984), si bien fueron los grandes propietarios de lanar trashumante los que contribuyeron a la perspectiva ganadera del Pirineo aragonés.

Son varios los aspectos en que puede señalarse el importante peso de la ganadería en la construcción de los paisajes en los altos valles pirenaicos. El más destacado es el escalonamiento altitudinal de los ecosistemas y la presencia de los pisos subalpino y alpino que fueron percibidos desde muy temprano como áreas de posible aprovechamiento ganadero. Es casi seguro que los habitantes pre-neolíticos serían conscientes de la estacionalidad de los recursos pastorales y de los movimientos de los herbívoros salvajes entre las áreas culminantes pirenaicas y las tierras bajas. Por eso los pocos habitantes que ocuparon tempranamente las partes bajas de los valles ascenderían a las zonas herbosas alpinas en verano y ampliarían progresivamente su extensión a expensas de los bosques subalpinos. Hay algunas, pocas, evidencias en el Pirineo: una de ellas es la presencia de un breve nivel de cenizas con 


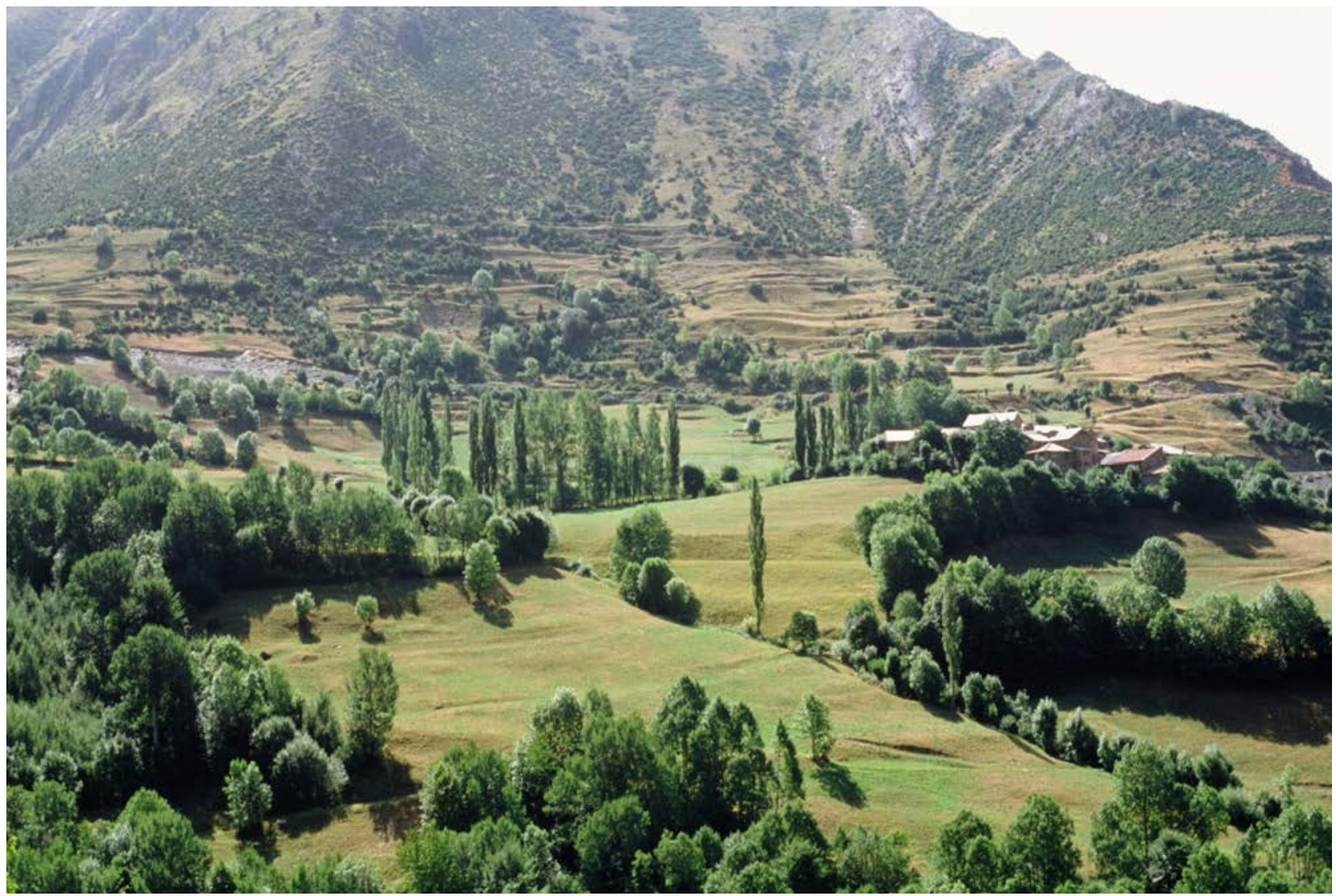

Figura 16: Prados de Fonchanina, en el alto Valle de Castanesa. Los prados suponían una pequeña extensión de la superficie cultivada en la economía tradicional, frente a la gran importancia de los cereales. Esto se explica porque la mayor parte del ganado practicaba la trashumancia y no necesitaba alimentarse con los recursos del valle durante el invierno, salvo en el caso del ganado de labor y quizás unas pocas ovejas. En cambio, se necesitaba producir grano para alimentar a la población local. Los campos de cereal se organizaban espacialmente en dos sectores que se alternaban un año tras otro, uno de los cuales se cultivaba y el otro permanecía

en barbecho. De esta forma, la gran extensión del cultivo cerealista favorecía también el pastoreo durante los meses intermedios, poco antes de subir a puertos de verano o de descender hacia los lugares de invernada. Desde la década de 1950 los campos de cereal fueron progresivamente sustituidos por prados de siega y de diente. Foto: J.M.G.R.

Figure 16: Meadows of Fonchanina, in the Upper Castanesa Valley. Meadows represented a small proportion of the cultivated areas in the old traditional economy, at least compared with the large extent occupied by cereal fields. The reason is that most of livestock was transhumant and did not need to feed from the valley resources in winter, except in the case of the labour animals and a few ewes. On the other hand, it was necessary to produce cereal to feed the local population. Cereal fields were usually organized into

two sectors that alternated year after year, one of them cultivated and the other in fallow. Consequently, the cereal fields also favoured grazing during the intermediate months, immediately before climbing to the summer grasslands and before descending to the winter areas. Since the 1950s, cereal fields were progressively substituted with grazing and cutting meadows. Photo: J.M.G.R.

edad en torno a 4000 años en los sedimentos acumulados en el lago de Tramacastilla (Montserrat, 1992) que indica un incendio de escasa entidad y una rápida recuperación de la vegetación forestal. En otras montañas hay evidencias anteriores, como, por ejemplo, en la Sierra de Urbión, donde los incendios del piso subalpino se remontan a algo más de 5000 años (García-Ruiz et al., 2016a y b). Con el tiempo, y a medida que las necesidades de pastos de verano fueron aumentando, se ampliaría la deforestación de los bosques subalpinos, de manera que el límite superior del bosque se vio profundamente alterado (García-Ruiz et al., 2015), así como su dinámica geomorfológica, con la formación de deslizamientos planares, poco profundos pero muy activos como agentes de erosión
(García-Ruiz et al., 2010). Es muy probable que en el Pirineo el momento de mayor expansión de los pastos subalpinos ocurriera durante los siglos X al XII, como así lo sugiere también el aumento de la tasa de sedimentación en el lago de Tramacastilla: Montserrat (1992). De ahí que pueda afirmarse sin lugar a dudas que, por encima de 1500 m s.n.m. (a veces menos en algunos lugares, como en Guarrinza, alto Valle de Hecho) el paisaje es eminentemente ganadero, porque fue transformado pensando en el aprovechamiento por parte de grandes rebaños (trashumantes y trasterminantes) desde mediados o finales de junio a finales de septiembre (Figuras 18 y 19). Los pocos bosques que han permanecido dentro de ese espacio subalpino se explican por su función de reserva de leña y ma- 


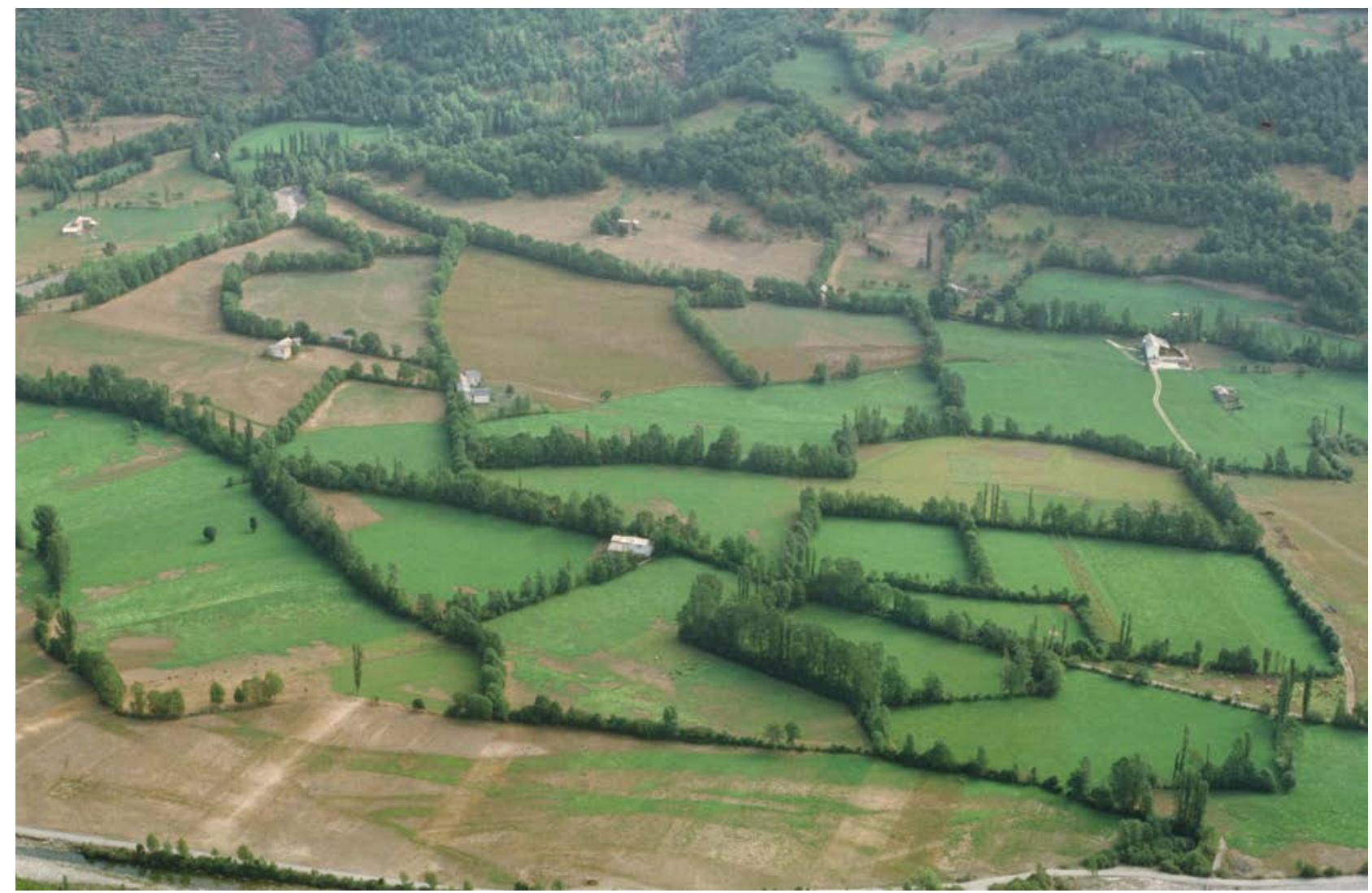

Figura 17: Antiguos campos de cereal cerca de Benasque, en el fondo del Valle del Ésera. En las últimas décadas se transformaron en prados para alimentar al ganado, favoreciendo un sistema de aprovechamiento ganadero más individualizado por medio del cercado de las parcelas. Foto: J.M.G.R.

Figure 17: Old cereal fields, close to Benasque, in the Ésera River valley bottom. They were transformed into meadows in the last decades to feed the livestock in winter, favouring a more individual stockbreeding by means of closed plots. Photo: J.M.G.R.

dera (Selva del Pacino en Sallent de Gállego: Figura 20) o porque su fuerte pendiente o la elevada pedregosidad de los suelos no auguraban una suficiente productividad en caso de que se hubieran sustituido por pastos (ese debió ser el caso del bosque en la Sierra de las Cutas, en el P.N. de Ordesa y Monte Perdido, sobre un karst muy accidentado y pendiente difícilmente aprovechable por el ganado ovino).

Los pastos subalpinos se han mantenido con escasos cambios gracias a una fuerte presión con distintos tipos de ganado. Balcells (1984) señala que a comienzos del siglo XX el Valle de Ansó (incluyendo también a Fago) contaba con un censo de más de 50.000 ovejas, además de los rebaños que subían en verano desde el Prepirineo y la Depresión del Ebro. En 1965 habían pasado a ser unas 44.000 y en $1975,28.000$, contando también con los corderos jóvenes. En 1999, 6.102 ovejas y 354 cabras. En 2009, 5.859 ovejas y 145 cabras. El número de ejemplares de vacuno ha sido muy inferior, destinado sobre todo a la producción de bueyes para labor y, en menor medida, para la producción de carne o leche: 609 vacas en 1940 y 1.063 en 1975, con tendencia creciente posterior a medida que el ganado ovino ha ido retrocediendo. En 1999,
1.049 vacas y 18 yeguas. En 2009, 924 vacas y 19 yeguas. Es importante tener en cuenta que la capacidad total de la Mancomunidad de Ansó-Fago es de 54.231 lanares y 1.000 cabezas de ganado mayor, mientras que los puertos subalpinos de la Mancomunidad de Hecho-Urdués tienen capacidad para 36.985 lanares y 1.000 cabezas de vacuno. En la Mancomunidad de Aragüés-Jasa, la capacidad de los puertos asciende a 10.345 lanares y 450 vacunos. En total entre los valles de Ansó, Hecho y Aragües ha habido una capacidad de carga para 101.000 lanares y 2.450 vacunos, lo que explica que parte de los puertos se arrendasen a ganaderos prepirenaicos o de la Depresión del Ebro, con una capacidad para 34.275 lanares, especialmente en la Mancomunidad de Hecho-Urdués (Balcells, 1984). Cifras no tan elevadas se han dado en otros valles, siendo especialmente altas en los valles de Tena (o Gállego), Broto, Bielsa-Gistaín, Benasque y Castanesa. En todos ellos también hubo yeguas para la producción de ganado de tiro y labor y cabras para la producción de carne y leche. Lo importante es que cada tipo de ganado está adaptado para consumir pastos de diferente composición y calidad, de manera que históricamente se han complementado para reforzar las características paisajísticas y 


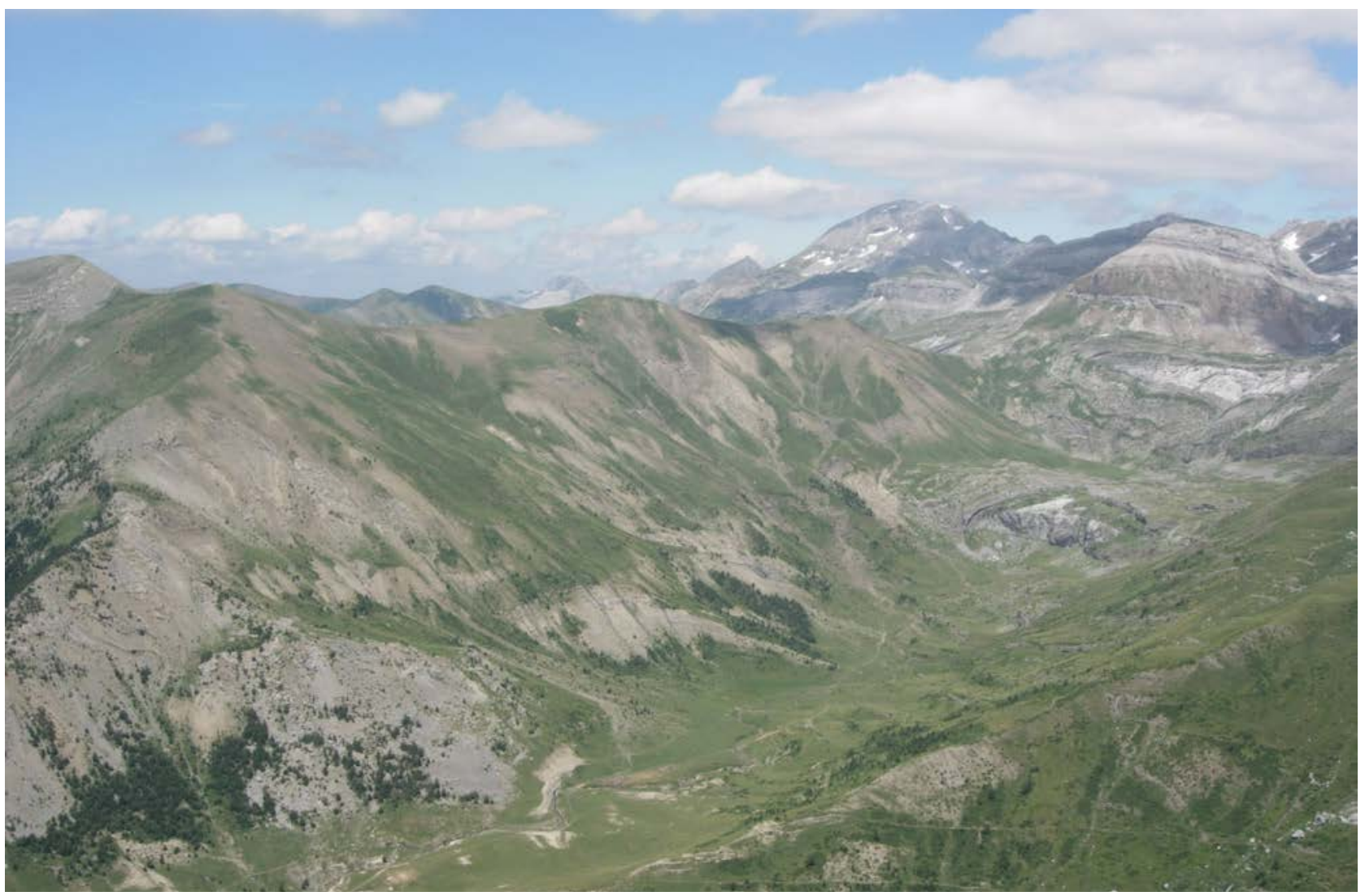

Figura 18: Cabecera del Valle de Aísa, donde el bosque original (que llegaría hasta cerca de 2200 m s.n.m.,) ha sido eliminado en diferentes momentos desde la Edad del Bronce para favorecer la expansión de los pastos subalpinos y así favorecer la ganadería trashumante con grandes rebaños de ovejas. En los lugares más pendientes, la deforestación ha causado graves problemas de erosión, con deslizamientos superficiales y cabeceras muy activas de barrancos que han desmantelado el suelo. El punto más elevado, en la parte superior derecha, corresponde al Pico Bisaurín. Foto: J.M.G.R.

Figure 18: In the headwater of the Aisa Valley, where the original forest (up to $2200 \mathrm{~m}$ a.s.l.) was wasted at distinct moments since the Bronze Age to favour the expansion of subalpine grasslands and the development of large transhumant sheep flocks.

Deforestation has caused severe erosion problems in the steepest slopes, with shallow landslides and active ravines. The highest point, on the upper right side of the photo, corresponds to the Bisaurin Peak. Photo J.M.G.R.

la alta producción de los pastos de verano, manteniendo a raya el restablecimiento de matorrales y árboles, tal como sugirió Montserrat Recoder (1964, 1965, 1972), favoreciendo la presencia de pastos con predominio de Nardus stricta, Trifolium alpinum y Festuca scoparia. Si, en ocasiones, esa presión no era suficiente, se recurría al fuego controlado de matas de Juniperus communis, la planta que con mayor frecuencia señala el embastecimiento de los pastos de verano, Calluna vulgaris y Vaccinium myrtillus (Villar \& García-Ruiz, 1977; Alados et al., 2018).

En la parte baja de los valles, en torno a los núcleos de población, la impronta paisajística del ganado es también muy visible, aunque prevalecen más los rasgos heredados por siglos de agricultura cerealista. Algunos campos muestran la presencia de setos formados por matorrales o por árboles podados (fresnos, avellanos) que rodean parcelas de pequeñas dimensiones que han servido tradicionalmente para marcar la propiedad privada frente al pastoreo abierto tras la cosecha, formando un patrón paisajístico de campos cerrados o bocage. Estos campos pudieron estar cultivados con cereales o permanentemente ocupados por prados de siega. En ambos casos solo podían ser pastados por el ganado (lanar o vacuno) de su propietario en otoño, invierno y primavera, por parte de pequeños rebaños no trashumantes o ganado vacuno, que ha sido estante hasta tiempos muy recientes.

Bien diferente es el caso de los llamados bajantes, también próximos a los núcleos de población, utilizados por el ganado trashumante en periodos intermedios, antes de ascender a los puertos de verano o antes de descender a los pastos de invierno en la Depresión del Ebro. También era utilizados desde octubre a mayo por los rebaños que no trashumaban, tanto ganado menor como mayor. Los bajantes incluían laderas localizadas por debajo de 1400 m s.n.m. y campos de cultivo que se habían cosechado en julio y que permanecían como rastrojo hasta el mes de noviembre del año siguiente, cuando tenía lugar una nueva siembra. Estos campos tenían un atractivo especial para el ganado, que al bajar de los puertos consumía la paja que quedaba en el campo tras la cosecha, y 


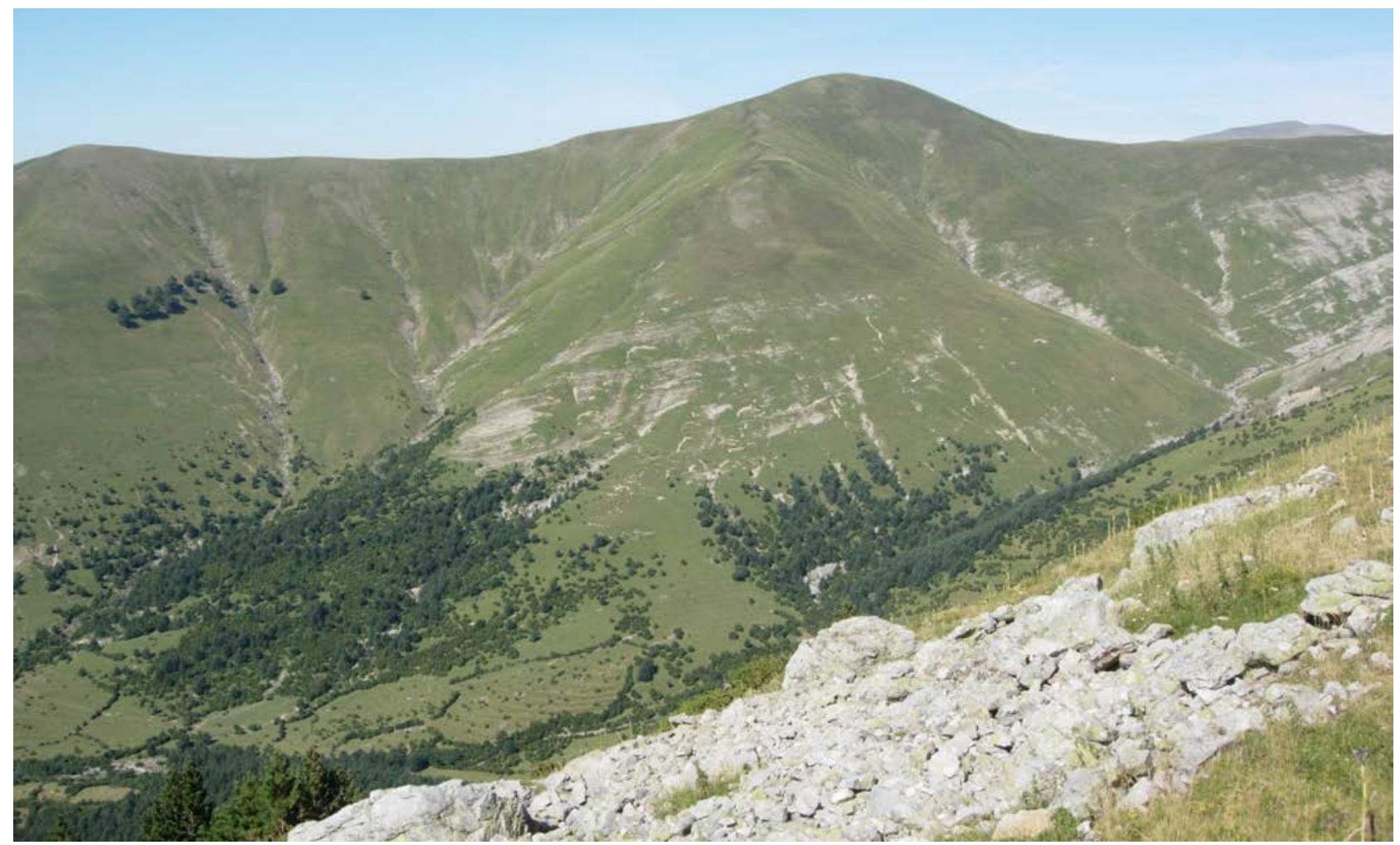

Figura 19: Cabecera del Valle de Escuaín, con pequeños restos de pinar y hayedo en un ambiente deforestado para ampliar la superficie de pastos subalpinos. Se observa también la importancia de la erosión (deslizamientos superficiales) tras la deforestación. En la parte inferior izquierda puede apreciarse la presencia de campos cercados y bancales (panares) que reflejan la necesidad de cultivar todo lo posible para la obtención de grano panificable. Como en la Figura 18, estos pastos subalpinos de aprovechamiento estival son los que explican la gran importancia tradicional de la ganadería ovina pirenaica, que en invierno tenía que desplazarse al centro de la Depresión del Ebro. Foto: J.M.G.R.

Figure 19: The headwaters of the Escuain Valley show small remnants of pine and beech tree forests, in a deforested, subalpine environment. Erosion is a relevant problem (shallow landslides) following deforestation. On the lower part (left) several closed

fields and panares can be seen, confirming the necessity of cultivating everywhere to produce cereals. Like in Figure 18, these subalpine grasslands explain the traditional importance of Pyrenean livestock, which needed to move towards the Centre of the Ebro Depression in winter. Photo: J.M.G.R.

también la hierba que crecía en primavera. El ganado estante consumía además el ricio, es decir los granos de cereal caídos en el momento de la cosecha y que habían brotado en otoño. El cultivo del cereal era tan importante para la gestión ganadera que anualmente los campos se organizaban en dos zonas, una cultivada y la otra en barbecho, esta última abierta para el pastoreo libre. Todos ellos, trashumantes y estantes, aprovechaban las áreas de matorral y bosque provocando una presión que puede considerarse, al menos ocasionalmente, como auténtico sobrepastoreo. Estas son las áreas más perjudicadas, pues tenían que alimentar al ganado trashumante durante un breve periodo (octubre y mayo) y al ganado estante durante la larga estación fría (excepto en los días de nieve). De ahí la presencia de áreas relativamente extensas, no muy alejadas de los pueblos, con vegetación submediterránea abierta, propia de estadios de degradación avanzados, y suelos erosionados (Villar \& García-Ruiz, 1977) (Figura 21). Es importante tener en cuenta que el efecto del pisoteo (y más durante la estación húmeda) contribu- ye al apelmazamiento del suelo, dificultando la infiltración y la germinación. Eran áreas afectadas por fuegos recurrentes, relativamente controlados, dada la tendencia al crecimiento de especies espinosas y la necesidad de favorecer el crecimiento de renuevos herbáceos. Esas quemas se provocaban entre febrero y marzo y, por su recurrencia poco antes de uno de los periodos más lluviosos del año, fueron un influyente factor erosivo.

\section{Los cambios recientes y sus impactos: la deconstrucción de un paisaje}

Como se ha comentado anteriormente, el paisaje que se ha venido describiendo hasta ahora responde a una determinada organización social y a un contexto socioeconómico general que ha cambiado profundamente desde mediados del siglo XX, incluyendo particularmente el descenso de la presión demográfica, la ausencia de mano de obra barata para sostener los elementos básicos del 


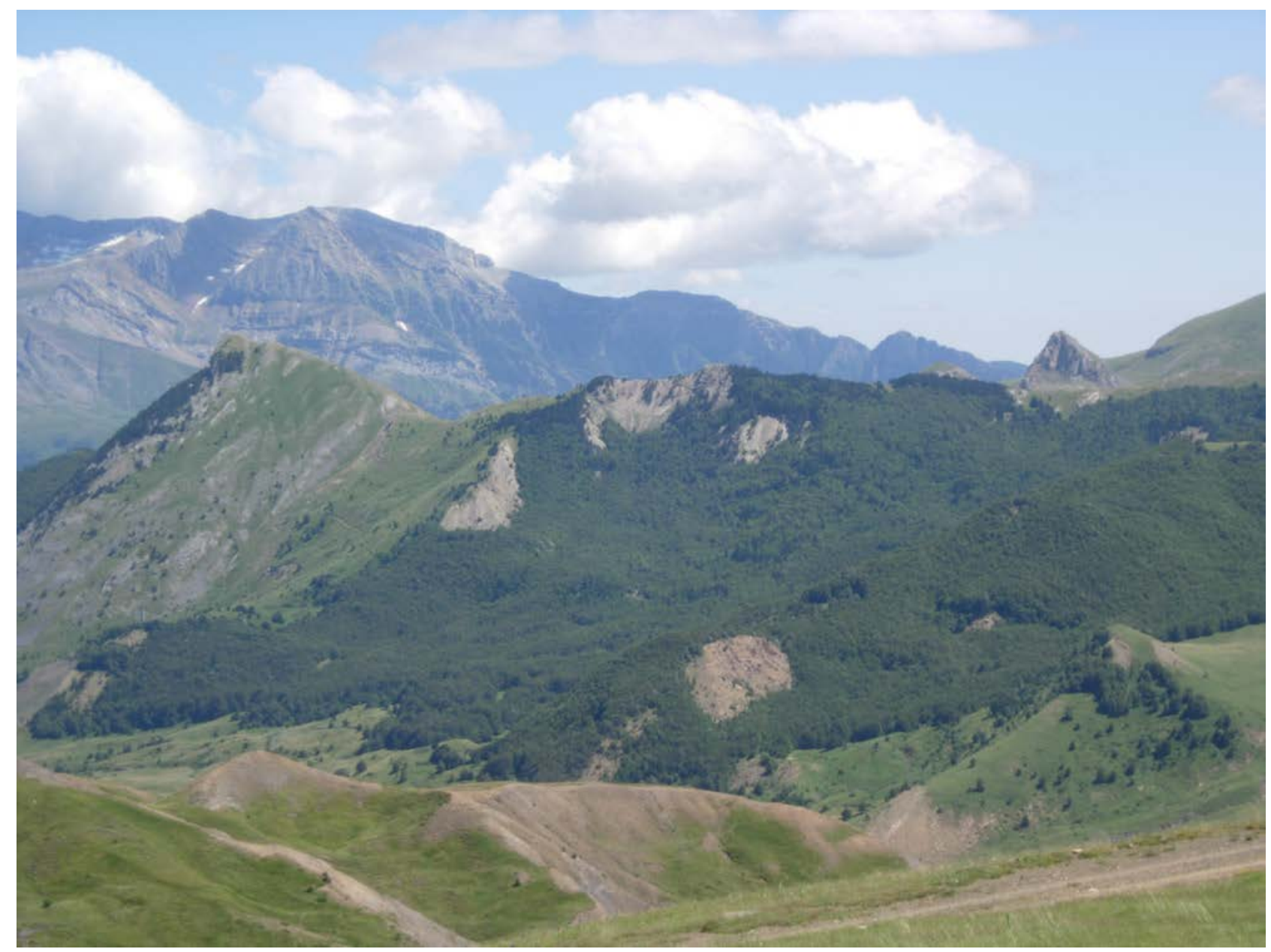

Figura 20: La Selva de Pacino, en el alto Valle del Gállego. Se trata de un bosque bien conservado que ha funcionado históricamente como reserva de leña y madera para la población de Sallent de Gállego. Foto: J.M.G.R.

Figure 20: The Pacino Forest, in the Upper Gállego Valley. This is a well-preserved forest that was historically considered as a wood reserve for the local population of Sallent de Gállego. Photo: J.M.G.R.

viejo sistema (por ejemplo, la trashumancia o el mantenimiento de los campos abancalados), y el desmoronamiento casi general de la casa como elemento básico de gestión del territorio. Eso explica lo que ha pasado en las últimas décadas: los sistemas de producción han cambiado radicalmente y los paisajes a los que estaban ligados han experimentado una transformación profunda mediante dos fenómenos íntimamente relacionados: la aculturación de la población pirenaica que vive de la agricultura y la ganadería (Esteva Fabregat, 1971; Balcells, 1984; Fernández-Giménez \& Fillat Estaqué, 2012) y la consiguiente deconstrucción del paisaje, entendiéndose por aculturación el progresivo abandono de las rutinas que han sido la base de los sistemas de explotación, la pérdida de la cohesión social que favorecía determinados trabajos colectivos y, en general, el deterioro de los modos de aprovechamiento del territorio mediante procedimientos aprendidos a lo largo de siglos.

Los paisajes de montaña son la consecuencia de la adaptación de las sociedades humanas a condiciones ex- tremas de dureza y fuertes contrastes estacionales, lo que ha obligado desde el principio a una compleja organización, a partir de una perspectiva global de las limitaciones que ofrece el medio. El crecimiento demográfico forzó a cultivar laderas más pendientes, a improvisar sistemas de cultivo sujetos a altos riesgos de erosión (la agricultura nómada, por ejemplo) y a sobreexplotar los recursos pastorales, sobre todo en estaciones intermedias. Probablemente, el sistema alcanzó su máxima capacidad de carga durante el siglo XVIII, antes de que se registrase el máximo demográfico de la segunda mitad del siglo XIX. Se ocupó todo lo posible e incluso así parte de la población inició un lento proceso migratorio que se acentuó a lo largo del siglo XX, particularmente después de 1950 (Collantes, 2005). A partir de entonces, nada del sistema tradicional pudo sostenerse, desmoronándose en unos pocos años. Lo que parecía sostenible no pudo soportar la fuerte atracción de los centros urbanos y la adopción de patrones de consumo que poco o nada tenían que ver con el anterior. Los pueblos más pequeños, los situados a media 


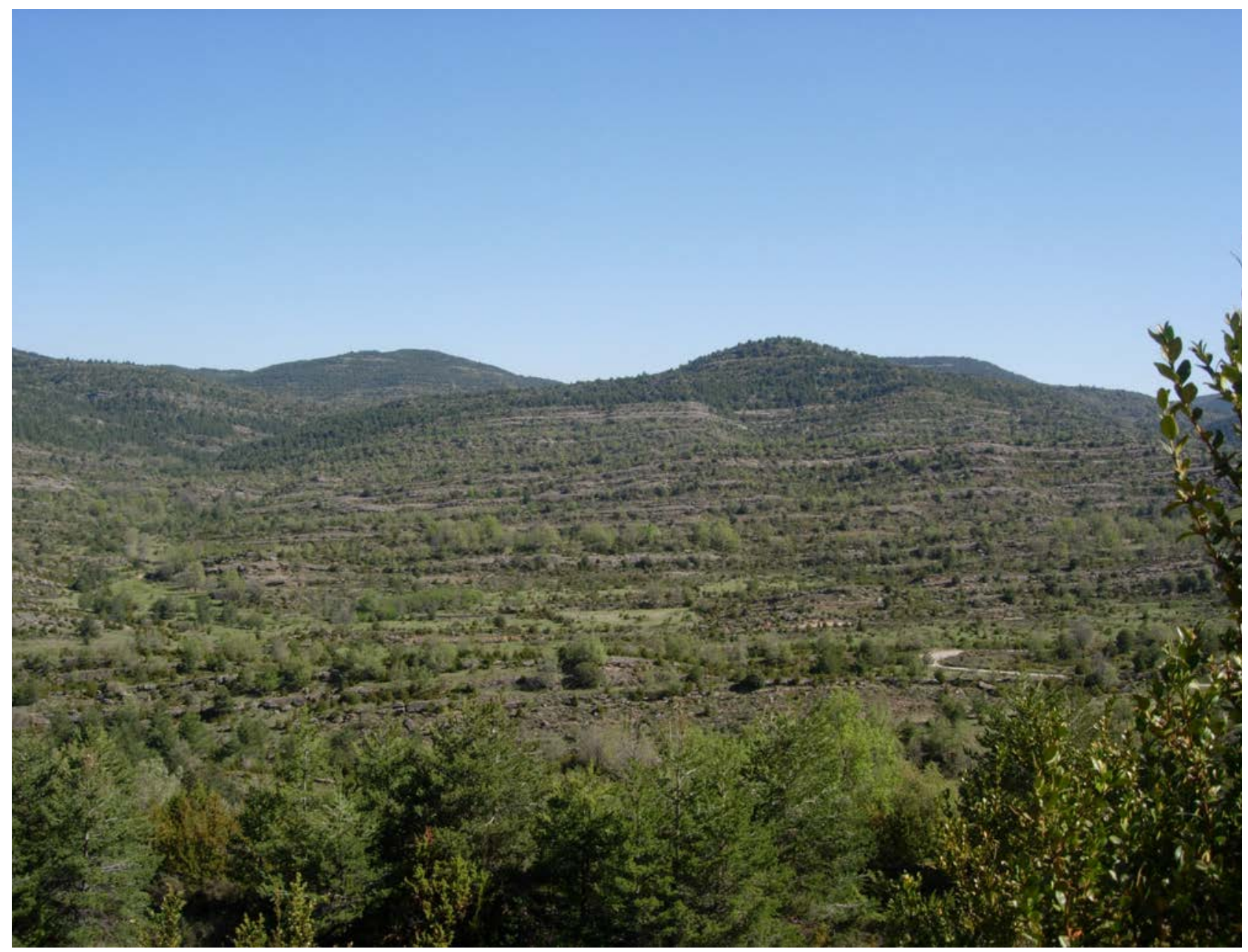

Figura 21: Las áreas submediterráneas han sido intensamente castigadas por los cultivos, los incendios recurrentes y el pastoreo durante todo el año. La consecuencia más importante ha sido la deforestación y la degradación de los suelos, quedando un paisaje de antiguos campos de cultivo, matorrales y bosques abiertos. Laderas de areniscas y arcillas cerca de Bara, al norte de la Sierra de

Guara. Foto: J.M.G.R.

Figure 21: Submediterranean areas of the Pyrenees show the effects of agriculture on steep slopes, recurrent fires and grazing along the whole year. The most relevant consequence has been deforestation and soil degradation, resulting in a landscape with old cultivated fields, shrubs and open forests. Alternating sandstone and lutite outcrops close to Bara, to the north of the Guara Sierra. Photo: J.M.G.R.

ladera entre campos pendientes, los que ocupaban minúsculas divisorias rodeadas de bancales imposibles de mecanizar, los que carecían de servicios mínimos (acceso por carretera, luz), los que ofrecían mucho trabajo a cambio de no poca miseria, todos ellos se despoblaron masivamente, dejando una larga lista de pueblos abandonados o en trance inmediato de serlo (Acín Fanlo \& Pinilla Navarro, 1995; Acín Fanlo, 1997). También los mejores pueblos entraron en un desgaste demográfico que se llevó a los hijos no herederos, a los pastores por cuenta ajena y a los pequeños propietarios, de manera que fue imposible seguir cultivando tierras que, en la mayor parte de los casos, producían para la supervivencia, y fue aún más difícil el mantenimiento de sistemas ganaderos que exigían mucha mano de obra sostenida hasta entonces con salarios bajísimos o por la ausencia de ofertas de trabajo en otros lugares. La consecuencia más clara es un abandono general de las tierras de cultivo, primero las más alejadas, las de más bajos rendimientos, las más pendientes, luego las demás en el caso de los pueblos abandonados, quedando sólo los fondos de valle y los pies de vertiente como únicas áreas de cultivo, dedicadas todavía al cereal en el Prepirineo y la Depresión Interior Altoaragonesa, y a prados de siega y de diente en los pueblos altopirenaicos con mayor tradición ganadera. En una generación se destruyó lo que se había tardado siglos en construir, es decir, un paisaje histórico en el que se había invertido muchísima energía y que representaba la superposición de distintas circunstancias históricas y de diferentes maneras de percibir la explotación del territorio. En palabras de Montserrat Recoder (2009), se trata del abandono suicida de sistemas muy productivos, con el consiguiente riesgo de 


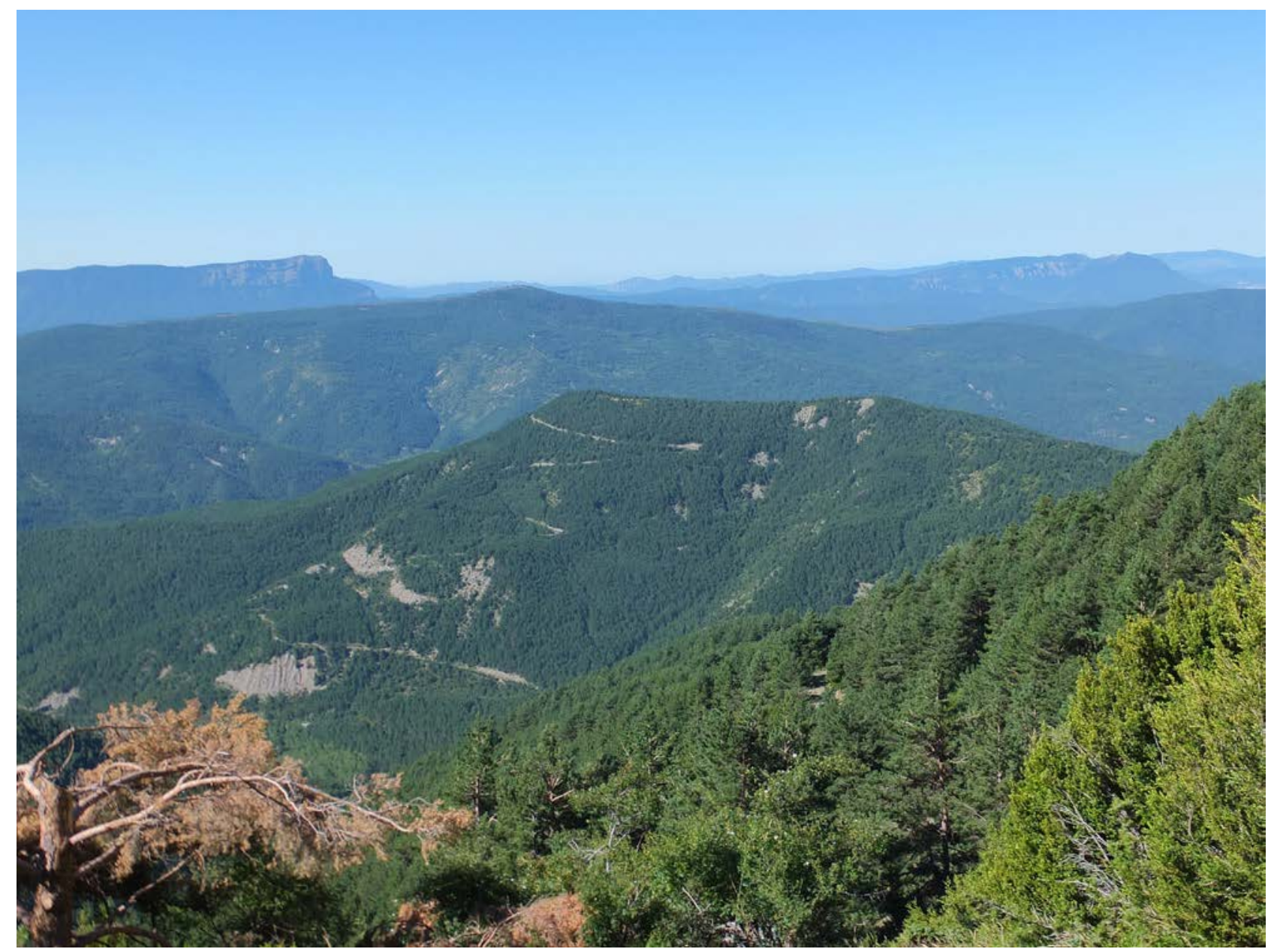

Figura 22: Desde mediados del siglo XX la despoblación acentuó la tendencia demográfica negativa en el Pirineo aragonés y provocó un masivo abandono de tierras de cultivo, empezando por las laderas más pendientes. La mayor parte de los campos iniciaron un complejo proceso de colonización vegetal que ha culminado con la presencia general de formaciones densas de matorral

y bosques (pinares principalmente), muchos de ellos incentivados mediante repoblaciones forestales. Además de gran parte del Prepirineo, el mejor ejemplo corresponde al valle del río Ijuez o de la Garcipollera (en la foto), afluente del río Aragón. En el valle del río Ijuez se despoblaron varios núcleos para extender el bosque y controlar el transporte de sedimentos hacia el río Aragón y el embalse de Yesa. Foto: J.M.G.R.

Figure 22: Since the mid-20th century depopulation stressed the negative demographic trend in the Aragón Pyrenees and caused generalized farmland abandonment, starting with the steepest slopes. Most of the fields were affected by a plant colonization process resulting in a general presence of dense shrub formations and forests (mainly pinewoods), most of them driven by means of artificial afforestation. The best example corresponds to the Ijuez Valley (in the photo), a tributary of the Aragón River. Several small villages were depopulated in the Ijuez Valley to expand the forest and to control sediment transfer towards the Aragón River and the Yesa Reservoir. Photo: J.M.G.R.

deterioro por incendio catastrófico, dando lugar a la expansión de matorrales que impiden o dificultan el pastoreo de noviembre a marzo. El reto más importante de cara al futuro es decidir cómo se gestiona este paisaje abandonado y recolonizado por bosques y matorrales, aspecto en el que hay todavía mucha controversia (Conti \& Fagarazzi, 2004; Cramer et al., 2007; Navarro \& Pereira, 2012; Nogués et al., 2016; Lasanta et al., 2015, 2018; Robledano Aymerich et al., 2016). El asunto es de gran transcendencia no solo porque afecta a la conservación de paisajes con gran valor cultural; también afecta a cuestiones tales como la biodiversidad (Lasanta Martínez et al., 2013b), el funcionamiento hidrológico de laderas y la generación de escorrentía (Beguería et al., 2003; García-Ruiz et al., 2011; Lana-Renault et al., 2018).

Matorrales y bosque ocupan la mayor parte de los antiguos campos de cultivo, a veces incentivados por repoblaciones forestales que se escudaron en la necesidad de controlar la erosión y la generación de escorrentía en las áreas que habían sufrido mayor presión, es decir, el Prepirineo, las laderas meridionales del flysch en contacto con la Depresión Interior Altoaragonesa y las proximidades de los pueblos altopirenaicos. A veces, las reforestaciones respondían a una política más inmediata: frenar la llegada 


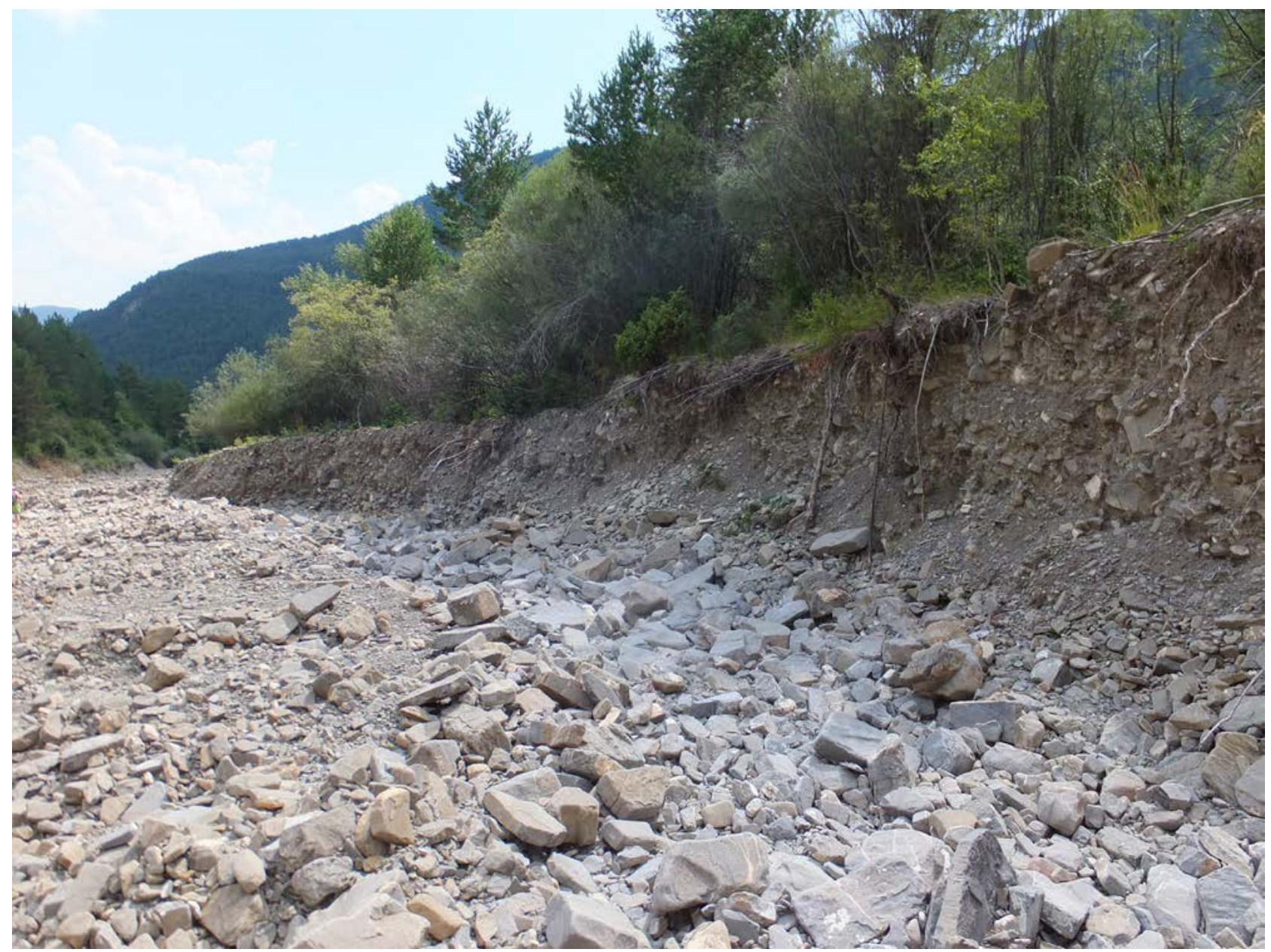

Figura 23: El cauce del río Ijuez, como el de muchos otros ríos pirenaicos, se caracteriza por el predominio de bloques y gravas poco rodadas y por la presencia de varios cauces que cambian de posición en momentos de avenida (braided rivers, ríos trenzados). Son cauces propios de ríos torrenciales, característicos de ambientes en los que las laderas suministran mucho sedimento. La

reforestación reciente de la cuenca del río Ijuez ha provocado una creciente desconexión entre laderas y cauce, al reducirse mucho la erosión. La consecuencia ha sido el encajamiento del lecho por el efecto hungry waters, es decir, el desequilibrio entre la energía disponible y el sedimento que llega desde las laderas. Foto: J.M.G.R.

Figure 23: The bed of the Ijuez River, like that of many rivers in the Pyrenees, is characterized by the predominance of large blocks and boulders and the presence of several channels that change in position during floods (braided rivers). They are characteristic of torrential rivers, with slopes yielding much sediment. Recent afforestation in the Ijuez River basin caused an increasing decoupling

between slopes and channel because of the declining erosion. The consequence has been the incision of the channel due to the

"hungry waters" effect, i.e. the unbalance between the available power and the sediment that is delivered from the slopes. Photo: J.M.G.R.

de sedimento hacia los embalses con el fin de prolongar su vida útil: así, en la cuenca drenada por el embalse de Yesa (río Aragón) se procedió a reforestar muchas áreas intensamente erosionadas en un entorno de margas acarcavadas y el Estado adquirió el valle del río Ijuez para convertirlo en un pinar homogéneo en el que la erosión en las laderas se ha reducido, pero el cauce se ha encajado y ha seguido aportando grandes volúmenes de sedimento grueso (Gómez-Villar et al., 2014; Sanjuán et al., 2016) (Figuras 22 y 23). En general, los cauces han experimentado cambios importantes, con estrechamiento y formación de sotos que tienden hacia la estabilización de barras centrales y laterales, y lo mismo ha ocurrido con muchos conos de deyección, que se han visto incididos en su parte proximal y parcialmente colonizados por la vegetación (Beguería et al., 2006).

El abandono de la agricultura ha implicado no solo el enmascaramiento de muchas laderas antaño cultivadas, en las que apenas puede distinguirse la presencia de los límites de campos cultivados (Lasanta et al., 2017b). También se ha abandonado toda práctica de conservación o reparación de los antiguos bancales, que tradicionalmente eran objeto de continuos trabajos de mantenimiento, controlando los desplomes de los muros y reconstruyéndolos para evitar la pérdida de suelo y el inicio de abarrancamiento. Como en otras áreas de montaña medi- 
terráneas, los bancales con muro de piedras están sujetos a distintos procesos erosivos con impacto negativo en la calidad del paisaje (Arnáez et al., 2017).

En el piso subalpino el descenso de la presión ganadera y, en gran parte también, el desequilibrio existente entre los distintos tipos de ganado, han favorecido la expansión del bosque en altitud. Como se ha indicado anteriormente, el actual límite superior del bosque es artificial y se sitúa muy frecuentemente en torno a $1600 \mathrm{~m}$ s.n.m., con una separación altitudinal de aproximadamente $600 \mathrm{~m}$ en relación con el treeline natural (que se sitúa en torno a 2200 m s.n.m.). Durante siglos el bosque y el matorral se han mantenido a raya gracias a la fuerte presión ganadera, que impedía el éxito de nuevos rebrotes. De ello se encargaban sobre todo tanto el ganado cabrío como el caballar; además el ganado lanar mantenía la calidad del pasto en las laderas, mientras el vacuno se centraba en las zonas de turbera y en los fondos de valle con poca pendiente. La drástica reducción de los ganados lanar, cabrío y caballar y la expansión espectacular del ganado vacuno son el motivo de los problemas a que se enfrentan los pastos de verano en el Pirineo aragonés: las laderas son infrapastoreadas y de ahí que en el límite superior actual del bosque aparezca una marcada orla de árboles jóvenes y brinzales que avanza de manera imparable a modo de frente de recolonización (Nadal-Romero et al., 2018) (Figuras 24 y 25). No es un fenómeno exclusivo del Pirineo aragonés; también ocurre en el Pirineo oriental (Batllori \& Gutiérrez, 2008) y en las sierras de Cebollera y Urbión, en el Sistema Ibérico riojano (Sanjuán et al., 2018). Además, el incremento de ganado vacuno, focalizado en las zonas más llanas del piso subalpino, representa un aporte extraordinariamente alto de nitrógeno que está cambiando la composición del pasto y su agotamiento temprano.

\section{Reflexiones finales: Qué queda del paisaje cultural y qué podemos deducir de su organización espacial}

Aunque los sistemas tradicionales han evolucionado continuamente y no puede presentarse un modelo inmuta-

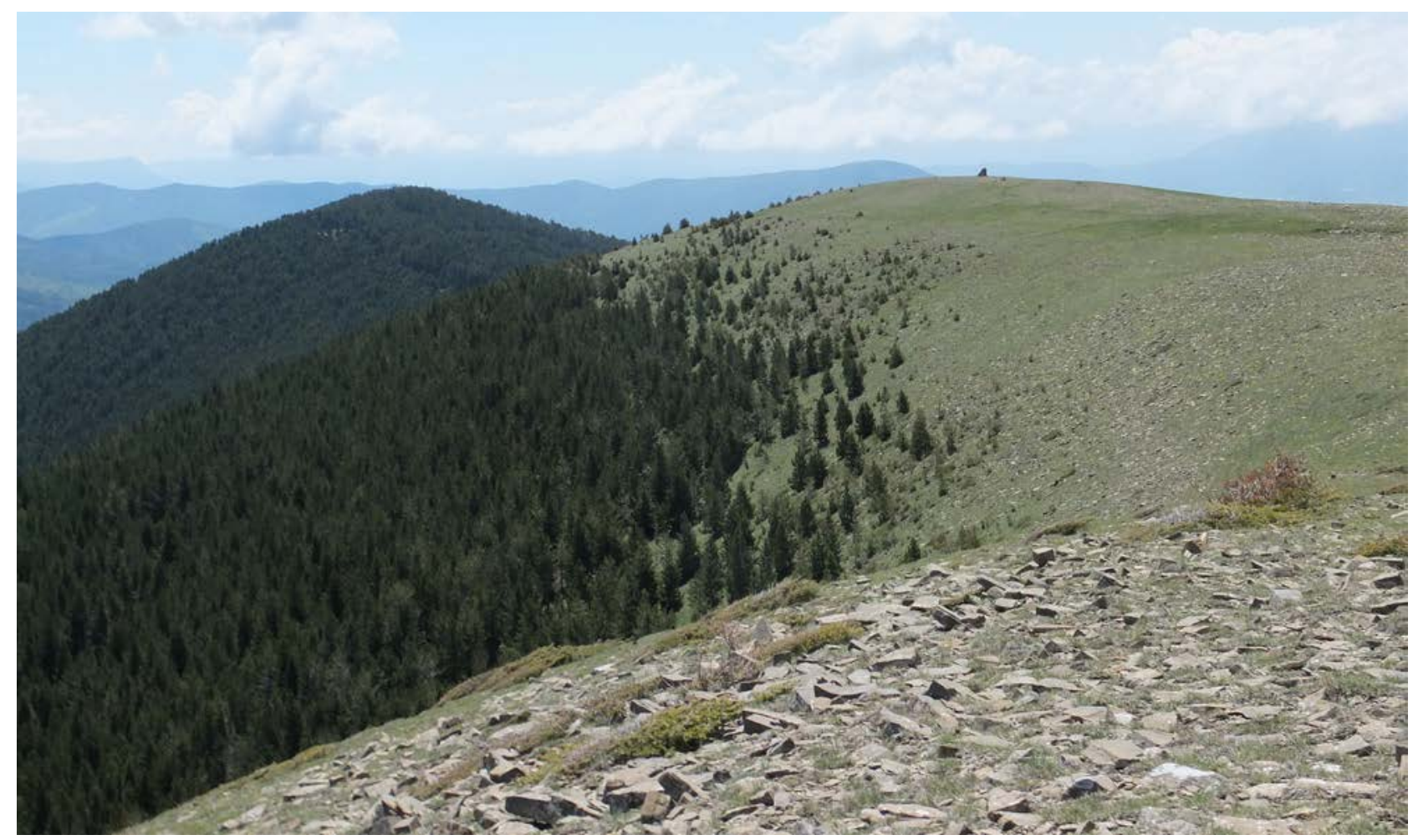

Figura 24: La divisoria de Las Blancas, entre los valles de los ríos Aragón, Isuerre y Estarrún, fue deforestada para favorecer su aprovechamiento por el ganado ovino en verano. La disminución de la presión ganadera desde mediados del siglo XX es la razón por la que el bosque se está de nuevo expandiendo hacia cotas cada vez más elevadas, formando una especie de frente de colonización con árboles jóvenes y brinzales de pino silvestre. La divisoria muestra también algunos sectores erosionados, con presencia masiva de piedras, como consecuencia de los procesos erosivos relacionados con la deforestación (deslizamientos planares). Foto: J.M.G.R.

Figure 24: Las Blancas divide, between the Aragón, Isuerre and Estarrún valleys, was deforested to favour summer grazing with sheep flocks. The decline of the livestock pressure since the mid-20th century is the reason why forest is again expanding towards higher areas, resulting in a colonization front with young trees and seedlings of Pinus sylvestris. The divide also shows some eroded sectors, with the massive presence of stones, as a consequence of erosion processes related to deforestation (shallow landslides). Photo: J.M.G.R. 


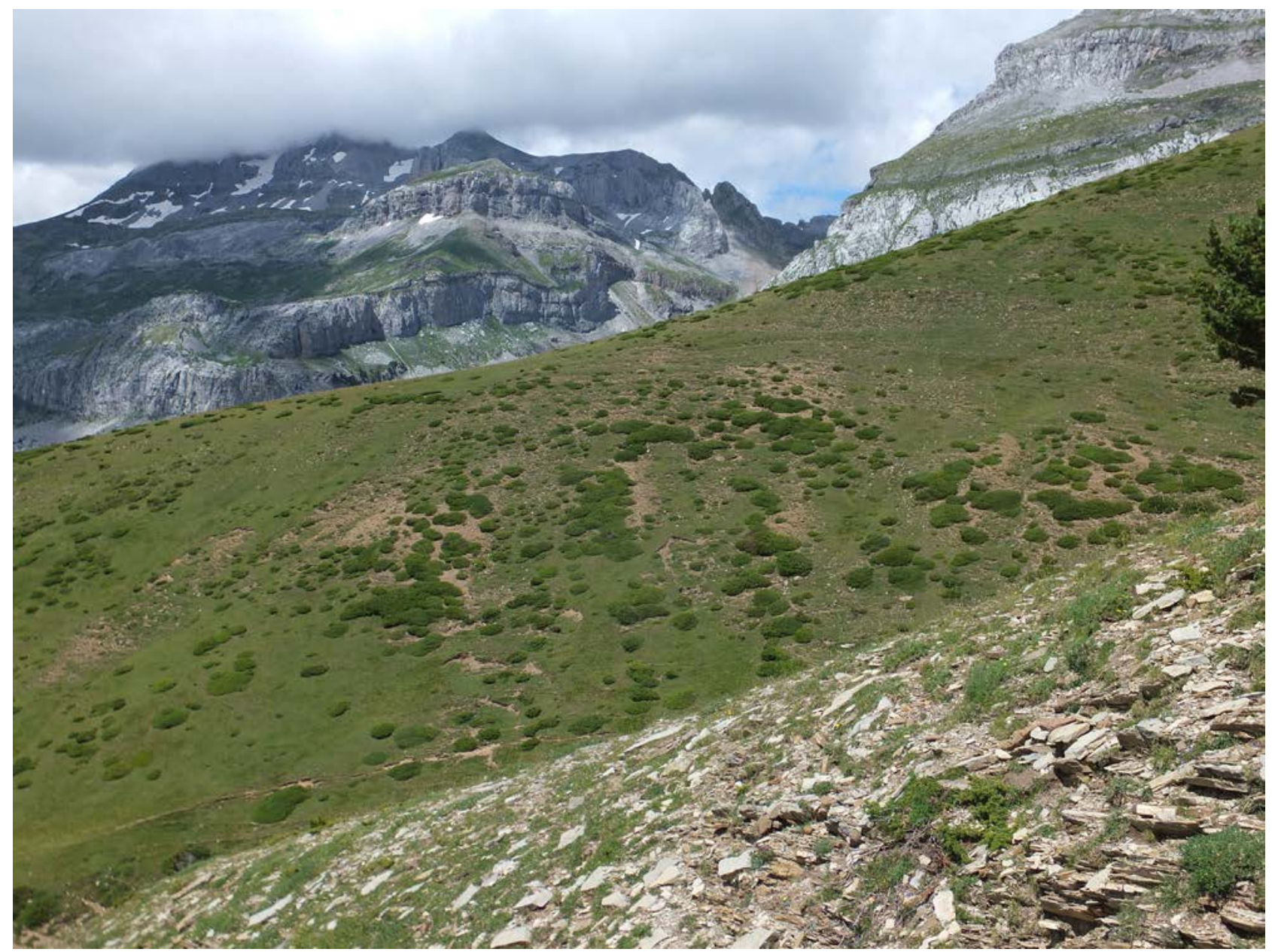

Figura 25: El piso subalpino pirenaico presenta localmente tendencia hacia la matorralización, especialmente por invasión de

Juniperus communis, que forma matas que crecen más lateralmente que en altura. Habitualmente estas zonas de enebros se quemaban en verano para frenar su expansión, aunque ahora este procedimiento no es tan necesario ante la falta de presión ganadera,

lo que favorece más su desarrollo. En la foto, laderas del Pico del Bozo en la cabecera del Valle de Aragüés, con algunas cicatrices

de deslizamientos superficiales y erosión alrededor de los rodales de enebros por causas que desconocemos, quizás por mayor frecuencia de pisoteo del ganado. Al fondo, el Pico Bisaurín oculto entre nubes. Foto: J.M.G.R.

Figure 25: The Pyrenean subalpine belt tends locally to woody encroachment, particularly with the invasion by Juniperus communis. Usually, these areas covered with junipers were burnt in summer to stop their expansion. Now such a procedure is not so necessary because of the declining livestock pressure. In the photo, slopes in the El Bozo Peak, headwater of the Aragüés Valley, with some shallow landslide scars and erosion around junipers due to unknown causes, maybe more frequent livestock trampling. Photo: J.M.G.R.

ble que sirva como referente, es cierto que el crecimiento demográfico de los siglos XVIII y XIX supuso un cambio más brusco y rápido, coincidiendo con un momento en que ciertas actividades de las zonas de montaña entraron en crisis. La pérdida de importancia del mercado de la lana y la consiguiente crisis de la trashumancia supuso un problema gravísimo, que vino acompañado por la desaparición de muchas actividades artesanales. En un contexto histórico en el que la emigración a los centros urbanos no ofrecía expectativas, la solución para la población pirenaica y de otras montañas españolas fue explotar al máximo los recursos locales, cultivando todas las laderas posibles y vendiendo la madera, que se exportaba por vía fluvial. Muchos ganaderos de pequeña entidad y pastores pasaron a dedicarse a actividades madereras, confirmando el descenso de los censos ganaderos (Villar \& GarcíaRuiz, 1977).

¿Qué queda hoy del paisaje cultural que alcanzó su máxima expresión a mediados del siglo XIX? Mucho menos de lo que creemos. El paisaje actual, como todas las fotografias de paisajes pertenecientes a siglos anteriores, es el resultado de una adaptación a las circunstancias que han condicionado la evolución de la población, la agricultura, la ganadería y la gestión forestal durante el último tercio del siglo XX y su prolongación a comienzos del XXI. Esas circunstancias, esquemáticamente, se definen por (i) un rápido descenso demográfico; (ii) la desestructuración de la institución de la casa como expresión del 
sentimiento de continuidad, basada en la jerarquización, el heredero único y la disponibilidad de mano de obra; (iii) la casi total expulsión del cereal en los valles altopirenaicos y su sustitución por prados de diente y de siega; (iv) la progresiva sustitución del ganado lanar por el vacuno, en un ejemplo de extensificación llevado al límite como respuesta frente a la escasez de mano de obra y, en muchos casos, la diversificación de las actividades económicas, favoreciendo una ganadería a tiempo parcial que es más compatible con el vacuno y el caballar que con el lanar. Estos cambios son tan radicales y afectan tanto a los sistemas de gestión del territorio, que es imposible aceptar que el paisaje construido a lo largo de muchos siglos no se resienta. Como señalan Taillefumier \& Piégay (2003) para los Préalpes, los paisajes de montaña se han simplificado, reduciéndose o incluso desapareciendo el mosaico de grano fino con múltiples piezas que requieren diferentes rutinas e interpretaciones, frente a la homogeneización que caracteriza a los paisajes más actuales, con grandes extensiones de bosque y matorrales que, a veces, encierran unas pocas áreas de prados.

Quedan los fondos de valle, con los campos de cultivo propios de las terrazas fluviales y de las artesas glaciares (Figura 26); campos relativamente grandes, rodeados ge-

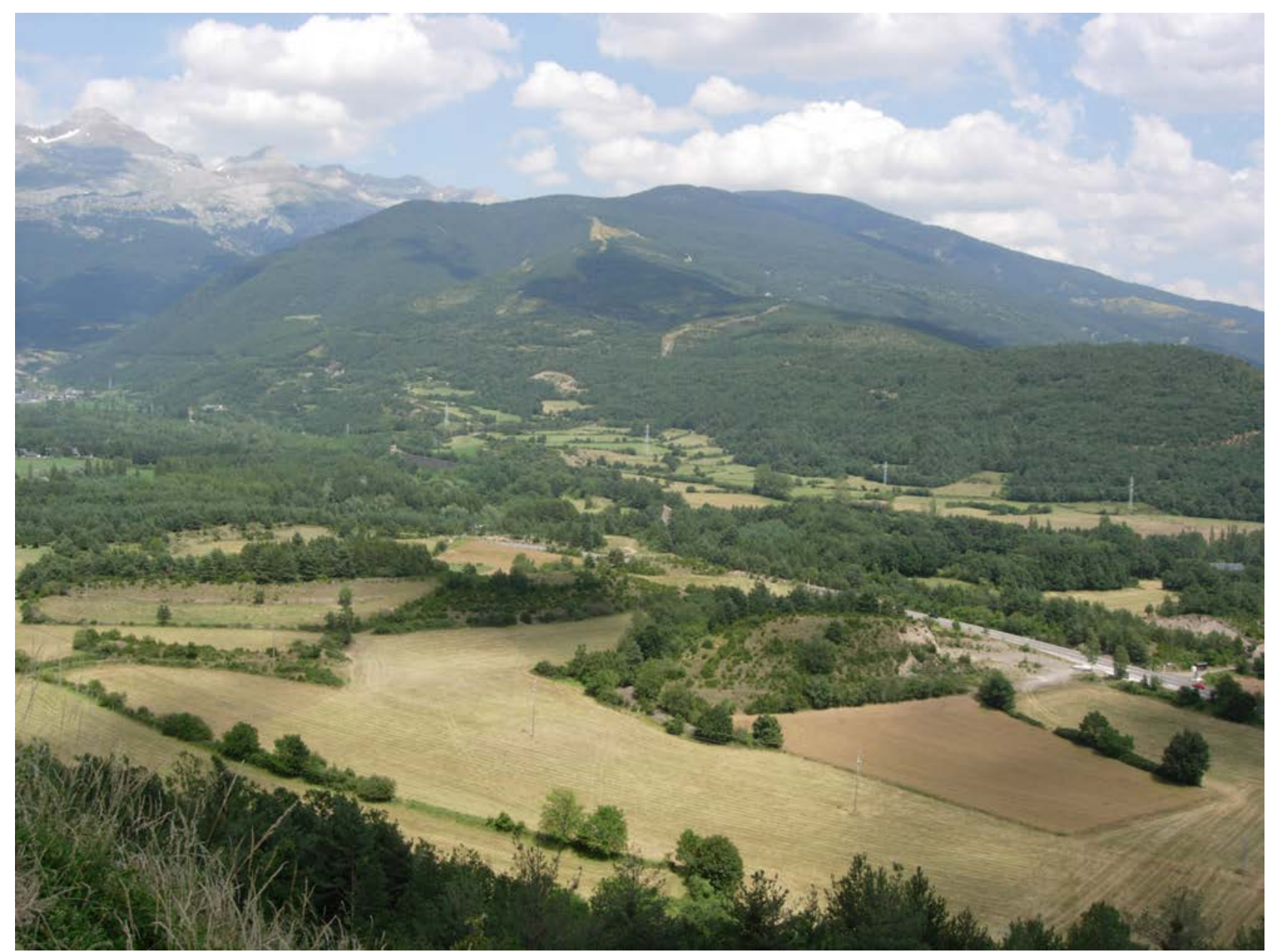

Figura 26: Los fondos de valle son los únicos que se aprovechan todavía intensivamente, con el cultivo de plantas forrajeras y, en menor medida, cereales, ascendiendo a veces por el pie de las vertientes. La vegetación de ribera ocupa una creciente extensión, reflejando la relativa estabilización de las estructuras sedimentarias, mientras las laderas están cubiertas de un bosque denso. El

paisaje tiende a simplificarse y a ser explotado de una manera cada vez más desintegrada, concentrándose la actividad en los fondos de valle mientras el resto del territorio se ha abandonado. Cubeta de Villanúa-Castiello de Jaca, en el Valle del Aragón. En primer plano, morrenas frontales cubiertas de bosque y matorral entre campos de cultivo. Al fondo a la izquierda, el Pico Collarada. Foto: J.M.G.R.

Figure 26: The valley bottoms are the only sites still used intensively, with cultivation of fodder and cereals, sometimes occupying also the foot of the slopes. The riparian vegetation is increasingly enlarging, suggesting the relative stabilization of the sedimentary structures, whereas the slopes are covered with dense forest. The landscape tends to be more simplified and is exploited in a more disintegrated manner, in such a way that the agrarian activity concentrates in the valley bottoms whereas the rest of the territory has been abandoned. End glacial basin of Villanúa-Castiello de Jaca, in the Aragón River Valley. In the foreground, frontal moraines covered with forest and shrubs among cultivated fields. In the background, to the left, the Collarada Peak. Photo: J.M.G.R. 


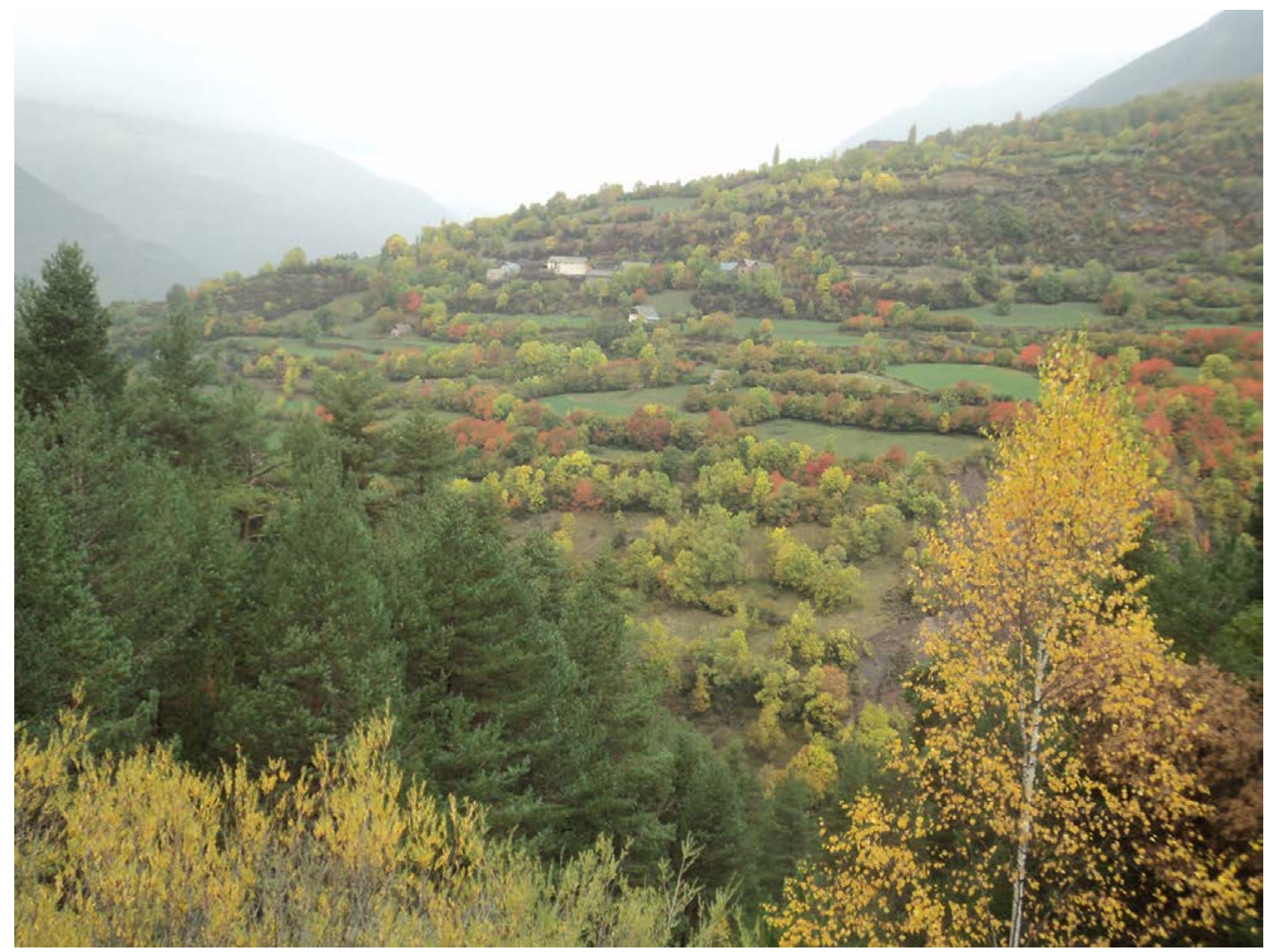

Figura 27: La evolución y conservación de algunos paisajes refleja el cuidado con que se explota el territorio. Los prados de San Juan de Plan fueron en su mayor parte antiguos campos de cereales que se fueron cerrando progresivamente para reafirmar el sentido de la propiedad y permitir un aprovechamiento ganadero más individual. Foto: T.L.

Figure 27: The evolution and conservation of some landscapes reflect the care with which the territory has been transformed and used. The meadows of San Juan de Plan were old cereal fields that were progressively closed to reassert the individual property and to enable a more individual livestock grazing. Photo: T.L.

neralmente de muros de piedra seca, a veces con árboles que no suelen formar un límite continuo, generalmente chopos y fresnos, algunos frutales. Estos campos se han revalorizado ante el abandono de las laderas y la necesidad de alimentar al ganado en invierno con recursos propios (García-Ruiz \& Balcells, 1978; Balcells, 1983; García-Ruiz \& Lasanta-Martínez, 1993). Los fresnos (Fraxinus excelsior), árbol principal de los setos, sobre todo en el sector oriental del Pirineo aragonés, muestran la evidencia de podas anuales que producen troncos anchos de los que surgen ramas que, una vez cortadas, sirven de alimento en otoño al ganado lanar y cabrío, especialmente en febrero, un mes difícil por la falta de hierba en los campos y bajantes (Fillat Estaqué, 2005); pero esas podas se espacian cada vez más en el tiempo y solo las mantienen algunos ganaderos aferrados a tradiciones más sentimentales que racionales. Los setos también aparecen salpicados de quejigos (Quercus cerrioides), chopos (Po- pulus nigra), acebos (Ilex aquifolium), avellanos (Corylus avellana), bojes (Buxus sempervirens), majuelos o espinos albares (Crataegus monogina), artos (Prunus spino$s a$ ) y zarzas (Rubus sp.). Menos notoriamente hay signos de un bocage auténtico, con setos de arbustos que, ocasionalmente, se encuentran bien cuidados, sometidos a podas anuales, a veces controlados por el propio ganado. Ese bocage aparece en los mejores lugares, es decir, en áreas de pendiente suave, con suelos profundos y en laderas solanas, con posibilidades de irrigación, reflejando un reforzamiento del concepto de propiedad frente al de los campos abiertos, que una vez cultivados podían pastarse con los rebaños del pueblo mientras se mantuvieran como rastrojos o en barbecho. Quizás el mejor ejemplo está en los actuales prados de San Juan de Plan (Valle de Gistaín), que se fueron cerrando progresivamente para convertirse en campos de plena propiedad sin implicarse en el pastoreo comunal (Fillat Estaqué, 2003a) (Figura 27). 
Antes de 1980, según Fillat Estaqué (2003b), la plena propiedad de la parcela correspondía a la cosecha de grano y paja, mientras que el rastrojo se incorporaba a los sistemas de pastoreo en común. Estudios de detalle muestran la importancia de las fuentes (en el contacto entre depósitos glaciares y el Permotrías) para prolongar la producción de los prados (Gómez García et al., 1982), favoreciendo a final de agosto una coloración contrastada que reivindica la heterogeneidad del paisaje y su conocimiento por parte de agricultores y ganaderos.

Es posible, no obstante, observar muchos de los rasgos del paisaje histórico en numerosas laderas que aún no han sido desdibujadas por la ocupación general del bosque, aunque los matorrales se imponen de manera generalizada. En el Sobrepuerto (entre los ríos Gállego y Ara), en la parte baja del valle de Hecho, y en tantos lugares en el entorno del Parque Nacional de Ordesa y Monte Perdido es posible ver los límites de los antiguos campos de cultivo, delimitados por un pequeño muro de piedra que apenas reduce la pendiente en la parte baja de cada parcela, con la presencia de árboles y arbustos que se han venido imponiendo por la falta de pastoreo; hay también bancales aún perfectamente conservados, cada vez con más matorral, guardando el complejo dibujo creado por agricultores y ganaderos de hace siglos, que construyeron un paisaje colectivo riquísimo, con mucha información ambiental aprovechable para la gestión integrada del territorio. Se conservan cada vez peor los caminos, en los que se observan las soluciones de detalle para frenar la erosión y acceder a todos los rincones; y se conservan los drenajes entre campos para evitar que el exceso de agua en época de lluvias pudiera evolucionar hacia desprendimientos del frente del bancal que desbaratasen el sistema. Un paseo por estos lugares, en Bestué o Puértolas, por ejemplo, nos lleva a épocas pasadas y nos ayuda a entender cómo pueden adaptarse los grupos humanos a la adversidad y a las grandes limitaciones que impone la ocupación y explotación de la montaña.

Se mantienen también, en un estado de conservación muy elevado, los panares, en los límites entre las laderas cultivables y los pastos subalpinos, representando las consecuencias de un crecimiento demográfico que exploró todas las posibilidades. Están, en general, bien cuidados los campos y los saltos entre bancales (con un denso tapiz herbáceo); también persisten las numerosas bordas que se distribuyen entre los panares y cuya función era henificar la hierba recogida durante los años en que no había cosecha cerealista e incluso servir de alojamiento temporal mientras se recogía la cosecha o se pastaban tanto la parte baja del piso subalpino como los panares, siguiendo un modelo similar al registrado por Fernández Mier et al. (2013) en la montaña leonesa y asturiana. Ahora se siguen dallando y pastando como hace décadas, aunque ya no se cultivan, dando lugar a un paisaje de connotaciones muy ganaderas, dominadas por el pastoreo a diente, especialmente en otoño para alargar el periodo de pastoreo, y la dalla. Algo parecido ha sucedido con algunos rellanos de obturación glaciar (por ejemplo, en el Valle de Aísa), donde los campos de cultivo también han evolucionado hacia prados de diente y de siega. Como en el resto de los altos valles pirenaicos, el paisaje está completamente subordinado a la actividad ganadera, tal como indicó también García Fernández (1975) para la montaña cantábrica.

Por último, quedan los pastos subalpinos, creados artificialmente en diferentes momentos desde el Neolítico o la Edad del Bronce, con el fin de superar la fuerte estacionalidad de la producción de hierba en las áreas de montaña. Es cierto que, como se ha señalado más arriba, el bosque tiende a recolonizar el antiguo espacio forestal, dando lugar a un frente de avance que se aprecia muy bien al cabo de varias décadas. No es un fenómeno general o no avanza de manera similar en todo el límite superior del bosque, lo que permite mantener relativamente bien conservado el espacio ganadero de aprovechamiento estival, con matices en la calidad de la hierba y en el momento más adecuado de pastoreo en función de la altitud, la exposición y las formas topográficas. Muchos puertos, es cierto, han dejado de pastarse, al menos con la intensidad de hace décadas, y ni siquiera la llegada de rebaños del Prepirineo o de la Depresión del Ebro es capaz de compensar el descenso de la ganadería en los altos valles pirenaicos. De ahí que numerosas laderas muestren al final del verano los signos de un embastecimiento, con hierbas muy altas que al no pastarse tienden a la acumulación de celulosa. Corresponden a los puertos más alejados, quizás los que más tardaron en pasar de bosque a pasto subalpino. Algunas zonas de pastos de verano, sin embargo, se enfrentan al impacto de estaciones de esquí, con la apertura de pistas de acceso, telesillas, balsas para la fabricación de nieve artificial y grandes aparcamientos (Figura 28). Este fenómeno representa la ocupación y transformación de los antiguos paisajes culturales, con la incorporación de nuevos usos que implican no solo un cambio paisajístico, sino también un cambio de funciones y de servicios ecosistémicos, a la vez que se perturba la estructura de la vegetación, la infiltración del agua en el suelo y la producción de sedimento. No deja de ser, querámoslo o no, un ejemplo de superposición de elementos dentro de un paisaje cultural que deja las huellas de un sistema social y económico también sujeto a aciertos y errores. Confirma, por otra parte, la influencia del mercado en la evolución de los paisajes.

En el Prepirineo el paisaje histórico se guarda mucho mejor porque la despoblación y el cultivo de muchos campos han fosilizado ciertas estructuras sin que se produzcan cambios de envergadura. Es cierto que se fue mucha población, más que en ningún otro lugar del Pirineo aragonés, pero la presencia de numerosos rellanos mecanizables, aunque mayoritariamente de pequeña dimensión, mantienen el cultivo cerealista que caracterizaba a las sierras prepirenaicas, siempre y cuando no fueran adquiridas para la repoblación forestal (especialmente al sur de San Juan de la Peña y Oroel). Se mantienen también algunas áreas que han evolucionado hacia paisajes ganaderos, quizás porque fueron utilizadas parcialmente por la ganadería en ambientes favorables, como Los Fenales de la cara norte de la Sierra de Guara (Figura 29), con mag- 


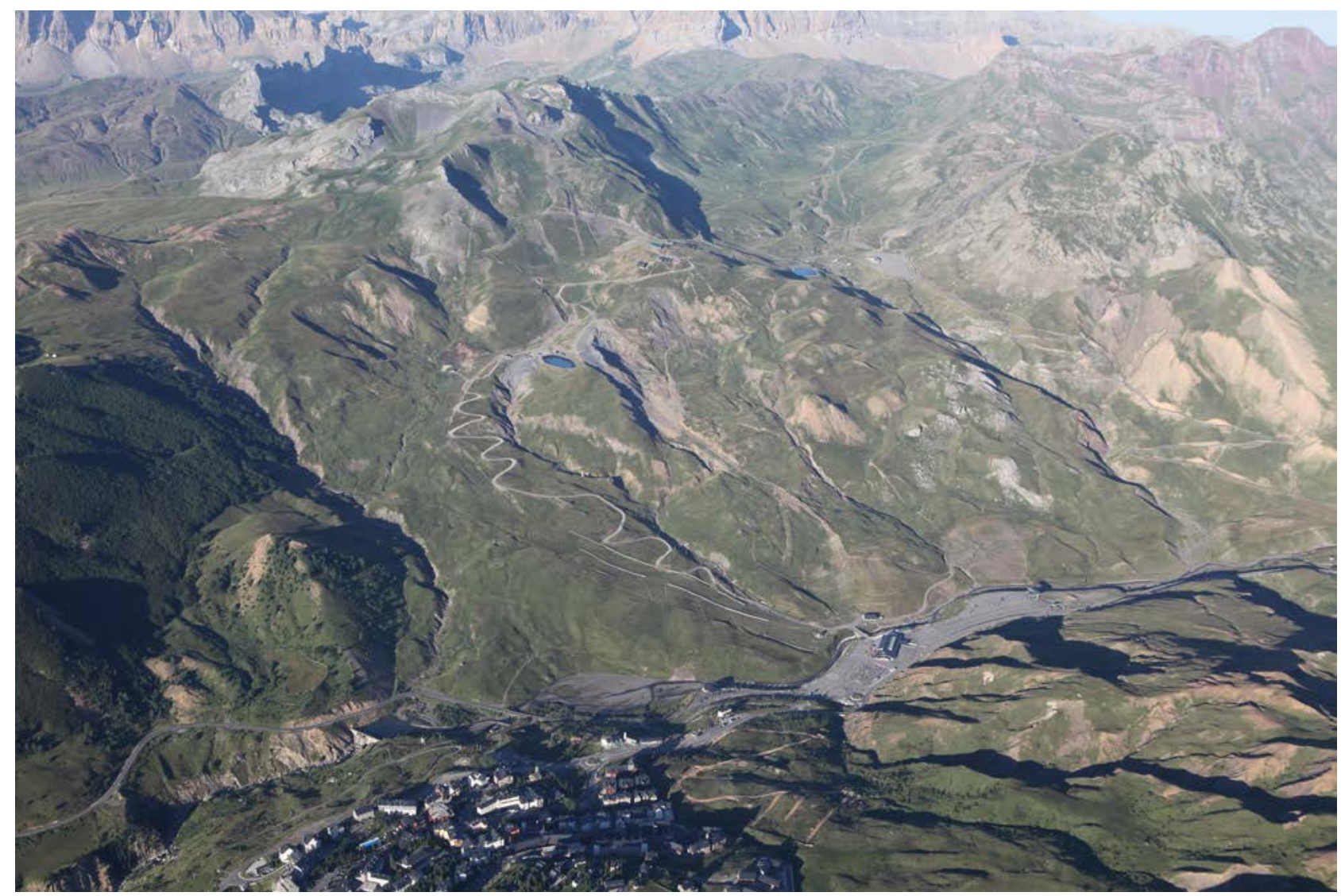

Figura 28: Perspectiva aérea de parte de la estación de esquí de Formigal. La urbanización aparece al pie de la imagen. Se observa (i) que la estación aprovecha la gran extensión de pastos de verano en la cabecera del alto Valle del Gállego; (ii) la presencia de nuevas infraestructuras ligadas a la estación de esquí, sobre todo el aparcamiento en el fondo del valle (a pie de pistas), las vías de acceso dentro de las áreas de esquí y las balsas para la fabricación de nieve artificial; y (iii) numerosas áreas erosionadas, muchas de ellas herederas de la dinámica geomorfológica normal del piso subalpino y más en un ambiente dominado por la presencia de pizarras. Se observan frecuentes cicatrices de deslizamientos y lenguas de despegue. La imagen permite ver que un paisaje originalmente forestal (del que queda un notable resto a la izquierda, en la Selva de Pacino) acabó convirtiéndose en una extensa superficie de pastos de verano que tuvieron una función importantísima para expandir la ganadería trashumante y una determinada organización social y, finalmente, ha pasado en las últimas décadas a cumplir funciones de ocio que rompen con los tradicionales usos ganaderos. Se trata, por tanto, de un ejemplo de transformación de un paisaje en el que van quedando huellas de diferentes percepciones del territorio por parte de las sociedades humanas. Foto: Francisco Gutiérrez Santolalla.

Figure 28: Aerial perspective of part of the ski resort of Formigal. The urbanization appears in the foreground. The image shows (i) that the resort takes advantage of the large extent of summer grasslands in the headwater of the Gállego Valley; (ii) the presence of new infrastructures linked to the ski resort, particularly the parking area in the valley bottom, the trails within the ski areas, and the ponds to produce artificial snow; and (iii) a number o eroded areas, many of them corresponding to the usual geomorphological dynamics in the subalpine belt in an environment dominated by shale. There are frequent landslide scars and tongues. The image allows us to see that the original forest (with a remarkable remnant on the left, in the Pacino Forest) became afterwards a large area of summer grasslands that favoured the expansion of the transhumant livestock and a certain social organization, and finally

developed leisure functions that are outside of the traditional livestock uses. Consequently, it is an example of landscape transformation in which the traces of distinct perceptions of the territory by human societies can be observed. Photo: Francisco Gutiérrez Santolalla.

níficos prados sobre suelos profundos y setos de bojes que cierran parcialmente los campos y que son (o han sido hasta tiempos recientes) podados de forma natural por el ganado. Por otro lado, la mayor parte de las laderas prepirenaicas muestran los efectos de la fuerte presión demográfica de los siglos XVIII y XIX: los cultivos, ya abandonados, en ladera, la degradación de la vegetación debida a la agricultura nómada, al sobrepastoreo y a los incendios recurrentes (gran extensión de Echinospartum horridum, Genista scorpius y Arctostaphylos uva-ursi) (Figura 30). Todas esas laderas forman parte de un paisaje llevado al extremo, también histórico porque representa los esfuerzos por sobrevivir a la escasez en un momento en que apenas había opciones. Por supuesto, las antiguas pardinas y masías han desaparecido como unidades de explotación diversificada en las que agricultura, ganade- 


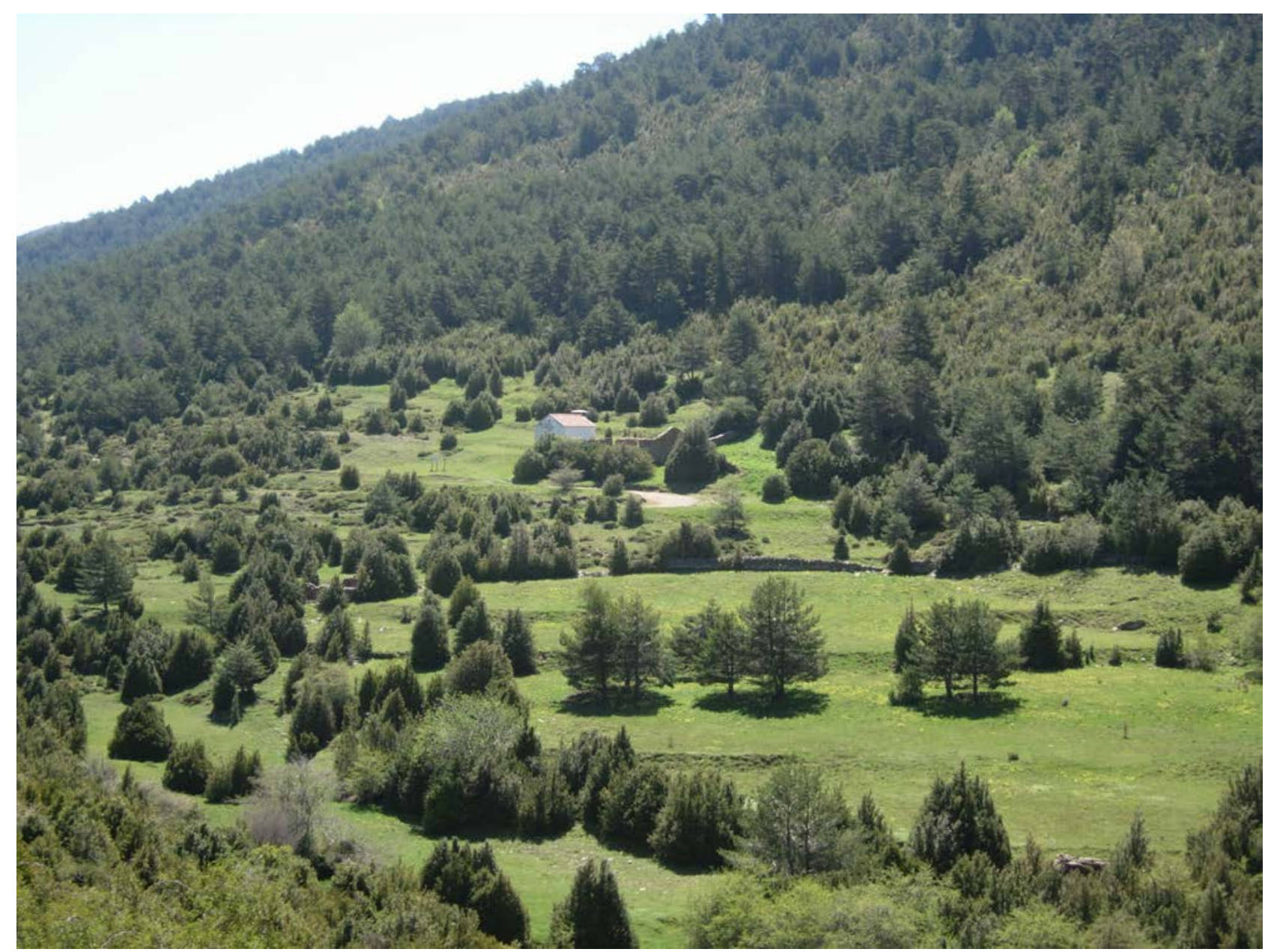

Figura 29: La mayor parte de los paisajes pirenaicos ha evolucionado a medida que lo hacían los sistemas de gestión del territorio y la demografía. Algunos campos abancalados con árboles y arbustos dispersos, que se cultivaban en el pasado con cereales, se han transformado en prados aprovechando unas favorables condiciones climáticas. Es el caso de Los Fenales de Guara, a más de $1400 \mathrm{~m}$ s.n.m., mostrando una confluencia evolutiva con los panares de los altos valles pirenaicos. Foto: J.M.G.R.

Figure 29: Most of the Pyrenean landscapes have evolved following the evolution of management systems and demography. Some bench-terraced fields with disperse trees and shrubs cultivated with cereals in the past, have been transformed into meadows because of the favourable climatic conditions. This is the case of Los Fenales, Guara Sierra, at an elevation higher than $1400 \mathrm{~m}$ a.s.l., showing an evolutionary confluence with the panares in the high Pyrenean valleys. Photo: J.M.G.R.

ría y explotación forestal se complementaban. Es cierto que algunas pardinas, muy pocas, se mantienen en explotación (Ferrera, Esporret) y que se han introducido modelos de gestión que tratan de recuperar lo mejor del paisaje cultural; así, en la pardina de Esporret (al pie meridional de San Juan de la Peña) se han recuperado antiguos campos de cultivo mediante desbroces y se han creado pequeñas balsas para favorecer el pastoreo integral y forzar el desplazamiento de ganado, incorporando yeguas y cabras, además del ganado vacuno de raza pirenaica, para mejorar progresivamente el pasto (Valdelvira-Salazar \& Balcells, 1986). Pero se trata de iniciativas excepcionales que todavía no han servido de ejemplo.

Los grandes cambios demográficos y el marco socioeconómico que se implanta progresivamente desde mediados del siglo XX explican la profunda transformación de las relaciones entre la sociedad pirenaica y el medio natural y la reorganización espacial de los paisajes. El sistema que, por convención, llamamos tradicional, anterior al desmoronamiento de los sistemas de explotación en el Pirineo, se caracterizaba por una explotación global de los recursos que aprovechaba el escalonamiento altitudinal de los pisos de vegetación y la heterogeneidad topográfica y topoclimática, de manera que existía una interdependencia entre las diferentes unidades paisajísticas para optimizar la productividad (Lasanta Martínez, 2002). Este sistema se apoyaba además en las migraciones temporales, actividades artesanales, comercio lanero y maderero $\mathrm{y}$, sobre todo, en la trashumancia, para intensificar los flujos económicos con el exterior. El sistema actual, que está en constante cambio en función del mercado y de las subvenciones, margina a gran parte del territorio para cen- 


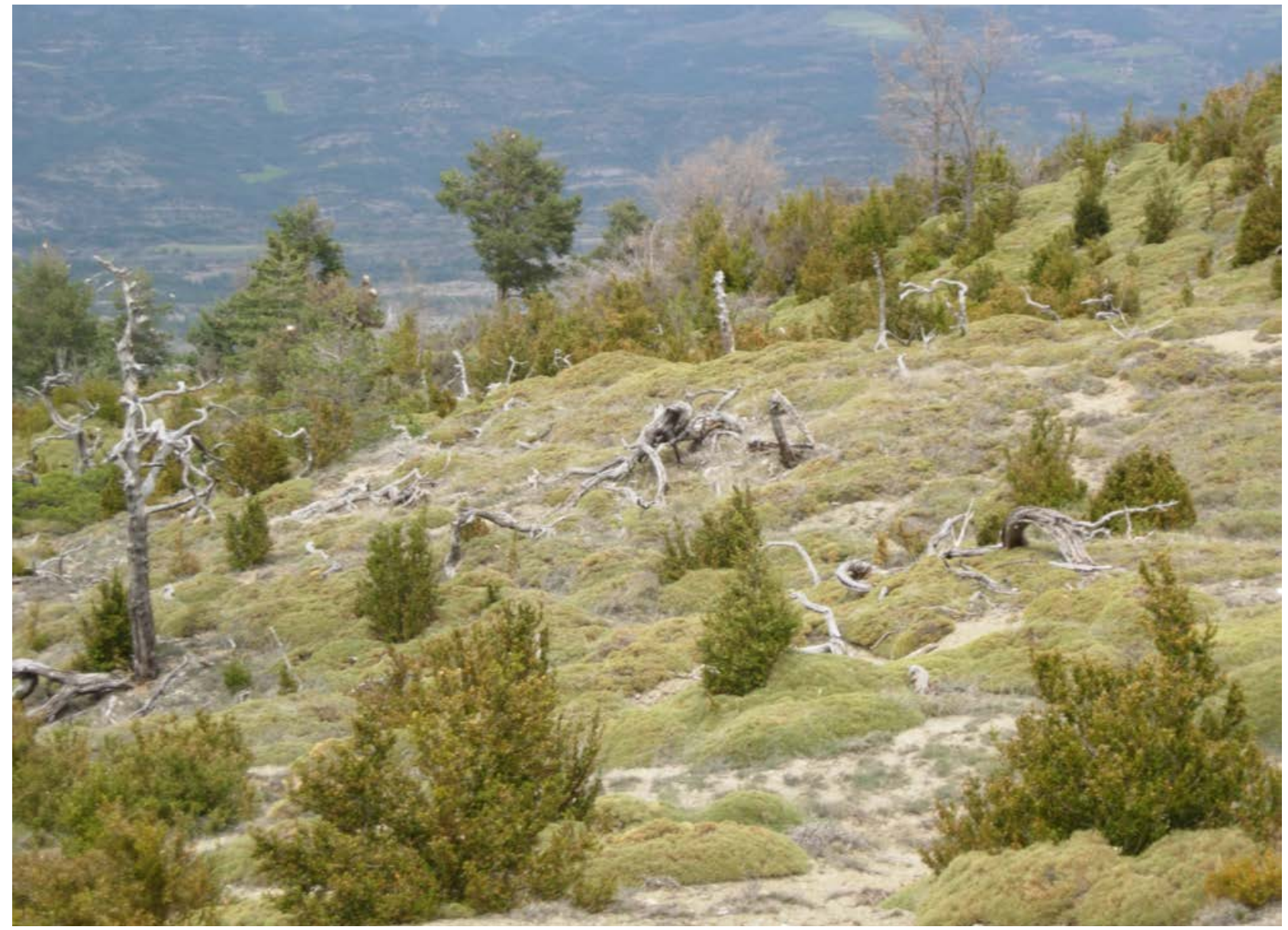

Figura 30: Muchos paisajes culturales son el reflejo de la adaptación de las sociedades humanas a las condiciones naturales y son la consecuencia de una determinada percepción de la heterogeneidad topográfica y topoclimática. En otros casos, sin embargo, tales paisajes son el resultado de una excesiva presión demográfica sobre un territorio sobreexplotado y con escasas posibilidades de recuperación, como ha sucedido en buena parte del Prepirineo. En la foto, ladera próxima a Ibirque, al norte de la Sierra de Guara, donde la utilización frecuente del fuego para mejorar la calidad del pasto y, ocasionalmente, la introducción de la agricultura nómada han dado lugar a intensos procesos de erosión y a la colonización por parte de un matorral dominado por bojes (Buxux sempervirens)

y erizones (Echinospartum horridum) entre restos de árboles quemados y algunos pinos supervivientes que son atacados por la procesionaria. Foto: J.M.G.R.

Figure 30: Many cultural landscapes are the consequence of adaptation of human societies to natural conditions and reflect a certain perception of the topographic and topoclimatic heterogeneity. In other cases, however, such landscapes are the result of an excessive population pressure on an overexploited territory with scarce possibilities of recovery, as it has occurred in a large part of the Pre-Pyrenees. In the photo, slope near to Ibirque, in the northern face of the Guara Sierra, where the frequent use of fire for improving the quality of grasslands and also, occasionally, the introduction of shifting agriculture have resulted in severe erosion processes and the colonization with shrubs dominated by Buxus sempervirens and Echinospartum horridum among remnants of burnt trees and some survivor pines that are invaded by processionary caterpillars. Photo: J.M.G.R.

trarse en los fondos de valle (producción intensiva de hierba, localización de actividades turísticas y de embalses), mientras se abandona la mayor parte de las laderas o se explotan muy extensivamente, permitiendo un crecimiento acelerado de matorrales y bosque. La importancia actual de los fondos de valle es tan grande que el número de unidades ganaderas de cada valle se relaciona fundamentalmente con la superficie de prados, mientras que en el sistema tradicional las unidades ganaderas se relacionaban con la extensión de los pastos subalpinos de aprovechamiento estival (García-Ruiz \& Lasanta-Martínez,
1993). Se ha pasado así de una organización espacial que utilizaba globalmente los recursos de la montaña a otra en que el espacio es explotado selectivamente con el fin de alcanzar la máxima productividad por persona empleada (Lasanta Martínez, 2002).

\section{Conclusiones}

Los paisajes culturales constituyen un patrimonio de gran riqueza en las áreas de montaña, especialmente en el 
mundo mediterráneo, donde la presencia humana ha dejado profundas huellas desde al menos el Neolítico. Tales paisajes representan las diferentes formas de percibir la apropiación y transformación del territorio para maximizar la productividad en función de las necesidades de la población, las posibilidades de comercialización (cuando las ha habido) y las dificultades que presenta el medio natural, especialmente climáticas y topográficas. Los habitantes montanos fueron muy pronto conscientes de las oportunidades que brinda el escalonamiento altitudinal de las montañas, desde ambientes submediterráneos hasta los alpinos. Eso significa que hay pisos (o cinturones) que se activan más tempranamente que otros, y que puede existir, con una adecuada organización, una complementariedad entre zonas altas y bajas, base de los sistemas ganaderos trasterminantes y trashumantes. Por eso, las áreas de montaña necesitan una organización social y territorial compleja, para hacer frente a la adversidad provocada por la rudeza del clima y la explotación de laderas pendientes, a veces muy alejadas de los asentamientos humanos. Esa organización social ha permitido construir paisajes que solo son sostenibles con un gran aporte de trabajo y que se destruyen en cuando falla alguno de los pilares básicos en que se fundamente la sociedad, en especial la disponibilidad de mano de obra abundante y barata.

La presencia de monumentos megalíticos en el piso subalpino confirma que hubo pastores que explotaron los pastos de verano desde el Neolítico o la Edad del Bronce, a la vez que se iniciaba el aprovechamiento agrícola en los fondos de valle. Desde entonces, se han ido ampliando las áreas de pastos de verano, para favorecer el crecimiento de los rebaños de ganado lanar, y de las zonas de cultivo, a medida que aumentaba la población o mejoraban las condiciones para la comercialización de productos locales, como fue el caso del mercado lanero desde el siglo XIII. A medida que fue aumentando la población surgió la necesidad de ampliar el espacio agrícola, con campos de cultivo remontando por laderas cada vez más pendientes y más alejadas de los núcleos de población, y se construyeron complejos sistemas de terrazas para asegurar el cultivo de cereales, el control de la escorrentía superficial y la conservación del suelo. En los momentos de mayor densidad demográfica, coincidiendo además con la crisis de los sistemas trashumantes y de actividades artesanales/industriales locales (producción textil, minería), se explotaron campos muy pendientes en régimen de rozas o cultivos itinerantes, además de conquistar el límite máximo posible del cultivo en torno a 1600-1800 m s.n.m. en los llamados panares.

Todo el proceso de construcción de los paisajes refleja diferentes etapas y distintas percepciones colectivas acerca de las posibilidades que ofrece la naturaleza a los seres humanos, siempre condicionadas por la organización social y el mercado. Con frecuencia hay también decisiones individuales, como ha sucedido en el caso de que los hijos no herederos se apropiasen (temporal o definitivamente) de tierras comunales para cultivar en difíciles condiciones, incentivando localmente la erosión y degradando la vegetación. Mientras la densidad de población no supe- ró un determinado umbral, se tiene la impresión de que las transformaciones paisajísticas buscaron la sostenibilidad o la pervivencia del sistema agropecuario como un todo global en el que la comprensión de las fuerzas que mueven a la reacción de la naturaleza frente a impactos humanos fue un factor clave.

Otra cuestión importante es que los paisajes culturales son el resultado de una construcción lenta, sometida a pruebas de error y acierto, lo que ha conducido a situaciones muy diversas marcadas por las situaciones limitantes que caracterizan a las montañas. Los primeros pobladores pirenaicos intuyeron, sin duda, muy pronto que la montaña es un ambiente de alta energía, condicionada por la tendencia al desplazamiento de agua, suelo y nutrientes en el sentido de la pendiente. El éxito de las sociedades dependió de que "el movimiento hacia abajo" fuera comprendido muy pronto. De ahí todos los esfuerzos por controlar la escorrentía y por construir terrazas, con un aporte excepcionalmente alto de energía para diseñar un nuevo paisaje en el que la escorrentía, el suelo y la gravedad son gestionados de la mejor forma posible. Naturalmente, este esfuerzo implica también un gran gasto de energía en la conservación del paisaje, que puede desmoronarse de manera irreversible por muchas razones, entre ellas la despoblación y el abandono de tierras de cultivo, que conducen a lo que podemos llamar una deconstrucción del paisaje. Esta última representa la pérdida de un patrimonio cultural que, estudiado a fondo, nos enseñaría mucho acerca de la forma óptima de aprovechar los recursos naturales y también de los errores que se han cometido en el pasado. En definitiva, el paisaje como algo vivo que refleja la suma de muchos acontecimientos y conocimientos siempre cambiantes.

\section{Agradecimientos}

Este trabajo se ha desarrollado con el apoyo del Proyecto de Investigación ESPAS (CGL2015-655698-R), financiado por la Agencia Estatal de Investigación (AEI)-FEDER.

\section{Referencias}

Acín Fanlo, J.L., 1997. Paisajes con memoria. Viaje a los pueblos deshabitados del Alto Aragón. Prames: 263 pp., Zaragoza.

Acín Fanlo, J.L. \& Pinilla Navarro, V., 1995, Coords. Pueblos abandonados ¿un mundo perdido?. Universidad de Zaragoza - Diputación de Huesca: 314 pp., Zaragoza.

Agnoletti, M., Conti, L., Frezza, L., Santoro, A., 2015. Territorial analysis of the agricultural terraced landscapes of Tuscany (Italy): Preliminary results. Sustainability, 7 (4): $4564-$ 4581. https://doi.org/10.3390/su7044564.

Alados, C.L., Sáiz, H., Nuche, P., Gartzia, M., De Frutos, Á. \& Pueyo, Y., 2018. Clearing vs. Burning for restoring grasslands after shrub encroachment. Cuadernos de Investigación Geográfica 45. http://doi.org/10.18172/cig.3589.

Antrop, M., 1997. The concept of tradictional landscapes as a base for landscape evaluation and planning. The example of 
Flandes Region. Landscape and Urban Planning, 38: 105117. https://doi.org/10.1016/S0169-2046(97)00027-3.

Antrop, M., 2005. Why landscapes of the past are important for the future. Landscape and Urban Planning, 70: 21-34. https://doi.org/10.1016/j.landurbplan.2003.10.002.

Arnáez, J., Lasanta, T., Errea, M.P. \& Ortigosa, L., 2011. Land abandonment, landscape evolution, and soil erosion in a Spanish Mediterranean mountain region: The case of Camero Viejo. Land Degradation \& Development, 22: 537-550. https://doi.org/10.1002/ldr.1032.

Arnáez, J., Lana-Renault, N., Ruiz-Flaño, P., Pascual, N., Lasanta, T., 2017. Mass soil movement on terraced landscapes of the Mediterranean mountain areas: A case study in the Iberian Range, Spain. Cuadernos de Investigación Geográfica, 43 (1): 83-100. https://doi.org/10.18172/cig.3211.

Asins, S., 2006. Linking historical Mediterranean terraces with water catchment, harvesting and distribution structures. En: J.P. Morel (Ed.), The archaeology of crop fields and gardens. Ediplugia, Bari, pp. 21-40.

Azcárate Luxán, M.V., 1990. El viñedo en el Sobrarbe durante el siglo XI: su localización. Espacio, Tiempo y Forma, Serie VI, Geografia, 3: 151-166.

Balcells, E., 1976. El Pirineo: Contraste de paisajes; enlace de pueblos. Imprenta del Ministerio de Asuntos Exteriores, Madrid.

Balcells, E., 1983. Evolución socio-económica reciente de tres comunidades comarcales pirenaicas y destino actual de las superficies más productivas de su demarcación. Cuadernos de Investigación Geográfica, 9: 41-82. https://doi. org/10.18172/cig.918.

Balcells, E., 1984. Estudio comparado de las cuencas altas del Subordán y del Veral y de las unidades étnicas que utilizan sus recursos. Pirineos, 123: 5-152.

Balcells, E., 1985. Valle del Aragón de Canfranc (Estudio descriptivo de recursos e historia de su utilización). Pirineos, 125: $117-140$.

Batllori, E. \& Gutiérrez, E., 2008. Regional tree line dynamics in response to global change in the Pyrenees. Journal of Ecology, 96: 1275-1288. https://doi.org/10.1111/ j.1365-2745.2008.01429.x.

Beguería, S., López-Moreno, J.I., Lorente, A., Seeger, M. \& García-Ruiz, J.M. 2003. Assessing the effect of climate oscillations and land-use changes on streamflow in the Central Spanish Pyrenees. Ambio, 32 (4): 283-286. https://doi. org/10.1579/0044-7447-32.4.283.

Beguería, S., López-Moreno, J.I., Gómez-Villar, A., Rubio, V., Lana-Renault, N. \& García-Ruiz, J.M., 2006. Fluvial adjustments to soil erosion and plant cover changes in the Central Spanish Pyrenees. Geografiska Annaler, Series A, Physical Geography, 88: 177-186. https://doi.org/10.1111/ j.1468-0459.2006.00293.x.

Beltrán, O. \& Vaccaro, I., 2017. Los comunales en el Pirineo Central. Idealizando el pasado y reelaborando el presente. Revista de Antropología Social, 26 (2): 235-257. https://doi. org/10.5209/RASO.57605.

Bernués, A., Rodríguez-Ortega, T., Ripoll-Bosch, R. \& Alfnes, F., 2014. Socio-cultural and economic valuation of ecosystem services provided by Mediterranean mountain agroecosystems. PLoS ONE, 9 (7): e102479. https://doi. org/10.1371/journal.pone.0102479.

Biarge, F., 2009. Sobrarbe. Letra menuda. Ediciones del Mallo, Huesca, 323 pp.

Biarge, F., 2011. Sobrarbe. Testigo directo. Ediciones del Mallo, Huesca, 312 pp.

Bielza de Ory, V., Corral Lafuente, J.L., Escolano Utrilla, S., Laliena Corbera, C., Sesma Muñoz, A. \& Ubieto Arteta, A., 1986. Estudio histórico-geográfico del valle de Bielsa (Huesca). Instituto de Estudios Altoaragoneses, Huesca, 224 pp.
Blondel, J., 2006. The "design" of Mediterranean landscapes: A millennial story of humans and ecological systems during the historic period. Human Ecology, 34: 713-729. https:// doi.org/10.1007/s10745-006-9030-4.

Buesa Conde, D.J., 1978. El Rey Sancho Ramírez. Guara Editorial, Zaragoza, $126 \mathrm{pp}$

Buil Guiral, L.J., 1997. Viaje por el Alto Aragón. Noviembre del año 1794. Huesca, La Val de Onsera.

Calvo Eito, C., Calvo Pérez, F.J., Calvo Pérez, I. \& Calvo Pérez, A., 2015. Valle de Hecho. Prames: Temas Aragoneses, Huesca, 640 pp.

Collantes, F., 2005. Declive demográfico y cambio económico en las áreas de montaña españolas, 1850-2000. Revista de Historia Económica, 23: 515-540.

Conti, G. \& Fagarazzi, L., 2004. Sustainable mountain development and the key-issue of abandonment of marginal rural areas. Planum, 11: 1-20.

Cramer, V.A., Hobbs, R.J. \& Standisch, R.J., 2007. What's new about old fields? Land abandonment and ecosystem assembly. Trends in Ecology and Evolution, 23 (2): 104-112. https://doi.org/10.1016/j.tree.2007.10.005.

Creus-Novau, J. \& Balcells, E., 1986. Reflexiones sobre los límites altitudinales de las residencias humanas permanentes en el alto Pirineo aragonés. Pirineos, 127: 153-174.

Davidson, I., 1980. Transhumance, Spain and Ethnoarchaeology. Antiquity, 54: 144-147. https://doi.org/10.1017/ S0003598X00103035.

Daumas, M., 1976. La vie rurale dans le Haut Aragon Oriental. Institutos de Estudios Oscenses y de Geografía Aplicada, Madrid, $774 \mathrm{pp}$.

Del Barrio, G., Creus, J. \& Puigdefábregas, J., 1990. Thermal seasonality of the high mountain belts of the Pyrenees. Mountain Research and Development, 10 (3): 227-233. https://doi.org/10.2307/3673602.

Díaz Muñoz, M.A., 1984. Criterios para el análisis de evolución de usos del suelo en zona de montaña: aplicación a un sector de Somosierra. Anales de Geografía de la Universidad Complutense, 4: 131-147.

Escalona Monge, J., 2001. Jerarquización social y organización del espacio. Bosques y pastizales en la Sierra de Burgos (siglos X-XII). En J. Gómez-Pantoja (Ed.), Los rebaños de Gerión. Pastores y trashumancia en Iberia antigua y medieval. Casa de Velázquez, Madrid, pp. 109-137.

Esteva Fabregat, C., 1971. Para una teoría de la aculturación en el Alto Aragón. Ethnica. Revista de Antropología, 2: 9-78.

Farina, A., 2000. The cultural landscape as a model for the integration of ecology and economics. BioScience, 50: 313-320. https://doi.org/10.1641/0006-3568(2000)050[0313:TCLAA $\mathrm{M}] 2.3 . \mathrm{CO} ; 2$

Faus Pujol, M.C. \& Rubio Gracia, J.L., 1984. La apropiación de los bienes comunales en Aragón. Geographicalia, 21-24: 77-86.

Fernández-Giménez, M.E. \& Fillat Estaqué, F., 2012. Pyrenean pastoralists ecological knowledge: Documentation and application to natural resource management and adaptation. Human Ecology, 40: 287-300. https://doi.org/10.1007/ s10745-012-9463-x.

Fernández Mier, M. \& Quirós Castillo, J.A., 2015. El aprovechamiento de los espacios comunales en el noroeste de la Península Ibérica entre el periodo romano y el medieval. $I l$ Capitale Culturale, 12: 689-717.

Fernández Mier, M., Aparicio Martínez, P., González Álvarez, D., Fernández-Fernández, J. \& Alonso González, P., 2013. La formación de los paisajes agrarios del Noroeste peninsular durante la Edad Media (siglos V al XII). Debates de Arqueología Medieval, 3: 359-374.

Fernández Piñar, C., 2019. Origen, localización y evolución de los panares en el municipio de Gistaín. Historia Agraria, 78. 
Fillat Estaqué, F., 2003a. Gestión semiextensiva de prados y pastos europeos ricos en especies. Caso particular de los Pirineos españoles. Pastos, 33 (2): 171-215.

Fillat Estaqué, F., 2003b. Un paisaje pirenaico de prados y pastos: cambios recientes y perspectivas. Acta Botanica Barcinonensia, 49: 313-324.

Fillat Estaqué, F., 2005. Otros usos de los setos. Fertilidad de la Tierra, 21: 6-9.

Galán Domingo, E. \& Ruiz-Gálvez, M., 2001. Rutas ganaderas, trasterminancia y caminos antiguos. El caso del Occidente peninsular entre el Calcolítico y la Edad del Hierro. En: J. Gómez-Pantoja (Ed.), Los rebaños de Gerión. Pastores y trashumancia en Iberia antigua y medieval. Casa de Velázquez, Madrid, pp. 263-278.

García Fernández, J., 1975. Organización del espacio y economía rural en la España Atlántica. Siglo XXI de España Editores, Madrid, $332 \mathrm{pp}$.

García-Ruiz, J.M., 1976. Modos de vida y niveles de renta en el Prepirineo del Alto Aragón Occidental. Instituto de Estudios Pirenaicos, Jaca, $272 \mathrm{pp}$.

García-Ruiz, J.M. \& Balcells, E., 1978. Tendencias actuales de la ganadería en el Pirineo Central. Estudios Geográficos, 153: $539-560$.

García-Ruiz, J.M. \& Lasanta-Martínez, T., 1990. Land-use changes in the Spanish Pyrenees. Mountain Research and Development, 10 (3): 267-279. https://doi.org/10.2307/3673606.

García-Ruiz, J.M. \& Lasanta-Martínez, T., 1993. Land-use conflicts as a result of land-use change in the Central Spanish Pyrenees: A review. Mountain Research and Development, 13 (3): 295-304. https://doi.org/10.2307/3673658.

García-Ruiz, J.M. \& Lana-Renault, N., 2011. Hydrological and erosive consequences of farmland abandonment in Europe, with special reference to the Mediterranean región-A review. Agriculture, Ecosystems and Environment, 140: $317-$ 338. https://doi.org/10.1016/j.agee.2011.01.003.

García-Ruiz, J.M., Lasanta, T., Ruiz-Flaño, P., Ortigosa, L., White, S., González, C. \& Martí, C., 1996. Land-use changes and sustainable development in mountain áreas: a case study in the Spanish Pyrenees. Landscape Ecology, 11 (5): 267-277. https://doi.org/10.1007/bf02059854.

García-Ruiz, J.M., Beguería, S., Alatorre, L.C. \& Puigdefábregas, J., 2010. Land cover changes and shallow landsliding in the Flysch Sector of the Spanish Pyrenees. Geomorphology, 124: 250-259. https://doi.org/10.1016/j.geomorph.2010.03.036.

García-Ruiz, J.M., López-Moreno, J.I., Vicente-Serrano, S.M., Lasanta-Martínez, T. \& Beguería, S., 2011. Mediterranean water resources in a global change scenario. Earth-Science Reviews, 105: 121-139. https://doi.org/10.1016/ j.earscirev.2011.01.006

García-Ruiz, J.M., López-Moreno, J.I., Lasanta, T., Vicente-Serrano, S.M., González-Sampériz, P., Valero-Garcés, B.L., Sanjuán, Y., Beguería, S., Nadal-Romero, E., Lana-Renault, N. \& Gómez-Villar, A., 2015. Los efectos geoecológicos del Cambio Global en el Pirineo Central español: Una revisión a distintas escalas espaciales y temporales. Pirineos, 170: e012. http://dx.doi.org/10.3989/Pirineos.2015.170005.

García-Ruiz, J.M., Sanjuán, Y., Gil-Romera, G., González-Sampériz, P., Beguería, S., Arnáez, J., Coba-Pérez, P., GómezVillar, A., Álvarez-Martínez, J., Lana-Renault, N., PérezCardiel, E. \& López de Calle, C., 2016a. Mid and late Holocene forest fires and deforestation in the subalpine belt of the Iberian range, northern Spain. Journal of Mountain Science, 13 (10): 1760-1772. https://doi.org/10.1007/s11629015-3763-8.

García-Ruiz, J.M., Sanjuán, Y., Arnáez, J., Beguería, S., Gómez-Villar, A., Álvarez-Martínez, J., Lana-Renault, N. \& Coba-Pérez, P., 2016b. La evolución del piso subalpino en la Sierra de Urbión (Sistema Ibérico, norte de España): un modelo de impacto geoecológico de actividades humanas en el valle de Ormazal. Pirineos, 171: e022. http://dx.doi. org/10.3989/Pirineos.2016.171006.

García-Ruiz, J.M., Arnáez, J. \& Lasanta, T., 2017. Complejidad y diversidad en el paisaje de la montaña riojana: Una perspectiva general sobre su proceso de construcción y transformación. Berceo, 173: 141-164.

Gómez García, D., Montserrat Martí, G. \& Fillat Estaqué, F., 1982. Utilización de métodos fotográficos en el estudio de la pradería de San Juan de Plan (Huesca). Pastos, 12 (2): 273-282.

Gómez Urdáñez, J.L. \& Moreno Fernández, J.R., 1997. El problema agrario en las sierras de La Rioja: de la propiedad a la subsistencia (siglos XVIII y XIX). Agricultura y Sociedad, 82: 79-113.

Gómez-Villar, A., Sanjuán, Y., García-Ruiz, J.M., Nadal-Romero, E., Álvarez-Martínez, J., Arnáez, J. \& Serrano Muela, M.P., 2014. Sediment organization and adjustment in a torrential reach of the Upper Ijuez River, Central Spanish Pyrenees. Cuadernos de Investigación Geográfica, 40 (1): 191-214. https://doi.org/10.18172/cig.2566.

González-Sampériz, P., Aranbarri, J., Pérez-Sanz, A., Gil-Romera, G., Moreno, A., Leunda, M., Sevilla-Callejo, M., Corella, J.P., Morellón, M., Oliva, B. \& Valero-Garcés, B., 2017. Environmental and climate change in the southern Central Pyrenees since the Last Glacial Maximum: A view from the lake records. Catena, 149: 668-688. http://dx.doi. org/10.1016/j.catena.2016.07.041.

Grove, D. \& Rackham, O., 2001. The nature of Mediterranean Europe: An ecological history. Yale University Press, New Haven.

Higgs, E.S., 1976. The history of European agriculture: The uplands. Philosophical Transactions of the Royal Society B, 275: 159-173. https://doi.org/10.1098/rstb.1976.0078.

Kaplan, J.O., Krumhardt, K.M. \& Zimmermann, N., 2009. The prehistoric and preindustrial deforestation of Europe. Quaternary Science Reviews, 28: 3016-3014. https://doi. org/10.1016/j.quascirev.2009.09.028.

Kinnaird, T., Bolòs, J., Turner, A. \& Turner, S., 2017. Opticallystimulated luminiscence profiling and dating of historic agricultural terraces in Catalonia (Spain). Journal of Archaeological Science, 78: 66-77. https://doi.org/10.1016/j. jas.2016.11.003.

Lana-Renault, N., López-Vicente, M., Nadal-Romero, E., Ojangurem R., Llorente, J.A., Errea, P., Regüés, D., Ruiz-Flaño, P., Khorchani, M., Arnáez, J., Pascual, N., 2018. Catchment based hydrology under post farmland abandonment scenarios. Cuadernos de Investigación Geográfica, 44 (2): 503534. http://doi.org/10.18172/cig.3475.

Lasanta, T., 1989. Evolución reciente de la agricultura de montaña: el Pirineo aragonés. Geoforma Ediciones, 220 pp., Logroño.

Lasanta, T., 1997. La transformación del paisaje de montaña media por la actividad agrícola en relación con las condiciones ambientales. En: J.M. García-Ruiz \& P. López-García (Eds.), Acción humana y desertificación en ambientes mediterráneos. Consejo Superior de Investigaciones Científicas, Zaragoza, pp. 145-172.

Lasanta Martínez, T., 2002. Los sistemas de gestión en el Pirineo Central español durante el siglo XX: del aprovechamiento global de los recursos a la descoordinación espacial en los usos del suelo. Ager, 2: 173-195.

Lasanta Martínez, T., Ortigosa Izquierdo, L.M. \& García-Ruiz, J.M., 1994. Distribución espacial de diferentes modelos de campos de cultivo en el Pirineo Central español. Ería, 33: 63-72.

Lasanta-Martínez, T., Vicente-Serrano, S.M. \& CuadratPrats, J.M., 2005. Mountain Mediterranean landscape 
evolution caused by the abandonment of traditional primary activities: a study of the Spanish Central Pyrenees. Applied Geography, 25: 47-65. https://doi.org/10.1016/ j.apgeog.2004.11.001.

Lasanta, T., Beguería, S. \& García-Ruiz, J.M., 2006. Geomorphic and hydrological effects of traditional shifting agriculture in a Mediterranean mountain area, Central Spanish Pyrenees. Mountain Research and Development, 26 (2): 146-152. https://doi.org/10.1002/ldr.2695.

Lasanta, T., Arnáez, J., Ruiz Flaño, P. \& Lana-Renault Monreal, N., 2013a. Los bancales en las montañas españolas: un paisaje abandonado y un recurso potencial. Boletín de la Asociación de Geógrafos Españoles, 63: 301-322. https://dialnet.unirioja.es/servlet/articulo? $\operatorname{codigo}=$ 4495823.

Lasanta Martínez, T., Errea Abad, M.P., Bouzebboudja, M.R., Medrano Moreno, L.M., 2013b. Pastoreo y desbroce de matorrales en Camero Viejo. Instituto de Estudios Riojanos, Logroño, $186 \mathrm{pp}$

Lasanta, T., Nadal-Romero, E. \& Arnáez, J., 2015. Managing abandoned farmland to control the impacto of re-vegetation on the environment. The state of art in Europe. Environmental Science \& Policy, 52: 99-109. https://doi.org/10.1016/j. envsci.2015.05.012.

Lasanta, T., Errea, M.P. \& Nadal-Romero, E., 2017a. Traditional agrarian landscape in the Mediterranean mountains. A regional and local factor analysis in the Central Spanish Pyrenees. Land Degradation \& Development, 28(5): 16261640. https://doi.org/10.1002/ldr.2695.

Lasanta, T., Nadal-Romero, E. \& Errea, M.P., 2017b. The footprint of marginal agriculture in the Mediterranean mountain landscape: An analysis of the Central Spanish Pyrenees. Science of the Total Environment, 599-600: 1823-1836. http://dx.doi.org/10.1016/j.scitotenv.2017.05.092.

Lasanta, T., Nadal-Romero, E., García-Ruiz, J.M., 2018. Clearing shrubland as a strategy to encourage extensive livestock farming in the Mediterranean mountains. Cuadernos de Investigación Geográfica 45. http://doi. org/10.18172/cig.3616.

MacDonald, D., Crabtree, J.R., Wiesinger, G., Dax, T., Stamou, N., Fleury, P., Gutiérrez Lazpita, J. \& Gibon, A., 2000. Agricultural abandonment in mountain areas of Europe: environmental consequences and policy response. Journal of Environmental Management, 59: 47-69. https://doi.org/10.1006/ jema.1999.0335.

Martí, C., Valero, B. \& García-Ruiz, J.M., 1997. Large historical debris flows in the Central Spanish Pyrenees. Physics and Chemistry of the Earth, 22 (3-4): 381-385. https://doi. org/10.1016/S0079-1946(97)00162-6.

Martí Bono, C.E. \& Puigdefábregas, J., 1983. Consecuencias geomorfológicas de las lluvias de noviembre de 1982 en las cabeceras de algunos valles pirenaicos. Estudios Geográfi$\cos , 170-171: 275-289$.

Martínez de Pisón, E., 2009a. Miradas sobre el paisaje. Biblioteca Nueva, Madrid, $285 \mathrm{pp}$.

Martínez de Pisón, E., 2009b. Los paisajes de los geógrafos. Geographicalia, 55: 5-25.

Martínez de Pisón, E., 2012. Imagen del paisaje. La Generación del 98 y Ortega y Gasset. Fórcola, Madrid, 208 pp.

Martínez-Casasnovas, J.A. \& Ramos, M.C., 2006. The cost of soil erosion in vineyard fields in the Penedés-Anoia Region (NE Spain). Catena, 68: 194-199. https://doi.org/10.1016/j. catena.2006.04.007.

Montes Ramírez, L., Domingo Martínez, R., Sebastián López, M., Linau Hernáez, P., 2016. Construyendo un paisaje. Megalitos, arte esquemático y cabañeras en el Pirineo central. ARPI. Arqueología y Prehistoria del Interior Peninsular, 04: 248-263.
Montserrat, J., 1992. Evolución glaciar y postglaciar del clima y la vegetación en la vertiente sur del Pirineos: Estudio palinológico. Instituto Pirenaico de Ecología, Zaragoza, $147 \mathrm{pp}$.

Montserrat Recoder, P., 1964. Ecología del pasto. Publicaciones del Centro Pirenaico de Biología experimental, 1 (5): 1-22.

Montserrat Recoder, P., 1965. Los sistemas agropecuarios. Anales de Edafología y Agrobiología, 24 (5-6): 343-351.

Montserrat Recoder, P., 1972. Estructura del sistema agropecuario. Anales de Edafología y Agrobiología, 31 (1-2): 151-156.

Montserrat Recoder, P., 2009. La cultura que hace el paisaje. Fertilidad de la Tierra, Estella, 237 pp.

Morellón, M., Valero-Garcés, B., González-Sampériz, P., Vegas-Villarrúbia, T., Rubio, E., Rieradevall, M., DelgadoHuertas, A., Mata, P., Romero, Ó., Engstrom, D., López-Vicente, M., Navas, A. \& Soto, J., 2011. Climate changes and human activities recorded in the sediments of Lake Estanya (NE Spain) during the Medieval Warm Period and Little Ice Age. Journal of Paleolimnology, 46: 423-452. https://doi. org/10.1007/s10933-009-9346-3.

Moreno, A., Pérez, A., Frigola, J., Nieto-Moreno, V., RodrigoGámiz, M., Martrat, B., González-Sampériz, P., Morellón, M., Martín-Puertas, C., Corella, J.P., Belmonte, A., Sancho, C., Cacho, I., Herrera, G., Canals, M., Grimalt, J.O., Jiménez-Espejo, F., Martínez-Ruiz, F., Vegas-Villarrúbia, T. \& Valero-Garcés, B.L., 2012. The Medieval Climate Anomaly in the Iberian Peninsula reconstructed from marine and lake records. Quaternary Science Reviews, 43: 16-32. https://doi. org/10.1016/j.quascirev.2012.04.007.

Moreno Fernández, J.R., 2002. La economía de montaña en el Antiguo Régimen: Los equilibrios tradicionales en el Pirineo Aragonés. Ager, 2: 43-80.

Moreno Gallo, I., 2006. Vias romanas. Ingeniería y técnica constructiva. Ministerio de Fomento, Madrid, $233 \mathrm{pp}$.

Muir, J., 2018. Cuaderno de montaña. Volcano, Las Rozas, $195 \mathrm{pp}$.

Nadal-Romero, E. \& Regüés, D., 2010. Geomorphological dynamics of sub-humid mountain badland areas: weathering, hydrological and suspended sediment transport processes. A case study in the Araguás catchment (Central Pyrenees), and implications for altered hydro-climatic regimes. Progress in Physical Geography, 34 (3): 123-150. https://doi. org/10.1177/0309133309356624.

Nadal-Romero, E., Otal-Otín, I., Lasanta, T., Sánchez-Navarrete, P., Errea, P. \& Cammeraat, E., 2018. Woody encroachment and soil carbon stocks in subalpine areas in the Central Spanish Pyrenees. Science of Total Environment, 636: 727 736. https://doi.org/10.1016/j.scitotenv.2018.04.324.

Navarro, L.M. \& Pereira, H.M., 2012. Rewilding abandoned landscapes in Europe. Ecosystems, 15: 900-912. https://doi. org/10.1007/s10021-012-9558-7.

Naveh, Z., 2000. What is holistic landscape ecology? A conceptual introduction. Landscape and Urban Planning, 50: 7-26. https://doi.org/10.1016/S0169-2046(00)00077-3.

Nogués-Bravo, D., Simberloff, D., Rahbek, C. \& Sanders, N.J., 2016. Rewilding is the new Pandora's box in conservation. Current Biology, 26: R83-R101. https://doi.org/10.1016/ j.cub.2015.12.044.

Olarieta, J.R., Rodríguez-Valle, F.L. \& Tello, E., 2008. Preserving and destroying soils, transforming landscape: soils and land-use changes in the Vallès County (Catalunya, Spain) 1853-2004. Land Use Policy, 25: 474-484 https://doi. org/10.1016/j.landusepol.2007.10.005.

Ortega Cantero, N. 2012. Los valores del paisaje: La Sierra de Guadarrama en el horizonte de Francisco Giner y la Institución Libre de Enseñanza. En: J. García Velasco y A. Morales Moya (Eds.), La Institución Libre de Enseñanza y Francisco Giner de los Ríos: nuevas perspectivas. 2. La 
Institución Libre de Enseñanza y la cultura española. Fundación Francisco Giner de los Ríos, Madrid, pp. 673-711.

Ortega Valcárcel, J., 1974. La transformación de un espacio rural. Las montañas de Burgos. Servicio de Publicaciones de la Universidad de Valladolid: $531 \mathrm{pp}$., Valladolid.

Palang, H., Helmfrid, S., Antrop, M. \& Alumäe, H., 2005. Rural landscapes: past processes and future strategies. Landscape and Urban Planning, 70: 3-8. https://doi.org/10.1016/ j.landurbplan.2003.10.001.

Pavelka, J., Smetanová, A., Rejman, J., Kovácik, P., 2017. An interdisciplinary tillage erosion experiment: establishing a new field don grasslands with reconstructed ard plough of the Bronze Age-Iron Age. Cuadernos de Investigación Geográfica, 43 (1): 101-118. https://doi.org/10.18172/cig.3131

Pérez-Sanz, A., González-Sampériz, P., Moreno, A., ValeroGarcés, B., Gil-Romera, G., Rieradevall, M., Tarrats, P., Lasheras-Álvarez, L., Morellón, M., Belmonte, A., Sancho, C., Sevilla-Callejo, M. \& Navas, A., 2013. Holocene climate variability, vegetation dynamics and fire regime in the central Pyrenees: the Basa de la Mora sequence (NE Spain). Quaternary Science Reviews, 73: 149-169. https://doi. org/10.1016/j.quascirev.2013.05.010.

Puigdefábregas, J. \& Balcells, E., 1970. Relaciones entre la organización social y la explotación del territorio en el Valle de El Roncal (Navarra Oriental). Pirineos, 98: 53-89.

Puigdefábregas, J. \& Fillat, F., 1986. Ecological adaptation of traditional land uses in the Spanish Pyrenees. Mountain Research and Development, 6 (1): 63-72. https://doi.org/10.2307/3673341

Puigdefábregas, J. \& Pérez-García, M., 2018. A neuro-scientific approach to environment care. Cuadernos de Investigación Geográfica, 45. http://doi.org/10.18172.cig.3585.

Pujadas, J.J. \& Comas, D., 1975. La casa en el proceso de cambio del Pirineo Aragonés. Cuadernos de Investigación. Geografia e Historia, 2: 51-62.

Quirós Castillo, J.A., 2011. La formación de los paisajes medievales en el norte peninsular: agricultura y ganadería en los siglos V-XII. Debates de Arqueología Medieval, 1: 161-165.

Riera, S., Wansard, G. \& Julià, R., 2004. 2000-year environmental history of a karstic lake in the Mediterranean prePyrenees: The Estanya lakes (Spain). Catena, 55: 293-324. https://doi.org/10.1016/S0341-8162(03)00107-3.

Robledano Aymerich, F., Romero Díaz, A., Belmonte Serrato, F., Fernández Carrillo, M.A., Martínez Hernández, C., Sánchez Martín, M. \& Zapata Pérez, V.M., 2016. Consecuencias del abandono de cultivos en la Región de Murcia y recomendaciones de gestión. En: A. Romero Díaz (Coord.), Abandono de cultivos en la Región de Murcia. Consecuencias ecogeomorfológicas. Ediciones de la Universidad de Murcia (Editum), Murcia, pp.227-263.

Rodríguez Gutiérrez, F., 1989. La organización agraria de la montaña central asturiana. Servicio Central de Publicaciones del Principado de Asturias: 636 pp., Oviedo.

Rodrigo Comino, J., Senciales, J.M., Ramos, M.C., MartínezCasasnovas, J.A., Lasanta, T., Brevik, E.C., Ries, J.B. \& Ruiz Sinoga, J.D., 2017. Understanding soil erosion processes in Mediterranean sloping vineyards (Montes de Málaga, Spain). Geoderma, 296: 47-59. https://doi.org/10.1016/j. geoderma.2017.02.021

Sanjuán, Y., Gómez-Villar, A., Nadal-Romero, E., ÁlvarezMartínez, J., Arnáez, J., Serrano-Muela, M.P., Rubiales, J.M., González-Sampériz, P. \& García-Ruiz, J.M., 2016. Linking land cover changes in the sub-alpine and montane belts to changes in a torrential river. Land Degradation \& Development, 27: 179-189. https://doi.org/10.1002/ 1dr.2294
Sanjuán, Y., Arnáez, J., Beguería, S., Lana-Renault, N., Lasanta, T., Gómez-Villar, A., Álvarez-Martínez, J., Coba-Pérez, P. \& García-Ruiz, J.M., 2018. Woody plant encroachment following grazing abandonment in the subalpine belt: a case study in northern Spain. Regional Environment Change, 18: 1103-1115. https://doi.org/10.1007/s10113-017-1245-y.

Sancho-Reinoso, A., 2013. Land abandonment and the dynamics of agricultural landscape in Mediterranean mountain environments: the case of Ribagorza (Spanish Pyrenees). Erdkunde, 67(4): 289-308. https://doi.org/10.3112/ erdkunde.2013.04.01.

Sayadi, S., González-Roa, M.C. \& Calatrava Requena, J., 2009. Public preferences for landscape features: The case of agricultural landscapes in mountainous Mediterranean areas. Land Use Policy, 26: 334-344. https://doi.org/10.1016/j. landusepol.2008.04.003.

Schmitz, M.F., de Aranzabal, I., Aguilera, P., Rescia, A.J., and Pineda, F.D., 2003. Relationship between landscape typology and socioeconomic structure: Scenarios of change in Spanish cultural landscape. Ecological Modelling, 168: 349-356. https://doi.org/10.1016/S0304-3800(03)00145-5

Serra, P., Pons, X. \& Saurí, D., 2008. Land-cover and land-use change in a Mediterranean landscape: a spatial analysis of driving forces integrating biophysical and human factors. Applied Geography, 28(3): 189-209. https://doi.org/10.1016/ j.apgeog.2008.02.001.

Strijker, D., 2005. Marginal lands in Europe -causes of decline. Basic and Applied Ecology, 6: 99-106. https://doi. org/10.1016/j.baae.2005.01.001.

Taillefumier, F. \& Piégay, H., 2003. Contemporary land use changes in Prealpine Mediterranean mountains: a multivariate GIS-based approach applied to two municipalities in the Southern French Prealps. Catena, 51: 267-296. https:// doi.org/10.1016/S0341-8162(02)00168-6

Tandaric, N., 2015. Towards a general theory of landscape systems: the integration of the geoecological and bioecological approaches. Miscellanea Geographica, 19 (1): 29-34. https://doi.org/10.2478/mgrsd-2014-0028.

Tarolli, P., Petit, F. \& Romano, N., 2014. Terraced landscapes: From an old best practice to a potential hazard for soil degradation due to land abandonment. Anthropocene, 6: 1025. https://doi.org/10.1016/j.ancene.2014.03.002.

Terán, M. de, 1947. Vaqueros y cabañas en los Montes de Pas. Estudios Geográficos, 28: 493-536.

Tomás y Valiente, F., 1972. El marco político de la desamortización en España ( $2^{\mathrm{a}}$ Edición). Editorial Ariel, Barcelona.

Turner, S., Bolòs, J. \& Kinnaird, T., 2017. Changes and continuities in a Mediterranean landscape: a new interdisciplinary approach to understanding historic character in western Catalonia. Landscape Research. https://doi.org/10.1080/014 26397.2017.1386778.

Utrilla Utrilla, J.F., Laliena Corbera, C. \& Navarro Espinach, G., 2005. Los recursos naturales y sus transformación en los Pirineos aragoneses durante la Edad Media. En: Les ressources naturelles des Pyrénées du Moyen Âge à l'époque modern. Actes du Congrès International RESOPYR-1, Presses Universitaires de Perpignan, pp. 19-48.

Valdelvira-Salazar, A. \& Balcells, E., 1986. La pardina de Esporret como unidad empresarial de las sierras prepirenaicas meridionales. Pirineos, 128: 79-118.

Villar, L. \& García-Ruiz, J.M., 1977. Explotación del territorio y evolución de pastos en dos valles del Pirineo occidental. Publicaciones del Centro Pirenaico de Biología Experimental, 8: 143-163.

Wulf, A., 2016. La invención de la naturaleza. El nuevo mundo de Alexander von Humboldt. Taurus, 578 pp., Madrid. 